\title{
Safety Effects of Horizontal Curve and Grade Combinations on Rural Two-Lane
}

\section{Highways}

PUBLICATION NO. FHWA-HRT-13-077

US. Department of Transportation

Federal Highway Administration

Research, Development, and Technology

Turner-Fairbank Highway Research Center 6300 Georgetown Pike

McLean, VA 22101-2296 


\section{FOREWORD}

The first edition of the American Association of State Highway and Transportation Officials (AASHTO) Highway Safety Manual (HSM) provides crash modification factors (CMFs) for the safety effects of horizontal curvature and percent grade on rural two-lane highways. ${ }^{(1)}$ However, the HSM does not provide a method to account for the interactions between these effects. Researchers have always presumed that there are interactions between the safety effects of horizontal and vertical alignment, but this has not been demonstrated for specific alignment combinations in a form useful for safety prediction.

This document is a final report highlighting research undertaken to quantify the safety effects of five specific combinations of horizontal and vertical alignment for rural two-lane highways. The research is based on data from the Federal Highway Administration's Highway Safety Information System (HSIS) for Washington State, including roadway characteristics, horizontal and vertical alignment, traffic volume, and crashes. The outcome is a set of safety prediction models for fatal and injury and property damage only crashes. CMFs representing safety performance relative to level tangents on rural two-lane highways were developed from the models for each of the five combinations of horizontal and vertical alignment to present the results in a form suitable for incorporation in the HSM. This report should be of interest to safety engineers and planners as well as other AASHTO HSM users.

Monique R. Evans

Director, Office of Safety

Research and Development

\section{Notice}

This document is disseminated under the sponsorship of the U.S. Department of Transportation in the interest of information exchange. The U.S. Government assumes no liability for the use of the information contained in this document. This report does not constitute a standard, specification, or regulation.

The U.S. Government does not endorse products or manufacturers. Trademarks or manufacturers' names appear in this report only because they are considered essential to the objective of the document.

\section{Quality Assurance Statement}

The Federal Highway Administration (FHWA) provides high-quality information to serve Government, industry, and the public in a manner that promotes public understanding. Standards and policies are used to ensure and maximize the quality, objectivity, utility, and integrity of its information. FHWA periodically reviews quality issues and adjusts its programs and processes to ensure continuous quality improvement. 
TECHNICAL REPORT DOCUMENTATION PAGE

\begin{tabular}{|c|c|c|c|c|}
\hline $\begin{array}{l}\text { 1. Report No. } \\
\text { FHWA-HRT-13-077 }\end{array}$ & \multicolumn{2}{|c|}{ 2. Government Accession No. } & \multicolumn{2}{|c|}{ 3. Recipient's Catalog No. } \\
\hline \multirow{2}{*}{\multicolumn{3}{|c|}{$\begin{array}{l}\text { 4. Title and Subtitle } \\
\text { Safety Effects of Horizontal Curve and Grade Combinations on Rural Two- } \\
\text { Lane Highways }\end{array}$}} & \multicolumn{2}{|l|}{\begin{tabular}{|l|} 
5. Report Date \\
January 2014
\end{tabular}} \\
\hline & & & \multicolumn{2}{|c|}{ 6. Performing Organization Code } \\
\hline \multicolumn{3}{|c|}{$\begin{array}{l}\text { 7. Author(s) } \\
\text { Karin M. Bauer and Douglas W. Harwood }\end{array}$} & \multicolumn{2}{|c|}{\begin{tabular}{|l|} 
8. Performing Organization Report No. \\
110785.01.001
\end{tabular}} \\
\hline \multirow{2}{*}{\multicolumn{3}{|c|}{$\begin{array}{l}\text { 9. Performing Organization Name and Address } \\
\text { MRIGlobal } \\
\text { 425 Volker Blvd } \\
\text { Kansas City, MO } 64110 \\
\end{array}$}} & \multicolumn{2}{|c|}{ 10. Work Unit No. (TRAIS) } \\
\hline & & & \multicolumn{2}{|c|}{$\begin{array}{l}11 . \text { Contract or Grant No. } \\
\text { DTFH61-11-C-00050 }\end{array}$} \\
\hline \multirow{2}{*}{\multicolumn{3}{|c|}{$\begin{array}{l}\text { 12. Sponsoring Agency Name and Address } \\
\text { Federal Highway Administration } \\
\text { Office of Safety Research and Development } \\
6300 \text { Georgetown Pike } \\
\text { McLean, VA 22101-2296 }\end{array}$}} & \multirow{2}{*}{\multicolumn{2}{|c|}{$\begin{array}{l}\text { 13. Type of Report and Period Covered } \\
\text { Final Report } \\
\text { December 2010-August } 2012 \\
\text { 14. Sponsoring Agency Code }\end{array}$}} \\
\hline & & & & \\
\hline \multicolumn{5}{|c|}{$\begin{array}{l}\text { 15. Supplementary Notes } \\
\text { This work was performed under subcontract with the University of North Carolina (UNC) Highway Safety Research } \\
\text { Center for Highway Safety Information System (HSIS) under Master Agreement No. 5-555697 Contract } \\
\text { No. DTFH61-06-C-000013 and under subcontract for HSIS under Master Agreement No. 5-55771 Contract } \\
\text { No. DTFH61-11-C-00050. The UNC Program Manager was David L. Harkey, and the Federal Highway } \\
\text { Administration HSIS Program Manager was Carol Tan, Ph.D. }\end{array}$} \\
\hline \multicolumn{5}{|c|}{$\begin{array}{l}\text { 16. Abstract } \\
\text { This report summarizes the results of research undertaken to quantify the safety effects of five types of horizontal } \\
\text { and vertical alignment combinations for rural two-lane highways. The research is based on Federal Highway } \\
\text { Administration Highway Safety Information System data for Washington State, including crash records from } 2003 \text { to } \\
\text { 2008. The outcome is a set of safety prediction models for fatal and injury and property damage only crashes. }\end{array}$} \\
\hline \multicolumn{5}{|c|}{$\begin{array}{l}\text { To present the results in a form suitable for incorporation in the American Association of State Highway and } \\
\text { Transportation Officials Highway Safety Manual, crash modification factors representing safety performance relative } \\
\text { to level tangents were developed from these models for each of the five combinations of horizontal and vertical } \\
\text { alignment-horizontal curves and tangents on straight grades, horizontal curves and tangents at type } 1 \text { crest vertical } \\
\text { curves, horizontal curves and tangents at type } 1 \text { sag vertical curves, horizontal curves and tangents at type } 2 \text { crest } \\
\text { vertical curves, and horizontal curves and tangents at type } 2 \text { sag vertical curves. }{ }^{(1)}\end{array}$} \\
\hline \multicolumn{2}{|c|}{$\begin{array}{l}\text { 17. Key Words } \\
\text { Safety, Horizontal curves, Vertical curves, Grade } \\
\text { interaction, Crests, Sags, Rural two-lane highways, } \\
\text { Crash modeling, Safety performance function, Crash } \\
\text { modification factor }\end{array}$} & \multicolumn{3}{|c|}{$\begin{array}{l}\text { 18. Distribution Statement } \\
\text { No restrictions. This document is available to the public } \\
\text { through the National Technical Information Service, } \\
\text { Springfield, VA } 22161\end{array}$} \\
\hline ity C & 2( & 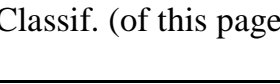 & $\begin{array}{l}\text { 21. No. of Pages } \\
63\end{array}$ & $\begin{array}{l}\text { 22. Price } \\
\text { N/A }\end{array}$ \\
\hline
\end{tabular}




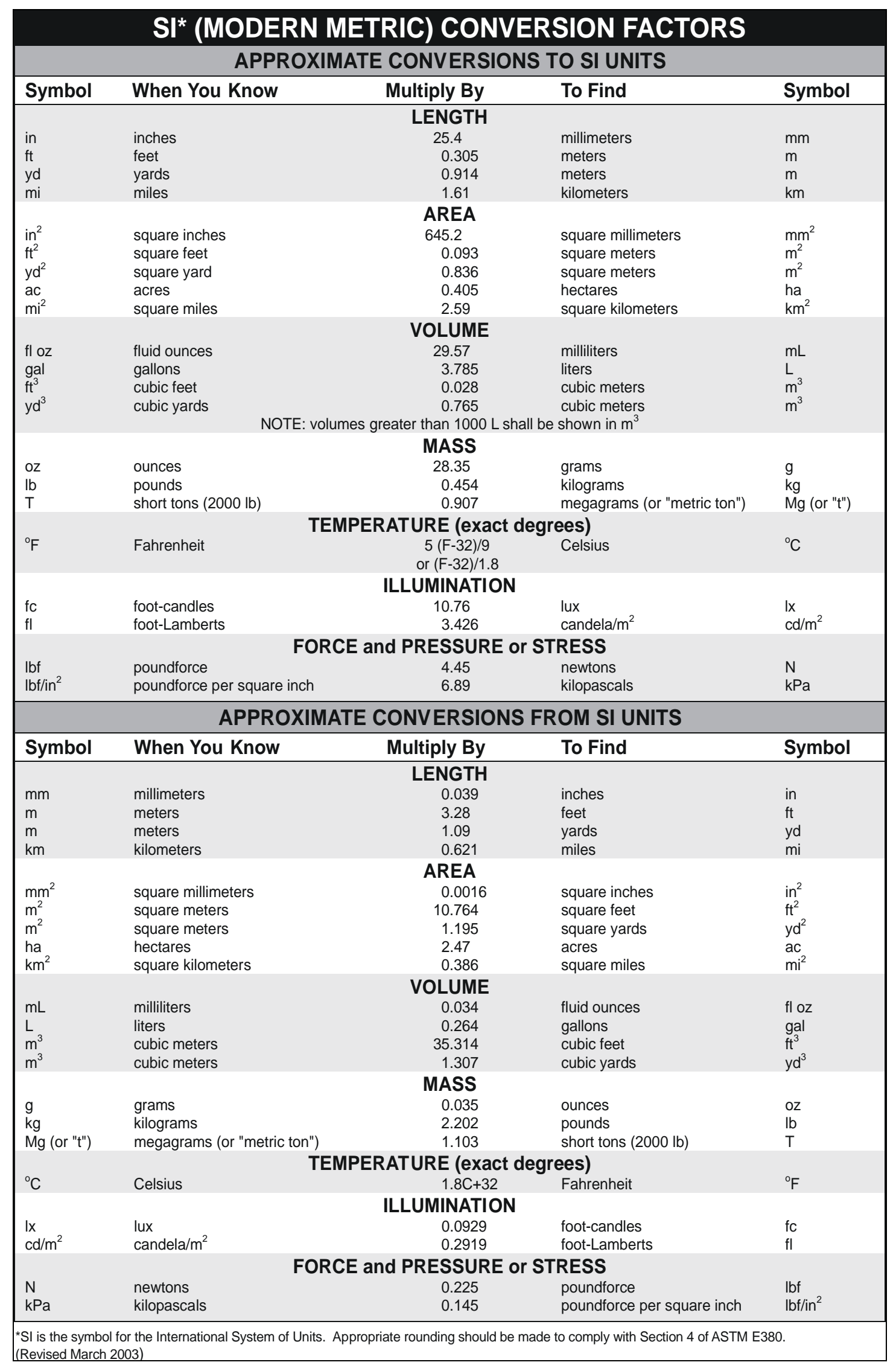




\section{TABLE OF CONTENTS}

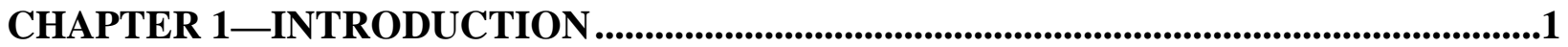

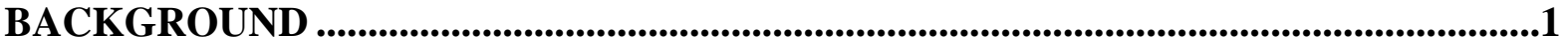

RESEARCH OBJECTIVES AND SCOPE ....................................................................1

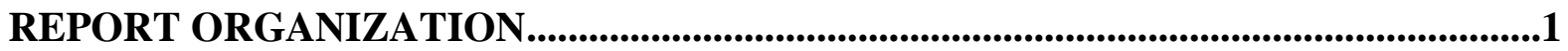

CHAPTER 2-STATE OF KNOWLEDGE LITERATURE REVIEW ..................................3

GEOMETRIC DESIGN CRITERIA.......................................................................................3

SAFETY EFFECTS OF HORIZONTAL ALIGNMENT.............................................................4

SAFETY EFFECTS OF VERTICAL ALIGNMENT .........................................................6

INTERACTIONS BETWEEN SAFETY EFFECTS OF HORIZONTAL AND

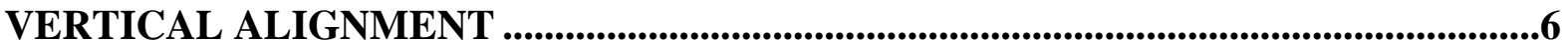

CHAPTER 3-DATABASE DESCRIPTION …...................................................................

DATABASE DEVELOPMENT ……...........................................................................................7

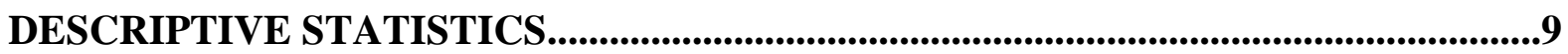

VALUE RANGE OF ROADWAY CHARACTERISTICS ..............................................12

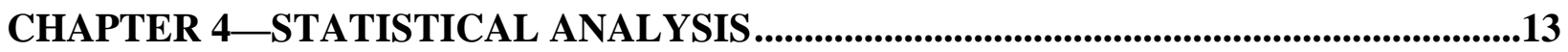

ANALYSIS APPROACH......................................................................................................13

Selection of Independent Variables Considered in Models................................................13

Assessment of Goodness-of-Fit of Final Models.........................................................15

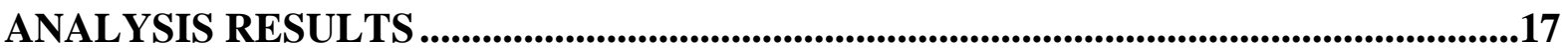

Horizontal Curves and Tangents on Straight Grades..........................................................17

Horizontal Curves and Tangents at Type 1 Crest Vertical Curves .....................................21

Horizontal Curves and Tangents at Type 1 Sag Vertical Curves .......................................26

Horizontal Curves and Tangents at Type 2 Crest Vertical Curves .......................................30

Horizontal Curves and Tangents at Type 2 Sag Vertical Curves .......................................34

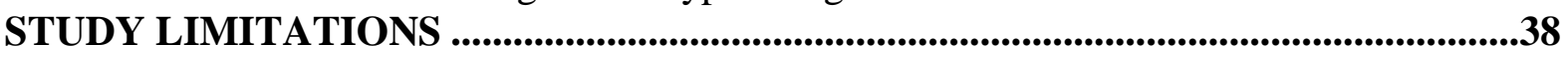

CHAPTER 5-CRASH MODIFICATION FACTORS ...............................................................39

HORIZONTAL CURVES AND TANGENTS ON STRAIGHT GRADES ......................39

HORIZONTAL CURVES AND TANGENTS AT TYPE 1 CREST VERTICAL

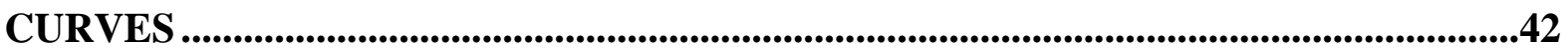

HORIZONTAL CURVES AND TANGENTS AT TYPE 1 SAG VERTICAL

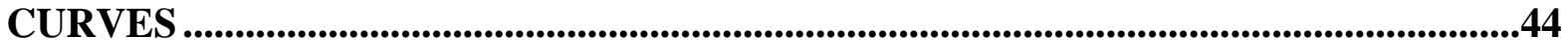

HORIZONTAL CURVES AND TANGENTS AT TYPE 2 CREST VERTICAL

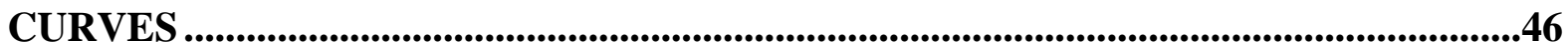

HORIZONTAL CURVES AND TANGENTS AT TYPE 2 SAG VERTICAL

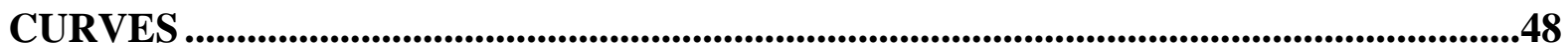

CMFS FOR COMBINED CRASH SEVERITY LEVELS .....................................................50

COMPARISON OF RESULTS TO EXISTING HSM CMFS .............................................51

CHAPTER 6-CONCLUSIONS AND RECOMMENDATIONS ............................................53

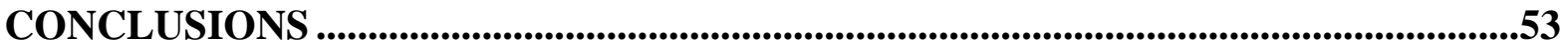

RECOMMENDATIONS...................................................................................................5

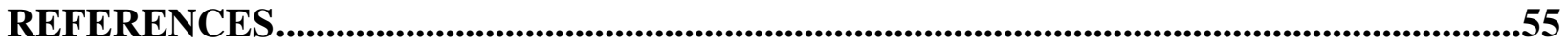




\section{LIST OF FIGURES}

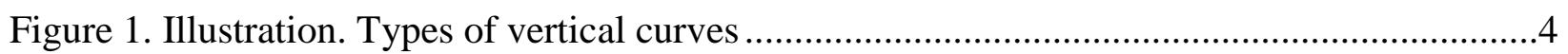

Figure 2. Equation. Relationship between crash rates and curve characteristics..............................

Figure 3. Equation. CMF for horizontal curves on rural two-lane highways .................................5

Figure 4. Equation. CMF for superelevation as a function of superelevation variance......................

Figure 5. Equation. CMF for percent grade on rural two-lane highways .........................................6

Figure 6. Equation. Probability of observing a given number of crashes........................................16

Figure 7. Equation. Probability of observing a given number of crashes expressed as a cumulative distribution ...........................................................................................................

Figure 8. Equation. Percent of roadway segments with unlikely low or high crash numbers.......16

Figure 9. Illustration. Alignment combinations used in the analysis of horizontal curves and

tangents on straight grades..........................................................................................................17

Figure 10. Equation. Predicted FI crashes on horizontal curves and tangents on straight grades (general form) ........................................................................................................18

Figure 11. Equation. Predicted PDO crashes on horizontal curves and tangents on straight

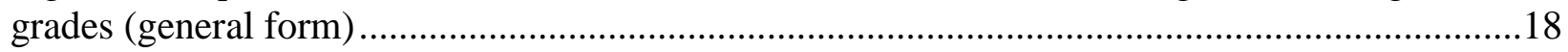

Figure 12. Equation. Predicted FI crashes on horizontal curves and tangents on straight grades (explicit form) ...........................................................................................................2

Figure 13. Equation. Predicted PDO crashes on horizontal curves and tangents on straight

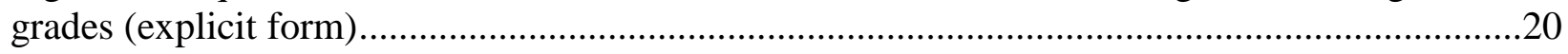

Figure 14. Equation. Predicted total crashes on horizontal curves and tangents on straight grades (general form) ............................................................................................................20

Figure 15. Illustration. Alignment combinations used in the analysis of horizontal curves and tangents at type 1 crest vertical curves..................................................................................22

Figure 16. Equation. Predicted FI crashes on horizontal curves and tangents at type 1 crest vertical curves (general form) .............................................................................................23

Figure 17. Equation. Predicted PDO crashes on horizontal curves and tangents at type 1 crest vertical curves (general form).

Figure 18. Equation. Predicted FI crashes on horizontal curves and tangents at type 1 crest vertical curves (explicit form) .............................................................................................25

Figure 19. Equation. Predicted PDO crashes on horizontal curves and tangents at type 1

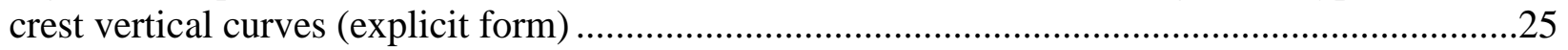

Figure 20. Equation. Predicted FI crashes on horizontal curves and tangents at type 1 crest vertical curves (alternate form) .........................................................................................26

Figure 21. Equation. Predicted PDO crashes on horizontal curves and tangents at type 1

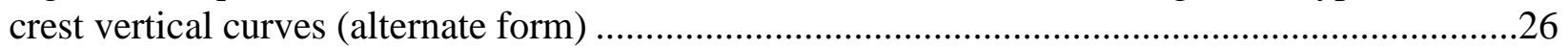

Figure 22. Illustration. Alignment combinations used in the analysis of horizontal curves and tangents at type 1 sag vertical curves ......................................................................................26

Figure 23. Equation. Predicted FI crashes on horizontal curves and tangents at type 1 sag vertical curves (general form)...........................................................................................28

Figure 24. Equation. Predicted PDO crashes on horizontal curves and tangents at type 1 sag vertical curves (general form)... .28

Figure 25. Equation. Predicted FI crashes on horizontal curves and tangents at type 1 sag vertical curves (explicit form) 
Figure 26. Equation. Predicted PDO crashes on horizontal curves and tangents at type 1 sag vertical curves (explicit form)

Figure 27. Equation. Predicted FI crashes on horizontal curves and tangents at type 1

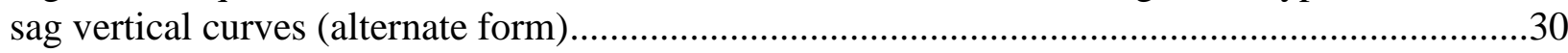

Figure 28. Equation. Predicted PDO crashes on horizontal curves and tangents at type 1

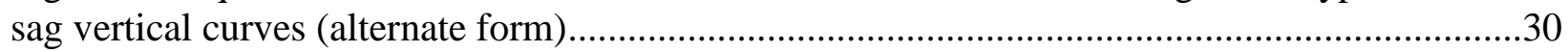

Figure 29. Illustration. Alignment combinations used in the analysis of horizontal curves

and tangents at type 2 crest vertical curves.....................................................................31

Figure 30. Equation. Predicted FI crashes on horizontal curves and tangents at type 2

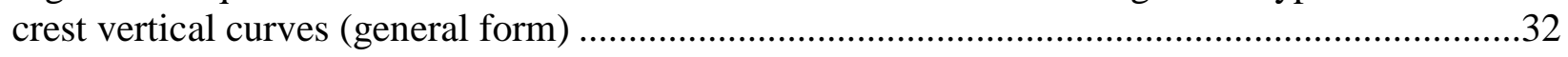

Figure 31. Equation. Predicted PDO crashes on horizontal curves and tangents at type 2

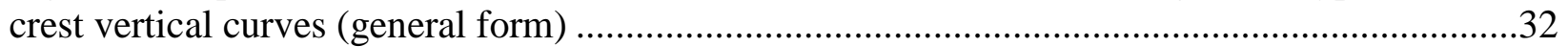

Figure 32. Equation. Predicted FI crashes on horizontal curves and tangents at type 2

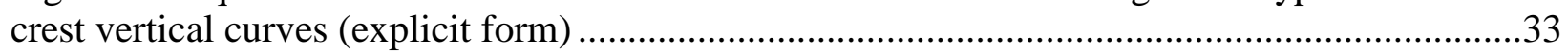

Figure 33. Equation. Predicted PDO crashes on horizontal curves and tangents at type 2

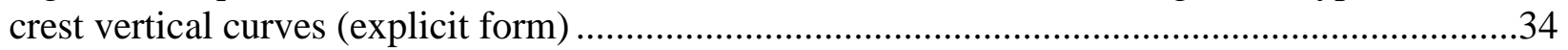

Figure 34. Illustration. Alignment combinations used in the analysis of horizontal curves

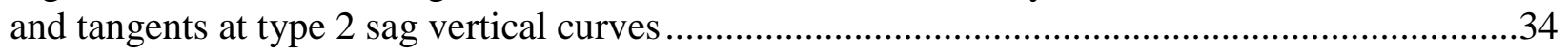

Figure 35. Equation. Predicted FI crashes on horizontal curves and tangents at type 2

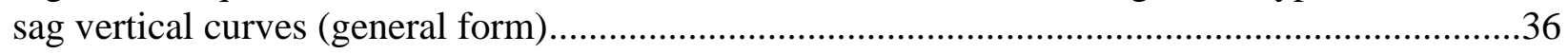

Figure 36. Equation. Predicted PDO crashes on horizontal curves and tangents at type 2

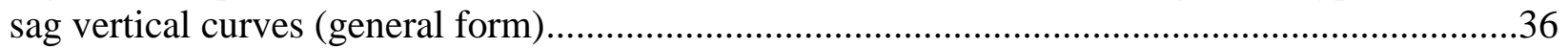

Figure 37. Equation. Predicted FI crashes on horizontal curves and tangents at type 2

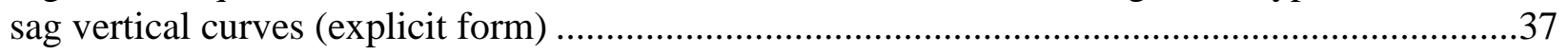

Figure 38. Equation. Predicted PDO crashes on horizontal curves and tangents at type 2

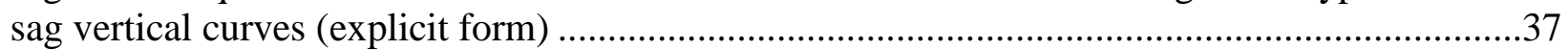

Figure 39. Equation. FI CMF for horizontal curves and tangents on straight grades....................39

Figure 40. Equation. PDO CMF for horizontal curves and tangents on straight grades ...............39

Figure 41. Graph. Predicted FI crashes/mi/year and CMFs for horizontal curves and

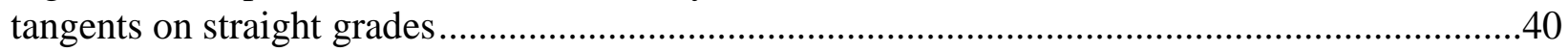

Figure 42. Graph. Predicted PDO crashes/mi/year and CMFs for horizontal curves

and tangents on straight grades.

Figure 43. Equation. FI CMF for horizontal curves and tangents at type 1 crest

vertical curves ......................................................................................................42

Figure 44. Equation. PDO CMF for horizontal curves and tangents at type 1 crest

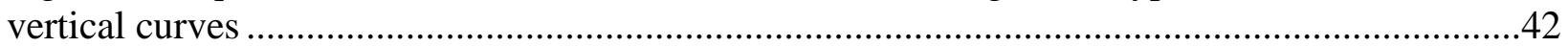

Figure 45. Graph. Predicted FI crashes/mi/year and CMFs for horizontal curves and

tangents at type 1 crest vertical curves .........................................................................43

Figure 46. Graph. Predicted PDO crashes/mi/year and CMFs for horizontal curves and

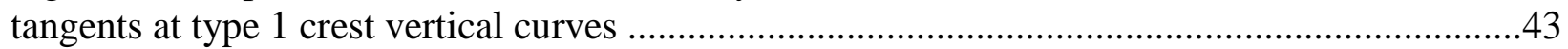

Figure 47. Equation. FI CMF for horizontal curves and tangents at type 1 sag vertical curves....44

Figure 48. Equation. PDO CMF for horizontal curves and tangents at type 1 sag vertical

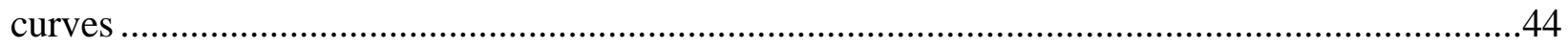

Figure 49. Graph. Predicted FI crashes/mi/year and CMFs for horizontal curves and

tangents at type 1 sag vertical curves. 
Figure 50. Graph. Predicted PDO crashes/mi/year and CMFs for horizontal curves and

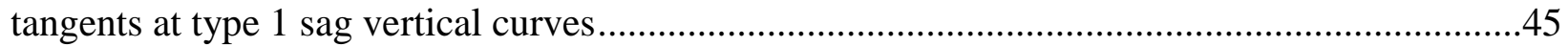

Figure 51. Equation. FI CMF for horizontal curves and tangents at type 2 crest vertical curves

Figure 52. Equation. PDO CMF for horizontal curves and tangents at type 2 crest vertical curves

Figure 53. Graph. Predicted FI crashes/mi/year and CMFs for horizontal curves and tangents at type 2 crest vertical curves

Figure 54. Graph. Predicted PDO crashes/mi/year and CMFs for horizontal curves and tangents at type 2 crest vertical curves

Figure 55. Equation. FI CMF for horizontal curves and tangents at type 2 sag vertical curves....48

Figure 56. Equation. PDO CMF for horizontal curves and tangents at type 2 sag vertical curves

Figure 57. Graph. Predicted FI crashes/mi/year and CMFs for horizontal curves and tangents at type 2 sag vertical curves.

Figure 58. Graph. Predicted PDO crashes/mi/year and CMFs for horizontal curves and tangents at type 2 sag vertical curves

Figure 59. Equation. CMF for combined crash severity level

Figure 60. Graph. Comparison of CMFs developed in this study to the combined AASHTO HSM CMFs for horizontal curves and grades for fixed radius and varying percent grades .51 Figure 61. Graph. Comparison of CMFs developed in this study to the combined AASHTO HSM CMFs for horizontal curves and grades for fixed percent grade and varying radii 


\section{LIST OF TABLES}

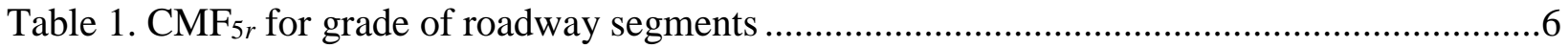

Table 2. Roadway length (mi) in available data from Washington HSIS database........................9

Table 3. Exposure (MVMT) in available data from Washington HSIS database (2003-2008)......9

Table 4. Fatal and injury (FI), property damage only (PDO), and total 6-year crash

frequencies in available data from Washington HSIS database ...............................................10

Table 5. FI, PDO, and total crash rates per MVMT in available data from Washington

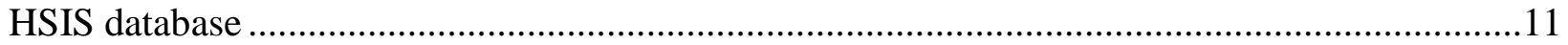

Table 6. Percent of sections with and without crashes on rural two-lane highways in

available data from Washington HSIS database (2003-2008) ................................................12

Table 7. Descriptive statistics for horizontal curves and tangents on straight grades ...................18

Table 8. FI and PDO crash modeling results for horizontal curves and tangents on

straight grades

Table 9. Descriptive statistics for horizontal curves and tangents at type 1 crest

vertical curves

Table 10. FI and PDO crash modeling results for horizontal curves and tangents at type 1

crest vertical curves

Table 11. Descriptive statistics for horizontal curves and tangents at type 1 sag

vertical curves

Table 12. FI and PDO crash modeling results for horizontal curves and tangents at type 1

sag vertical curves

Table 13. Descriptive statistics for horizontal curves and tangents at type 2 crest

vertical curves

Table 14. FI and PDO crash modeling results for horizontal curves and tangents at type 2

crest vertical curves....

Table 15. Descriptive statistics for horizontal curves and tangents at type 2 sag vertical curves

Table 16. FI and PDO crash modeling results for horizontal curves and tangents at type 2 sag vertical curves

Table 17. Example CMFs for FI and PDO crashes on horizontal curves and tangents on straight grades

Table 18. Example CMFs for FI and PDO crashes on horizontal curves and tangents at type 1 crest vertical curves...

Table 19. Example CMFs for FI and PDO crashes on horizontal curves and tangents at type 1 sag vertical curves

Table 20. Example CMFs for FI and PDO crashes on horizontal curves and tangents at type 2 crest vertical curves

Table 21. Example CMFs for FI crashes on horizontal curves and tangents at type 2 sag vertical curves

Table 22. Example CMFs PDO crashes on horizontal curves and tangents at type 2 sag vertical curves 



\section{CHAPTER 1-INTRODUCTION}

This chapter presents an introduction to the report, including key background information for the research, research objectives and scope, and the organization of this report.

\section{BACKGROUND}

The safety effects of horizontal curves and grades on highways have been quantified separately, but it is not currently known whether and how the safety performance of horizontal curves and grades interact. Furthermore, there are established safety effects for crest and sag vertical curves, and it is not known whether and how the safety performance of crest and sag vertical curves interacts with any horizontal curves that may be present. The research presented in this report was undertaken as part of the Federal Highway Administration (FHWA) Highway Safety Information System (HSIS) contract to investigate these issues and provide results in a form useful to highway designers and highway safety engineers.

\section{RESEARCH OBJECTIVES AND SCOPE}

The objective of the research was to quantify the safety effects of horizontal and vertical alignment combinations and to present the results in a form suitable for incorporation in the American Association of State Highway and Transportation Officials (AASHTO) Highway Safety Manual (HSM). ${ }^{(1)}$

The scope of the work initially included horizontal and vertical alignment for the four facility types whose safety performance is addressed in the first edition of the HSM: ${ }^{(1)}$

- Rural two-lane highways.

- Rural multilane undivided highways.

- Rural multilane divided highways.

- Urban and suburban arterials.

The research found that only rural two-lane highways had sufficient data for which modeling efforts appeared promising.

\section{REPORT ORGANIZATION}

The remainder of this report is organized as follows:

- Chapter 2 reviews the existing state of knowledge about the safety effects of horizontal curves and grades prior to the current research.

- Chapter 3 describes the HSIS database used for analysis. 
- Chapter 4 discusses the statistical analysis approach and presents the results of the safety analysis.

- Chapter 5 details how crash modification factors (CMFs) are derived.

- Chapter 6 presents the conclusions and recommendations. 


\section{CHAPTER 2-STATE OF KNOWLEDGE LITERATURE REVIEW}

This chapter reviews the existing state of knowledge about the safety effects of horizontal curves and grades prior to the current research.

\section{GEOMETRIC DESIGN CRITERIA}

Design criteria for horizontal and vertical alignment are presented in chapter 3 of the AASHTO Policy on Geometric Design of Highways and Streets, commonly known as the Green Book. ${ }^{(2)}$ Many State highway agencies have their own design manuals, but they tend to closely resemble the AASHTO Green Book in the areas of horizontal and vertical alignment. ${ }^{(2)}$

The key design parameters for horizontal curves include the following:

- Radius of curvature.

- Length of curve.

- Superelevation.

- Transition design.

Straight road sections with no horizontal curvature are generally referred to as "tangents" because they are usually tangent to any horizontal curves that they adjoin.

The fundamental design parameter for vertical alignment is the percent grade, which is defined as 100 times the change in roadway elevation per unit length of roadway measured in the horizontal plane. A road section with constant percent grade, regardless of its horizontal alignment, is generally referred to as a straight grade. Where the grade of the roadway changes, the straight grade sections are normally joined by a parabolic vertical curve. Figure 1 illustrates the four types of vertical curves (two types of crest vertical curves and two types of sag vertical curves) that are used in highway design. Key design parameters for vertical curves include the following:

- Algebraic difference in grade.

- Length of curve.

- Ratio of algebraic difference in grade and length of curve $(K)$, which represents the sharpness of the vertical curve. 

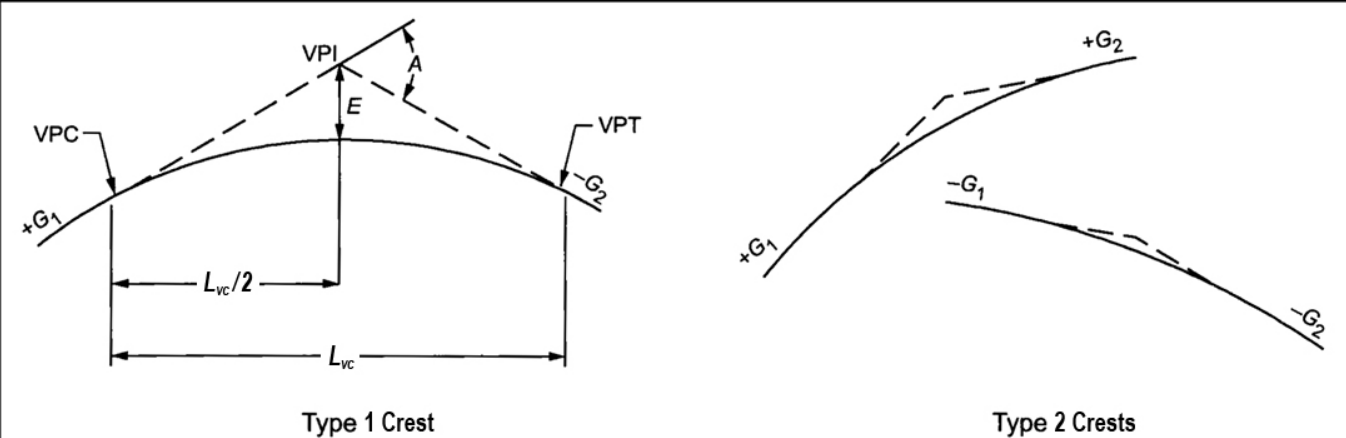

Type 2 Crests

Crest Vertical Curves

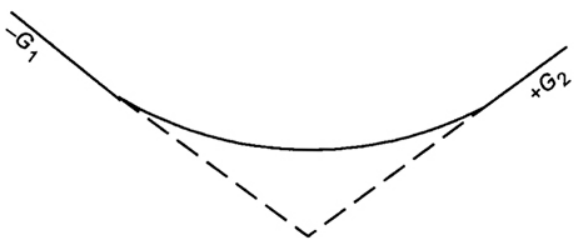

Type 1 Sag

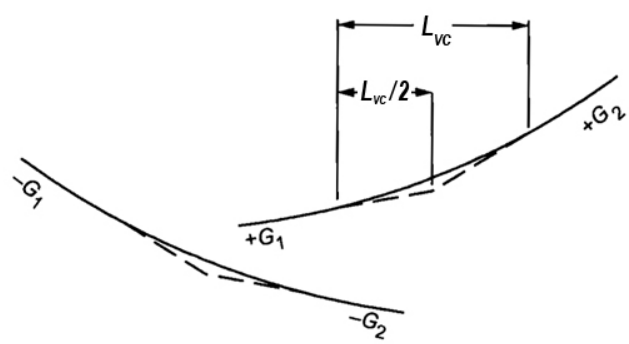

Type 2 Sags

Sag Vertical Curves

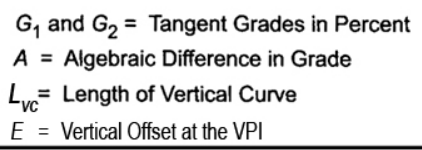

Source: AASHTO. Used by permission.

Figure 1. Illustration. Types of vertical curves. ${ }^{(2)}$

\section{SAFETY EFFECTS OF HORIZONTAL ALIGNMENT}

The most widely used safety relationship for horizontal curves on rural two-lane highways was developed by Zegeer et al. in the early 1990s as follows: ${ }^{(3,4)}$

$$
N=\left[1.55\left(L_{C}\right)(V)+0.014(D)(V)-0.012(S)(V)\right](0.978)^{W-30}
$$

\section{Figure 2. Equation. Relationship between crash rates and curve characteristics.}

Where:

$N=$ Total number of crashes on curve per year.

$L_{C}=$ Length of curve (mi).

$V=$ Volume of vehicles (in millions) passing through the curve in a 1-year period.

$D=$ Degree of curvature (5,730/radius of curvature $(\mathrm{ft}))$.

$S=$ Presence of spiral transitions, where $S=0$ if no spirals exist and $S=1$ if spirals do exist.

$\mathrm{W}=$ Width of roadway on curve $(\mathrm{ft})$. 
$D$, which represents the deflection angle for the curve per $100 \mathrm{ft}$ of curve length, is an obsolete measure that is no longer used in the AASHTO Green Book ${ }^{(2)}$ Therefore, the equivalent to degree of curvature expressed in terms of the radius of curvature is provided. The original Zegeer et al. model was expressed in terms of predicting crash frequency for a 5-year period; the model in figure 2 is expressed on a per-year basis for ease of comparison to other models.

No safety relationships for horizontal curvature have been developed for highway types other than rural two-lane highways, although such relationships for freeways have been developed in National Cooperative Highway Research Program Project 17-45. ${ }^{(5)}$

An assessment of literature conducted by Harwood, et al., as part of the development of the FHWA Interactive Highway Safety Design Model, concluded that the Zegeer, et al. model in figure 2 was the most useful and accurate model to account for the safety effect of horizontal curves on rural two-lane highways. ${ }^{(6,7)}$ Harwood et al. expressed the Zegeer, et al. model as a $\mathrm{CMF}$ in the following form: ${ }^{(6)}$

$$
C M F_{H C}=\frac{1.55 L_{C}+\frac{80.2}{\mathrm{R}}-0.012 S}{1.55 L_{C}}
$$

\section{Figure 3. Equation. CMF for horizontal curves on rural two-lane highways.}

Where:

$C M F_{H C}=\mathrm{CMF}$ for horizontal curvature on a rural two-lane highway. $\mathrm{R}=$ Radius of curvature $(\mathrm{ft})$.

The base condition for this CMF is a tangent roadway. The AASHTO HSM adopted the CMF in figure 3 to represent the safety effects of horizontal curvature on rural two-lane highways. ${ }^{(1)}$

The AASHTO HSM also includes a CMF for the safety effect of superelevation for horizontal curves of rural two-lane highways as a function of superelevation variance in the following form:

$$
\begin{gathered}
C M F_{S V}=1.00 \text { for } S V<0.01 \\
C M F_{S V}=1.00+6(S V-0.01) \text { for } 0.01 \leq S V<0.02 \\
C M F_{S V}=1.06+3(S V-0.02) \text { for } S V \geq 0.02
\end{gathered}
$$

Figure 4. Equation. CMF for superelevation as a function of superelevation variance.

Where:

$C M F_{S V}=\mathrm{CMF}$ for superelevation variance on a rural two-lane highway. $S V=$ Superelevation variance ( $\mathrm{ft} / \mathrm{ft}$ ), which represents the design superelevation rate presented in the AASHTO Green Book minus the actual superelevation of the curve. ${ }^{(2)}$

CMF was also adapted by Harwood et al. from the work of Zegeer et al. ${ }^{(3,4,6)}$ The base condition for CMF is a horizontal curve with superelevation within $0.01 \mathrm{ft} / \mathrm{ft}$ of the applicable design superelevation presented in the AASHTO Green Book. ${ }^{(2)}$

No CMFs for horizontal curvature on rural multilane undivided highways, rural multilane divided highways, or urban and suburban arterials are included in the AASHTO HSM. ${ }^{(1)}$ 


\section{SAFETY EFFECTS OF VERTICAL ALIGNMENT}

Table 1 presents the AASHTO HSM CMF, denoted as $\mathrm{CMF}_{5 r}$, which represents the safety effect of percent grade on rural two-lane highways.

Table 1. CMF for grade of roadway segments. ${ }^{(1)}$

\begin{tabular}{|c|c|c|}
\hline $\begin{array}{c}\text { Level Grade } \\
(\leq \mathbf{3} \text { percent })\end{array}$ & $\begin{array}{c}\text { Moderate Terrain } \\
\mathbf{3} \text { percent }<\text { Grade } \\
\leq \mathbf{6} \text { percent })\end{array}$ & $\begin{array}{c}\text { Steep Terrain } \\
\mathbf{(} \mathbf{6} \text { percent })\end{array}$ \\
\hline 1.00 & 1.10 & 1.16 \\
\hline
\end{tabular}

The base condition for the CMFs shown in table 1 is a level roadway. Figure 5 represents the underlying functional form for CMF shown in table 1.

$$
C M F_{G}=1.016^{a b s(G)}
$$

Figure 5. Equation. CMF for percent grade on rural two-lane highways.

Where:

$C M F_{G}=\mathrm{CMF}$ for percent grade on a rural two-lane highway. $a b s(G)=$ Absolute value of percent grade.

The CMF in this form, as a continuous function, is a more useful representation of the safety effect of percent grade than the form shown in table 1, as the stepwise function in table 1 may be misleading.

The CMF for percent grade shown in table 1 and figure 5 applies only to straight grades. There are no CMFs in the AASHTO HSM for crest or sag vertical curves on rural two-lane highways. Also, there are no vertical alignment CMFs in the AASHTO HSM for facility types other than rural two-lane highways.

\section{INTERACTIONS BETWEEN SAFETY EFFECTS OF HORIZONTAL AND VERTICAL ALIGNMENT}

While the AASHTO HSM provides CMFs for the safety effects of horizontal curvature and percent grade on rural two-lane highways, it does not have any method for accounting for the interactions between these effects. In other words, in the AASHTO HSM procedures for rural two-lane highways, the safety effect of a horizontal curve is the same whether it is located on a level roadway, a straight grade, or a vertical curve. Similarly, the safety effect of a straight grade is the same whether it is located on a tangent roadway or on a horizontal curve. Researchers have always assumed that there are interactions between the safety effects of horizontal and vertical alignment, but this has not been demonstrated in a form useful for safety prediction. Recent research by Easa and You have partially addressed this issue with separate models for horizontal curves and horizontal tangents, but they did not tie their models back to a common base condition (such as a level tangent roadway) or express the modeling results in a form that could be considered a CMF. ${ }^{(8,9)}$ 


\section{CHAPTER 3-DATABASE DESCRIPTION}

This chapter describes the database used in the analysis. The research was performed with HSIS data for State highways in Washington. This is the only data source that includes system-wide data on curve and grade geometry that can be linked to system-wide roadway characteristics, traffic volume, and crash data.

\section{DATABASE DEVELOPMENT}

Research began with a review of available databases that contain roadway data (including horizontal and vertical alignment), traffic volume data, and crash data in a format that could be linked by location, with a primary focus on available HSIS data. The only dataset found with sufficient detail concerning horizontal and vertical alignment was HSIS data for State highways in Washington.

Preliminary data processing was performed to identify the following types of roadways on the Washington State highway system (note that the abbreviations are used in table 2 through table 5):

- Rural two-lane highways (R2U).

- Rural four-lane undivided highways (R4U).

- Rural four-lane divided highways (nonfreeways) (R4D).

- Urban/suburban two-lane undivided arterials (U2U).

- Urban/suburban three-lane arterials with a center two-way left-turn lane (U3T).

- Urban/suburban four-lane undivided arterials (U4U).

- Urban/suburban four-lane divided arterials (nonfreeways) (U4D).

- Urban/suburban five-lane arterials with a center two-way left-turn lane (U5T).

Roadway segments with atypical features such as passing and climbing lanes as well as roadway segments with transitions between grades identified as angle points were eliminated from consideration. Angle points most likely represent crest or sag vertical curves that were too short or not well enough defined to be measured properly. Finally, a limited set of roadways with obvious data problems, such as successive vertical curves whose lengths appeared to overlap, were also eliminated from consideration. The descriptive statistics for the roadway data shown below are based on the roadway lengths that were retained for analysis after the initial screening.

Next, each roadway segment was classified into categories by its horizontal and vertical alignment. Horizontal alignment was classified as follows:

- Tangent roadways. 
- Roadways on horizontal curves.

Vertical alignment was classified as follows:

- Level roadways.

- Straight grades (constant percent grade of 1 percent or more).

- Type 1 crest vertical curves.

- $\quad$ Type 2 crest vertical curves.

- Type 1 sag vertical curves.

- Type 2 sag vertical curves.

Figure 1 illustrates the distinction between types 1 and 2 crest and sag vertical curves. Every roadway segment was defined by its horizontal alignment, vertical alignment, and combination of horizontal and vertical alignments. Since there were two horizontal alignment categories and six vertical alignment categories, there were a total of 12 possible combinations of horizontal and vertical alignments. Where horizontal and vertical curves overlap, their beginnings and ends may not coincide; therefore, a new roadway segment began at any point where the horizontal or vertical alignment changed. Thus, some segments might include all of a horizontal or vertical curve, while others might include only part of a horizontal or vertical curve. The length of every roadway segment was determined for use in the analysis as well as the length of any horizontal curve that was wholly or partially within the segment and the length of any vertical curve $\left(L_{V C}\right)$ that was wholly or partially within the segment. Additionally, each horizontal curve was characterized by its radius. No data on the superelevation of horizontal curves were available for analysis. Each straight grade was characterized by its percent grade $(G)$. Each vertical curve was characterized by its approach grade $\left(G_{1}\right)$ and departure grade $\left(G_{2}\right)$, its algebraic difference in grade $\left(A=a b s\left(G_{1}-G_{2}\right)\right)$, and the ratio of its length to its algebraic difference in grade $\left(K=L_{V C} / A\right)$.

Crash data for a 6-year period (2003 to 2008) were obtained and used in the analysis. Each crash was assigned to a particular roadway segment, with particular horizontal and vertical alignment based on its assigned milepost location. Since the results of this research are intended for use in the roadway segment procedures of the AASHTO HSM, only nonintersection crashes were considered. Nonintersection crashes are those that did not occur at an intersection and were not classified by the investigating officer or data coder as related to the operation of an intersection. The traffic volume for each roadway segment was determined from available traffic volume data.

Some of the roadway segments included in the analysis may have contained minor intersections, but crashes occurring at or related to those intersections have been excluded from the analysis. No major intersections were included within a roadway segment because a change in traffic volume along the roadway would have led to the creation of a roadway segment boundary. 
Driveway crashes are considered roadway segment crashes. As a result, they were included in the analysis. The amount of driveway access within segments may have varied, but all of the segments were located in areas classified as rural.

\section{DESCRIPTIVE STATISTICS}

The following discussion presents descriptive statistics for the roadway sections available for analysis including roadway length (miles), exposure (million vehicle miles traveled in the 6-year period (MVMT)), crash frequencies, and crash rates per MVMT for specific combinations of horizontal and vertical alignment and roadway type. Roadway length, exposure, crash frequency, and crash rate are presented in table 2 through table 5, respectively.

Of the 6,944 mi of roadway in the entire Washington HSIS database, 4,785 mi (69 percent) are on rural two-lane highways. Of these, 3,457 mi were used for analysis. Rural two-lane highways with passing or climbing lanes and segments with missing or obviously incorrect alignment data (e.g., overlapping curves) were excluded from the study. Therefore, based on data availability, the analysis of the safety effects of horizontal curve and grade combinations in this report focused on rural two-lane highways only.

Table 2. Roadway length (mi) in available data from Washington HSIS database.

\begin{tabular}{|c|c|c|c|c|c|c|c|c|c|}
\hline \multirow{2}{*}{$\begin{array}{c}\text { Alignment } \\
\text { Type }\end{array}$} & \multirow{2}{*}{$\begin{array}{l}\text { Roadway } \\
\text { Element }\end{array}$} & \multicolumn{3}{|c|}{ Rural Highways } & \multicolumn{5}{|c|}{ Urban/Suburban Arterials } \\
\hline & & R2U & R4D & R4U & U2U & U3T & U4D & U4U & U5T \\
\hline \multirow{3}{*}{ Horizontal } & Tangent & $2,472.1$ & 122.4 & 4.9 & 122.1 & 15.9 & 24.2 & 46.3 & 48.0 \\
\hline & Curve & 985.0 & 54.0 & 1.2 & 43.3 & 2.5 & 6.4 & 13.1 & 8.9 \\
\hline & Total & $3,457.1$ & 176.4 & 6.1 & 165.4 & 18.4 & 30.7 & 59.4 & 56.9 \\
\hline \multirow{6}{*}{ Vertical } & Straight grade & $2,260.7$ & 107.6 & 4.0 & 112.4 & 12.2 & 17.6 & 37.5 & 36.2 \\
\hline & Type 1 crest & 364.5 & 19.9 & 0.1 & 14.7 & 1.7 & 4.5 & 6.0 & 6.3 \\
\hline & Type 2 crest & 300.8 & 20.1 & 0.5 & 13.3 & 2.0 & 2.7 & 6.1 & 5.5 \\
\hline & Type 1 sag & 252.1 & 12.8 & 0.5 & 12.0 & 1.2 & 3.7 & 3.9 & 5.1 \\
\hline & Type 2 sag & 279.1 & 16.0 & 0.9 & 13.0 & 1.3 & 2.2 & 5.9 & 3.8 \\
\hline & Total & $3,457.1$ & 176.4 & 6.1 & 165.4 & 18.4 & 30.7 & 59.4 & 56.9 \\
\hline
\end{tabular}

Table 3. Exposure (MVMT) in available data from Washington HSIS database (2003-2008).

\begin{tabular}{|c|c|c|c|c|c|c|c|c|c|}
\hline \multirow{2}{*}{$\begin{array}{c}\text { Alignment } \\
\text { Type }\end{array}$} & \multirow{2}{*}{$\begin{array}{l}\text { Roadway } \\
\text { Element }\end{array}$} & \multicolumn{3}{|c|}{ Rural Highways } & \multicolumn{5}{|c|}{ Urban/Suburban Arterials } \\
\hline & & R2U & R4D & R4U & U2U & U3T & U4D & U4U & U5T \\
\hline \multirow{3}{*}{ Horizontal } & Tangent & $16,675.2$ & $3,648.2$ & 113.5 & $3,228.2$ & 483.5 & $1,408.2$ & $2,613.9$ & $2,826.3$ \\
\hline & Curve & $6,194.2$ & $1,587.6$ & 35.1 & $1,108.8$ & 76.5 & 351.3 & 684.0 & 500.3 \\
\hline & Total & $22,869.5$ & $5,235.8$ & 148.6 & 4,336.9 & 560.0 & $1,759.5$ & $3,297.9$ & $3,326.5$ \\
\hline \multirow{6}{*}{ Vertical } & Straight grade & $14,847.0$ & $3,216.5$ & 91.6 & $2,894.0$ & 366.8 & 991.4 & $2,072.1$ & $2,091.4$ \\
\hline & Type 1 crest & $2,616.4$ & 636.6 & 2.3 & 398.3 & 54.3 & 265.9 & 341.4 & 375.6 \\
\hline & Type 2 crest & $1,870.5$ & 521.2 & 11.9 & 364.1 & 62.4 & 162.4 & 341.5 & 322.7 \\
\hline & Type 1 sag & $1,772.6$ & 392.6 & 23.4 & 344.5 & 38.0 & 209.3 & 227.4 & 309.4 \\
\hline & Type 2 sag & $1,762.9$ & 469.0 & 19.4 & 336.0 & 38.5 & 130.5 & 315.5 & 227.4 \\
\hline & Total & $22,869.5$ & $5,235.8$ & 148.6 & $4,336.9$ & 560.0 & $1,759.5$ & $3,297.9$ & $3,326.5$ \\
\hline
\end{tabular}


Table 4. Fatal and injury (FI), property damage only (PDO), and total 6-year crash frequencies in available data from Washington HSIS database.

\begin{tabular}{|c|c|c|c|c|c|c|c|c|c|}
\hline \multirow{2}{*}{$\begin{array}{c}\text { Alignment } \\
\text { Type }\end{array}$} & \multirow{2}{*}{$\begin{array}{l}\text { Roadway } \\
\text { Element }\end{array}$} & \multicolumn{3}{|c|}{ Rural Highways } & \multicolumn{5}{|c|}{ Urban/Suburban Arterials } \\
\hline & & R2U & R4D & R4U & U2U & U3T & U4D & $\mathbf{U} 4 \mathbf{U}$ & U5T \\
\hline \multicolumn{10}{|c|}{ FI Crash Frequencies in 6 Years (2003-2008) } \\
\hline \multirow{3}{*}{ Horizontal } & Tangent & 7,360 & 865 & 77 & 2,564 & 335 & 1,557 & 5,100 & 2,867 \\
\hline & Curve & 3,659 & 353 & 11 & 772 & 55 & 406 & 1,017 & 245 \\
\hline & Total & 11,019 & 1,218 & 88 & 3,336 & 390 & 1,963 & 6,117 & 3,112 \\
\hline \multirow{6}{*}{ Vertical } & Straight grade & 7,347 & 740 & 63 & 2,313 & 260 & 1,291 & 3,570 & 2,117 \\
\hline & Type 1 crest & 1,168 & 125 & 1 & 260 & 25 & 262 & 634 & 323 \\
\hline & Type 2 crest & 826 & 97 & 5 & 292 & 39 & 156 & 780 & 222 \\
\hline & Type 1 sag & 896 & 108 & 4 & 235 & 29 & 101 & 577 & 304 \\
\hline & Type 2 sag & 782 & 148 & 15 & 236 & 37 & 153 & 556 & 146 \\
\hline & Total & 11,019 & 1,218 & 88 & 3,336 & 390 & 1,963 & 6,117 & 3,112 \\
\hline \multicolumn{10}{|c|}{ PDO Crash Frequencies in 6 Years (2003-2008) } \\
\hline \multirow{3}{*}{ Horizontal } & Tangent & 10,519 & 1,403 & 213 & 3,753 & 519 & 2,841 & 9,012 & 4,323 \\
\hline & Curve & 4,758 & 621 & 14 & 1,264 & 77 & 741 & 1,800 & 426 \\
\hline & Total & 15,277 & 2,024 & 227 & 5,017 & 596 & 3,582 & 10,812 & 4,749 \\
\hline \multirow{6}{*}{ Vertical } & Straight grade & 10,222 & 1,273 & 185 & 3,451 & 401 & 2,259 & 6,250 & 3,315 \\
\hline & Type 1 crest & 1,498 & 229 & 10 & 397 & 55 & 527 & 1,208 & 461 \\
\hline & Type 2 crest & 1,264 & 162 & 4 & 437 & 64 & 310 & 1,390 & 333 \\
\hline & Type $1 \mathrm{sag}$ & 1,154 & 177 & 13 & 383 & 37 & 227 & 1,037 & 402 \\
\hline & Type 2 sag & 1,139 & 183 & 15 & 349 & 39 & 259 & 927 & 238 \\
\hline & Total & 15,277 & 2,024 & 227 & 5,017 & 596 & 3,582 & 10,812 & 4,749 \\
\hline \multicolumn{10}{|c|}{ Total Crash Frequencies in 6 Years $(2003-2008)$} \\
\hline \multirow{3}{*}{ Horizontal } & Tangent & 17,879 & 2,268 & 290 & 6,317 & 854 & 4,398 & 14,112 & 7,190 \\
\hline & Curve & 8,417 & 974 & 25 & 2,036 & 132 & 1,147 & 2,817 & 671 \\
\hline & Total & 26,296 & 3,242 & 315 & 8,353 & 986 & 5,545 & 16,929 & 7,861 \\
\hline \multirow{6}{*}{ Vertical } & Straight grade & 17,569 & 2,013 & 248 & 5,764 & 661 & 3,550 & 9,820 & 5,432 \\
\hline & Type 1 crest & 2,666 & 354 & 11 & 657 & 80 & 789 & 1,842 & 784 \\
\hline & Type 2 crest & 2,090 & 259 & 9 & 729 & 103 & 466 & 2,170 & 555 \\
\hline & Type 1 sag & 2,050 & 285 & 17 & 618 & 66 & 328 & 1,614 & 706 \\
\hline & Type 2 sag & 1,921 & 331 & 30 & 585 & 76 & 412 & 1,483 & 384 \\
\hline & Total & 26,296 & 3,242 & 315 & 8,353 & 986 & 5,545 & 16,929 & 7,861 \\
\hline
\end{tabular}


Table 5. FI, PDO, and total crash rates per MVMT in available data from Washington HSIS database.

\begin{tabular}{|c|c|c|c|c|c|c|c|c|c|}
\hline \multirow{2}{*}{$\begin{array}{c}\text { Alignment } \\
\text { Type }\end{array}$} & \multirow{2}{*}{$\begin{array}{c}\text { Roadway } \\
\text { Element }\end{array}$} & \multicolumn{3}{|c|}{ Rural Highways } & \multicolumn{5}{|c|}{ Urban/Suburban Arterials } \\
\hline & & R2U & R4D & R4U & U2U & U3T & U4D & U4U & U5T \\
\hline \multicolumn{10}{|c|}{ FI Crash Rate per MVMT } \\
\hline \multirow{2}{*}{ Horizontal } & Tangent & 0.441 & 0.237 & 0.679 & 0.794 & 0.693 & 1.106 & 1.951 & 1.014 \\
\hline & Curve & 0.591 & 0.222 & 0.313 & 0.696 & 0.719 & 1.156 & 1.487 & 0.490 \\
\hline \multirow{5}{*}{ Vertical } & Straight grade & 0.495 & 0.230 & 0.688 & 0.799 & 0.709 & 1.302 & 1.723 & 1.012 \\
\hline & Type 1 crest & 0.446 & 0.196 & 0.432 & 0.653 & 0.460 & 0.985 & 1.857 & 0.860 \\
\hline & Type 2 crest & 0.442 & 0.186 & 0.421 & 0.802 & 0.625 & 0.961 & 2.284 & 0.688 \\
\hline & Type 1 sag & 0.505 & 0.275 & 0.171 & 0.682 & 0.763 & 0.483 & 2.537 & 0.982 \\
\hline & Type 2 sag & 0.444 & 0.316 & 0.775 & 0.702 & 0.961 & 1.173 & 1.762 & 0.642 \\
\hline \multicolumn{10}{|c|}{ PDO Crash Rate per MVMT } \\
\hline \multirow{2}{*}{ Horizontal } & Tangent & 0.631 & 0.385 & 1.877 & 1.163 & 1.073 & 2.017 & 3.448 & 1.530 \\
\hline & Curve & 0.768 & 0.391 & 0.399 & 1.140 & 1.007 & 2.110 & 2.632 & 0.852 \\
\hline \multirow{5}{*}{ Vertical } & Straight grade & 0.688 & 0.396 & 2.020 & 1.192 & 1.093 & 2.279 & 3.016 & 1.585 \\
\hline & Type 1 crest & 0.573 & 0.360 & 4.323 & 0.997 & 1.012 & 1.982 & 3.539 & 1.227 \\
\hline & Type 2 crest & 0.676 & 0.311 & 0.337 & 1.200 & 1.025 & 1.909 & 4.070 & 1.032 \\
\hline & Type 1 sag & 0.651 & 0.451 & 0.555 & 1.112 & 0.974 & 1.085 & 4.560 & 1.299 \\
\hline & Type 2 sag & 0.646 & 0.390 & 0.775 & 1.039 & 1.013 & 1.985 & 2.938 & 1.047 \\
\hline \multicolumn{10}{|c|}{ Total Crash Rate per MVMT } \\
\hline \multirow{2}{*}{ Horizontal } & Tangent & 1.072 & 0.622 & 2.556 & 1.957 & 1.766 & 3.123 & 5.399 & 2.544 \\
\hline & Curve & 1.359 & 0.614 & 0.712 & 1.836 & 1.726 & 3.265 & 4.118 & 1.341 \\
\hline \multirow{5}{*}{ Vertical } & Straight grade & 1.183 & 0.626 & 2.707 & 1.992 & 1.802 & 3.581 & 4.739 & 2.597 \\
\hline & Type 1 crest & 1.019 & 0.556 & 4.755 & 1.649 & 1.472 & 2.967 & 5.396 & 2.087 \\
\hline & Type 2 crest & 1.117 & 0.497 & 0.758 & 2.002 & 1.650 & 2.870 & 6.354 & 1.720 \\
\hline & Type 1 sag & 1.156 & 0.726 & 0.726 & 1.794 & 1.737 & 1.567 & 7.097 & 2.282 \\
\hline & Type 2 sag & 1.090 & 0.706 & 1.550 & 1.741 & 1.975 & 3.158 & 4.701 & 1.689 \\
\hline
\end{tabular}

Note: Crash rates cannot be added; therefore, no totals are shown.

The majority of rural two-lane roadway segments included in the analysis experienced no crashes in the 6-year period. Table 6 shows the percentage of roadway segments with no crashes and with one or more crashes for each roadway and severity type. The data clearly show the highly skewed crash distribution for all severity types and all roadway types. The high percentages of roadway segments without crashes (78 to 89 percent for FI crashes and 72 to 84 percent for PDO crashes) provided a challenge in modeling crash frequencies. 
Table 6. Percent of sections with and without crashes on rural two-lane highways in available data from Washington HSIS database (2003-2008).

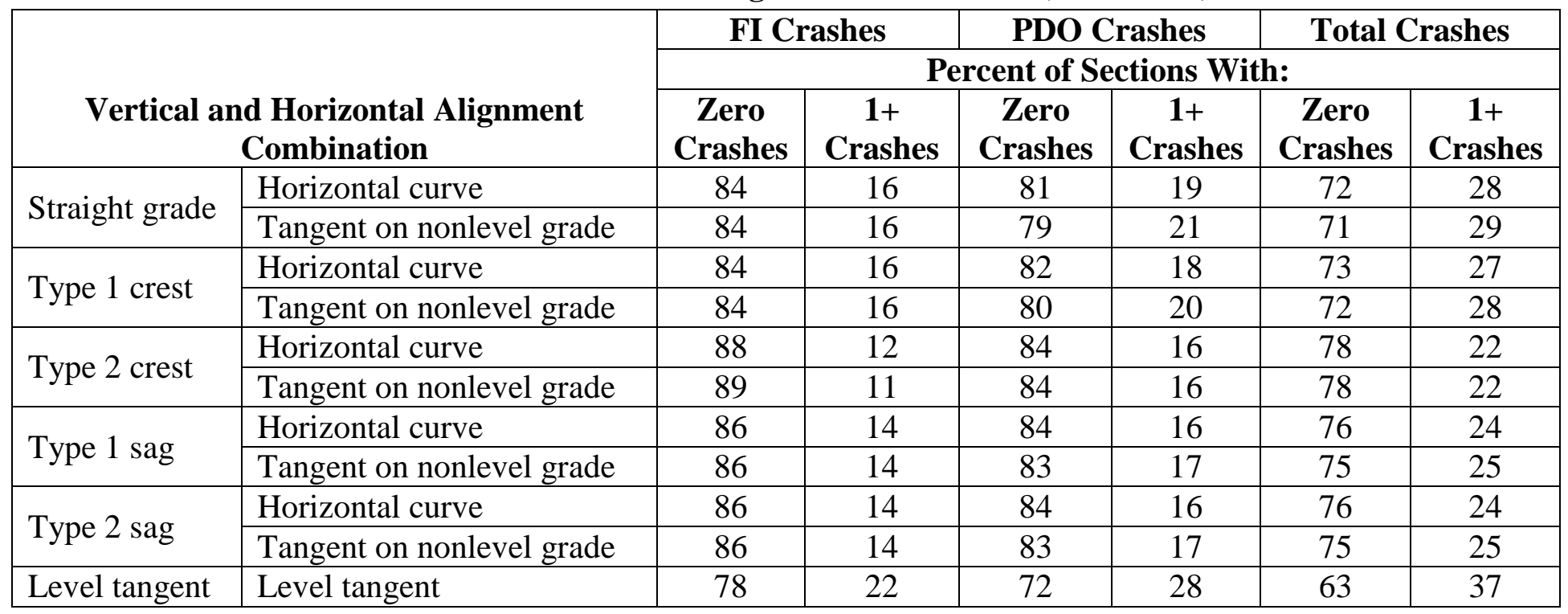

\section{VALUE RANGE OF ROADWAY CHARACTERISTICS}

Prior to statistical modeling, the parameters of interest were assessed for extreme values (both high and low). This was done using a combination of plots of crash rates per MVMT versus selected parameters and distributions of the individual parameters. The following rules were implemented:

- Roadway segments less than $0.01 \mathrm{mi}$ long were excluded from analysis (such short segments likely represent small overlaps in horizontal and vertical features and are unlikely to be useful analysis sections).

- For type 1 crest and type 1 sag vertical curves, segments where both initial $\left(G_{1}\right)$ and final $\left(G_{2}\right)$ grades were less than 1 percent in absolute value were excluded (such minor vertical curves are very close to being level).

- For type 2 crest and type 2 sag vertical curves, segments where $A=a b s\left(G_{1}-G_{2}\right)$ was less than 1 percent were excluded (such minor vertical curves are very close to being straight grades).

- All records with $K$ exceeding 1,000 were excluded (these were typically long, vertical curves with small grade changes and could be classified as straight grades, including level grades).

- All records with a curve radius exceeding $11,460 \mathrm{ft}$ were excluded (these could be classified as tangents for all practical purposes).

- Horizontal curves with a radius less than $100 \mathrm{ft}$ were included in the analysis, but the radius was set at $100 \mathrm{ft}$ based on guidance in the AASHTO HSM. ${ }^{(1)}$ 


\section{CHAPTER 4-STATISTICAL ANALYSIS}

The overall statistical approach to estimating the safety effects of horizontal curve and grade combinations on rural two-lane highways is presented in this chapter along with the results for each type of combination for FI and PDO crashes.

\section{ANALYSIS APPROACH}

The safety effects of horizontal curve and grade combinations are estimated based on a crosssectional analysis using a generalized linear model approach assuming a negative binomial (NB) distribution of crash counts and an exponential model using the combined crash data from all 6 years and selected roadway geometrics. FI and PDO crashes were modeled separately for each of the five types of horizontal curve and grade combinations.

\section{Selection of Independent Variables Considered in Models}

The parameters considered in each model may include the following:

- Average annual daily traffic (AADT) (averaged across all 6 years).

- Segment length.

- Horizontal curve radius.

- Absolute value of percent grade.

- Horizontal curve length.

- Vertical curve length.

- Algebraic difference between the initial and final grades $(A)$.

- $\quad$ Measure of the sharpness of vertical curvature $(K)$.

- Relevant interactions of selected parameters.

For each type of horizontal curve and grade combination, the dataset used for modeling included the roadway segments for the relevant curve and grade combination but also all level tangents (i.e., no horizontal curvature and grade $<1$ percent) to serve as the base condition.

Modeling was performed by encoding each parameter, or a transformation of it, so as to treat roadway segments on horizontal curve and grade combinations separately from tangent roadways on nonlevel grades and from level tangents (base condition). Segments for all of these types were used to develop a single model. This is equivalent to using indicator variables for each type of roadway segment. For example, since the natural log of the inverse radius was used in some of the models, the radius was recoded as $\ln \left(2 \times \frac{5,730}{R}\right)$ based on the following reasoning: 
the smallest value of $\frac{5,730}{R}$ for horizontal curves in the database is 0.5 . Therefore, the ratio, $\frac{5,730}{R}$, was multiplied by 2 such that the smallest value of $\ln \left(2 \times \frac{5,730}{R}\right)$ becomes zero. This term was then set equal to zero for all tangents. This approach ultimately allows for the computation of CMFs using the developed models (discussed in further detail in chapter 5 of this report).

Within each vertical alignment type (i.e., straight grades, type 1 crest vertical curves, type 1 sag vertical curves, type 2 crest vertical curves, and type 2 sag vertical curves), the functional form of the relationship between crash frequency (FI or PDO) and the parameters listed was assessed separately. The following approach was used to explore the appropriate functional form for these relationships:

- Each parameter, other than AADT, was categorized into three groups, which were typically of equal size (tertiles).

- A crash prediction model was developed including AADT and only the interaction of all categorized parameters (this is a standard analysis of variance (ANOVA) using an NB distribution and a log link).

- The safety effect of one parameter was plotted against the cell means of another parameter, encoding the data by the levels of the third parameter. If a four-way interaction was included, then multiple sets of plots were generated.

- The shape of the relationship between safety effects and a given parameter across the levels of another parameter was assessed.

- These trends were assessed for each model to determine whether they were consistent. If not, an assessment was made to determine whether interactions exist.

Based on the visual assessment of these relationships, a final model form was selected using all parameters and relevant interactions. The parameters in these final model forms were continuous variables. In other words, the categorization into three groups was used only for exploring the potential functional forms for the data and was not used in the final models.

Before analyzing crashes on horizontal curves, tangents on nonlevel grades, and level tangents using a single model, the effect of vertical curve characteristics was assessed using tangents alone. This was done by comparing the effect of vertical curve characteristics on crashes/mi/year between level tangents and tangents on nonlevel grades for each type of vertical curve. This subset of data represents the largest proportion of the database. If a vertical curve parameter showed a statistically significant effect for tangents on nonlevel grades, then that parameter was included as such in the model using all three types of roadway (horizontal curves, level tangents, and tangents on nonlevel grades).

An attempt was also made to model crashes on horizontal curves and tangents by allowing separate intercepts and AADT slopes (i.e., an analysis of covariance) for each segment type to assess whether the relationship between crash frequency and AADT differs among horizontal 
curves, tangents on nonlevel grades, and base condition tangents. This modeling effort was inconclusive (e.g., slopes were inconsistent and counterintuitive) and therefore abandoned.

Final crash prediction models were derived for horizontal curves and tangents using the same group of level tangent sections as the base condition for all five horizontal curve and grade combinations. A stepwise approach was used where all parameters and interactions were included. The least significant interaction(s) and then the least significant parameter(s) were eliminated one at a time until all remaining interactions and parameters were significant. This is known as backwards stepwise selection. At each step, extreme data points were excluded from the data using leverage estimates, residuals, or Cook's D criterion, all statistical criteria to evaluate the goodness-of-fit of the model to the data. In general, a 5 percent significance level associated with the type 3 chi-squared statistic was selected. All analyses were performed using a procedure for fitting generalized linear models of SAS ${ }^{\circledR}$ Version 9.3. ${ }^{(10)}$

It should be noted that additional geometric features for roadway segments, such as lane and shoulder widths, were not included in the analysis. The decision to exclude other geometric features was made because they were outside the scope of the current research. Experience with the Zegeer et al. results found that the roadway width term was dropped out of the final CMF. ${ }^{(3,4,6)}$ Also, it was unlikely that the available data would support inclusion of additional terms.

\section{Assessment of Goodness-of-Fit of Final Models}

Once a model for a specific horizontal and vertical alignment combination was finalized, its goodness-of-fit to the observed crash data was evaluated. For each alignment combination and severity level, predicted crash frequencies versus observed frequencies were plotted and assessed to determine how well the data followed the line of equality. However, it should be recognized that perfect or near perfect agreement between predicted and observed crash frequencies should not be expected no matter how good the methodology is. The predicted crash frequencies, at their best, represent an estimate of the long-term average crash frequency for similar roadway segments. The observed crash frequency is simply one observation from a random process whose mean is estimated by the predicted crash frequency. There is no reason to expect that one observation from a random process should exactly equal the long-term mean. In addition, the methodology cannot predict a crash frequency of zero because each model has a positive intercept. This is reasonable because no roadway segment can ever be expected to be crash-free in the long term. However, in any given time period, it is reasonable to expect that many roadway segments, particularly lower volume segments, will experience zero observed crashes.

To assess the goodness-of-fit of each model, the level of agreement between predicted and observed crash frequencies was estimated based on the percentage of extreme observations in the 6-year period at the 5 percent significance level. Consideration of the likelihood of extreme observed crash frequencies, either high or low, is a method that directly takes into account the parameters of the NB distribution (i.e., mean and dispersion) of crash frequencies at a particular type of roadway segment.

Let $O_{i}$ denote the number of observed crashes of a given type (FI or PDO) on a roadway segment, $i$, during the 6-year period. The likelihood of observing $O_{i}$ crashes in 6 years is then 
computed under the assumption that $O_{i}$ is an observation from a NB distribution with mean $\mu_{i}$ and dispersion parameter $k$. The mean is the predicted number of crashes in the 6-year period calculated using the prediction model applicable for roadway segment $i$. The dispersion parameter is obtained when developing the final model.

The likelihood, $p_{i}$, of observing $O_{i}$ or fewer crashes at roadway segment $i$ can then be written as follows:

$$
p_{i}=\operatorname{prob}\left(\text { Number of crashes } \leq O_{i}\right. \text { ) }
$$

Figure 6. Equation. Probability of observing a given number of crashes.

Or:

$$
p_{i}=\sum_{x=0}^{O_{i}} f_{i}(x)
$$

Figure 7. Equation. Probability of observing a given number of crashes expressed as a cumulative distribution.

Where $f_{i}(x)$ is the probability distribution function for an NB with $\mu_{i}$ and $k$ and values of $x=0,1$, $2, \ldots, O_{i}$. If $p_{i} \geq 0.5$, then $p_{i}$ was calculated as $1-p_{i}$. This approach is equivalent to calculating the area under the cumulative distribution curve at either low or high tail of the distribution.

The following two final single-value criteria used to assess how well the observed crash frequencies can be estimated by the proposed methodology are proposed:

- The percent of roadway segments of a given alignment combination with observed crash frequencies outside the upper and lower 2.5 percentile of the theoretical distribution. This value, Pctunlikely, is calculated as follows:

$P c t_{\text {unlikely }}=100$ (Number of segments where $p_{i} \leq 0.025 /$ Total number of segments)

Figure 8. Equation. Percent of roadway segments with unlikely low or high crash numbers.

On average, the value of Pctunlikely would be close to 5 percent if the methodology is to fit the observed data reasonably well because one would expect that on average, 5 percent of the observed values be outside the middle 95 percent of the distribution. Such observed crash frequencies would be considered extreme (low or high) crash frequencies under the estimated distribution.

- The average probability of more extreme than observed crash frequency. This is the average $p_{i}$ across all segments $i$ of a given roadway type for a particular crash type (FI or PDO). On average, the mean would be close to 0.25 if the methodology is to fit the observed data reasonably well. 


\section{ANALYSIS RESULTS}

This section presents the final modeling results for the five alignment categories for rural two-way highways. Each subsection is organized as follows:

- Basic description of database used.

- $\quad$ Final predictive regression equations.

- ANOVA tables.

- Goodness-of-fit results.

For each alignment category considered, a level tangent roadway serves as the base condition.

\section{Horizontal Curves and Tangents on Straight Grades}

The following three alignment combinations shaded in figure 9 were included in the analysis:

- Horizontal curves on straight grades (including both level and nonlevel alignments) (number of roadway segments $(N)=8,095$ and total roadway length $=595 \mathrm{mi}$ ).

- Tangents on nonlevel grades (grade $\geq 1$ percent) $(N=7,569$ and total roadway length $=727 \mathrm{mi})$.

- Level tangents-base condition (grade $<1$ percent) $(N=5,701$ and total roadway length $=779 \mathrm{mi})$.

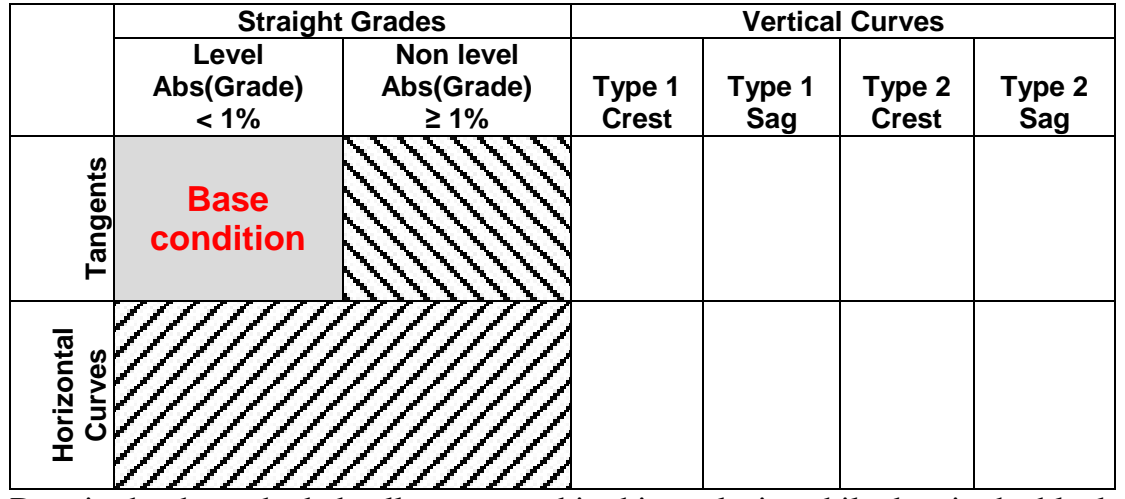

Data in the three shaded cells were used in this analysis, while data in the blank cells were not used in this analysis.

Figure 9. Illustration. Alignment combinations used in the analysis of horizontal curves and tangents on straight grades.

Basic descriptive statistics such as sample size (i.e., number of roadway sections); total roadway length; and minimum, maximum, mean, and median values for specific parameters) are shown in table 7 for each of the three alignment types included in the analysis. 
Table 7. Descriptive statistics for horizontal curves and tangents on straight grades.

\begin{tabular}{|c|c|c|c|c|}
\hline Parameter & Minimum & Maximum & Mean & Median \\
\hline \multicolumn{5}{|c|}{$\begin{array}{l}\text { Horizontal Curves on Straight Grades } \\
(\mathrm{N}=\mathbf{8 , 0 9 5} \text {; total roadway length }=595 \mathrm{mi})\end{array}$} \\
\hline AADT (vehicles/day) & 169 & 26,088 & 2,695 & 1,664 \\
\hline Section length (mi) & 0.01 & 0.75 & 0.07 & 0.05 \\
\hline Horizontal curve length (mi) & 0.01 & 1.19 & 0.15 & 0.11 \\
\hline Curve radius (ft) & 100 & 11,459 & 2,067 & 1,433 \\
\hline Grade (percent) & 0 & 9.67 & 2.11 & 1.53 \\
\hline FI crashes per MVMT & 0 & 39.50 & 0.75 & \\
\hline PDO crashes per MVMT & 0 & 46.26 & 0.91 & \\
\hline Total crashes per MVMT & 0 & 54.62 & 1.66 & \\
\hline \multicolumn{5}{|c|}{$\begin{array}{l}\text { Tangents on Nonlevel Grades } \\
\text { (N = 7,569; total roadway length = } 727 \mathrm{mi})\end{array}$} \\
\hline AADT (vehicles/day) & 169 & 26,088 & 2,700 & 1,644 \\
\hline Section length (mi) & 0.01 & 0.99 & 0.10 & 0.06 \\
\hline \multicolumn{5}{|l|}{ Horizontal curve length (mi) } \\
\hline \multicolumn{5}{|l|}{ Curve radius (ft) } \\
\hline Grade (percent) & 1.00 & 10.85 & 3.10 & 2.64 \\
\hline FI crashes per MVMT & 0 & 39.33 & 0.61 & \\
\hline PDO crashes per MVMT & 0 & 44.14 & 0.80 & \\
\hline Total crashes per MVMT & 0 & 53.48 & 1.42 & \\
\hline \multicolumn{5}{|c|}{$\begin{array}{l}\text { Level Tangents-Base Condition } \\
\text { (N = 5,701; total roadway length = } 779 \mathrm{mi})\end{array}$} \\
\hline AADT (vehicles/day) & 169 & 26,088 & 3,285 & 2,153 \\
\hline Section length (mi) & 0.01 & 0.98 & 0.14 & 0.09 \\
\hline \multicolumn{5}{|l|}{ Horizontal curve length (mi) } \\
\hline \multicolumn{5}{|l|}{ Curve radius (ft) } \\
\hline \multicolumn{5}{|l|}{ Grade (percent) } \\
\hline FI crashes per MVMT & 0 & 34.21 & 0.46 & \\
\hline PDO crashes per MVMT & 0 & 39.50 & 0.67 & \\
\hline Total crashes per MVMT & 0 & 55.38 & 1.13 & \\
\hline
\end{tabular}

Note: No roadway segments exist in the shaded cells.

The final crash prediction models for FI and PDO crashes are as follows:

$$
N_{F I}=\exp \left[b_{0}+b_{1} \ln (\mathrm{AADT})+b_{2} G+b_{3} \ln \left(2 \times \frac{5,730}{\mathrm{R}}\right) \times I_{H C}+b_{4}\left(\frac{1}{\mathrm{R}}\right)\left(\frac{1}{L_{C}}\right) \times I_{H C}\right]
$$

Figure 10. Equation. Predicted FI crashes on horizontal curves and tangents on straight grades (general form).

$$
N_{P D O}=\exp \left[b_{0}+b_{1} \ln (\mathrm{AADT})+b_{2} G+b_{3} \ln \left(2 \times \frac{5,730}{\mathrm{R}}\right) \times I_{H C}+b_{4}\left(\frac{1}{\mathrm{R}}\right)\left(\frac{1}{L_{C}}\right) \times I_{H C}\right]
$$

Figure 11. Equation. Predicted PDO crashes on horizontal curves and tangents on straight grades (general form). 
Where:

$N_{F I}=$ FI crashes per mile per year .

$N_{P D O}=$ PDO crashes per mile per year.

AADT $=$ Vehicles per day.

$G=$ Absolute value of percent grade ( 0 percent for level tangents; $\geq 1$ percent otherwise).

$R=$ Curve radius $(\mathrm{ft})$ (missing for tangents).

$I_{H C}=$ Horizontal curve indicator (1 for horizontal curves; 0 otherwise).

$L_{C}=$ Horizontal curve length (mi) (not applicable for tangents).

$\ln =$ Natural logarithm function.

$b_{0}, \ldots, b_{4}=$ Regression coefficients.

The regression results, including the coefficient estimate, dispersion parameter, standard error, confidence limit, chi-squared statistic, and significance level for all statistically significant parameters and interaction are shown in table 8.

Table 8. FI and PDO crash modeling results for horizontal curves and tangents on straight grades.

\begin{tabular}{|c|c|c|c|c|c|c|c|}
\hline $\begin{array}{l}\text { Parameter } \\
\text { Description }\end{array}$ & $\begin{array}{l}\text { Regression } \\
\text { Coefficient }\end{array}$ & $\begin{array}{c}\text { Coefficient } \\
\text { Estimate }\end{array}$ & $\begin{array}{c}\text { Standard } \\
\text { Error }\end{array}$ & $\begin{array}{c}\text { Lower } \\
\text { 95 Percent } \\
\text { Confidence } \\
\text { Limit } \\
\end{array}$ & $\begin{array}{c}\text { Upper } \\
95 \text { Percent } \\
\text { Confidence } \\
\text { Limit } \\
\end{array}$ & $\begin{array}{c}\text { Chi- } \\
\text { Squared } \\
\text { Statistic }\end{array}$ & $\begin{array}{c}\text { Significance } \\
\text { Level }\end{array}$ \\
\hline \multicolumn{8}{|c|}{ FI Crashes/Mi/Year } \\
\hline Intercept & $b_{0}$ & -8.76 & 0.15 & -9.05 & -8.46 & N/A & $\mathrm{N} / \mathrm{A}$ \\
\hline $\ln (\mathrm{AADT})$ & $b_{1}$ & 1.00 & 0.02 & 0.96 & 1.03 & $3,052.7$ & $<0.0001$ \\
\hline Grade & $b_{2}$ & 0.044 & 0.01 & 0.03 & 0.06 & 27.5 & $<0.0001$ \\
\hline $\begin{array}{l}\text { 1/radius } \\
\text { term }^{\mathrm{a}}\end{array}$ & $b_{3}$ & 0.19 & 0.02 & 0.16 & 0.22 & 116.3 & $<0.0001$ \\
\hline $\begin{array}{l}1 / \mathrm{R} \times 1 / L_{C} \\
\text { interaction }\end{array}$ & $b_{4}$ & 4.52 & 0.79 & 2.97 & 6.07 & 26.8 & $<0.0001$ \\
\hline Dispersion & N/A & 0.85 & 0.04 & 0.77 & 0.94 & N/A & N/A \\
\hline \multicolumn{8}{|c|}{ PDO Crashes/Mi/Year } \\
\hline Intercept & $b_{0}$ & -8.63 & 0.14 & -8.89 & -8.36 & N/A & N/A \\
\hline $\ln (\mathrm{AADT})$ & $b_{1}$ & 1.03 & 0.02 & 1.00 & 1.06 & $4,003.5$ & $<0.0001$ \\
\hline Grade & $b_{2}$ & 0.040 & 0.01 & 0.03 & 0.05 & 29.1 & $<0.0001$ \\
\hline $\begin{array}{l}\text { 1/radius } \\
\text { term }^{a}\end{array}$ & $b_{3}$ & 0.13 & 0.02 & 0.10 & 0.16 & 67.4 & $<0.0001$ \\
\hline $\begin{array}{l}1 / \mathrm{R} \times \mathrm{I} / L_{C} \\
\text { interaction }\end{array}$ & $b_{4}$ & 3.80 & 0.84 & 2.15 & 5.45 & 17.3 & $<0.0001$ \\
\hline Dispersion & N/A & 0.80 & 0.03 & 0.73 & 0.87 & N/A & N/A \\
\hline
\end{tabular}

${ }^{\mathrm{a}} 1 /$ radius term $=\ln (2 \times 5,730 / \mathrm{R})$.

N/A = Not applicable.

Applying figure 8, the percentage of roadway segments with extremely high observed FI crash frequencies was 6.09 percent across all roadway segments, which was only slightly above the expected 5 percent. The percentages were 6.12 percent for segments on level tangents, 6.25 percent for segments on tangents on nonlevel grades, and 5.91 percent for segments on 
horizontal curves on straight grades, indicating that a few roadway segments in these roadway categories experienced unusually high FI crash frequencies given the prediction model used. None of the segments experienced extremely low FI crash frequencies under the assumed model at the 5 percent significance level.

Similarly, the percentage of roadway segments with extremely high observed PDO crash frequencies was 6.56 percent across all roadway segments, which was slightly higher than that for FI crashes. The percentages were 6.71 percent for segments on level tangents, 6.90 percent for segments on tangents on nonlevel grades, and 6.14 percent for segments on horizontal curves on straight grades, indicating that a few roadway segments in these roadway categories experienced unusually high PDO crash frequencies given the prediction model used. None of the segments experienced extremely low PDO crash frequencies under the assumed model at the 5 percent significance level.

The average probability of predicting a more extreme than observed FI crash frequency was calculated using figure 7 . Across all roadway segments, the average probability was 0.13 . The average probability was 0.14 for segments on level tangents, 0.11 for segments on tangents on nonlevel grades, and 0.13 for segments on horizontal curves on straight grades, all considerably lower than the theoretically expected value of 0.25 .

Similarly, the average probability of predicting a more extreme than observed PDO crash frequency was 0.14 across all roadway segments. The average probability was 0.16 for segments on level tangents, 0.13 for segments on tangents on nonlevel grades, and 0.15 for segments on horizontal curves on straight grades, all considerably lower than the theoretically expected value of 0.25. For both FI and PDO crashes, these low probabilities are an indication that the model might not provide an adequate fit to the data. This is not too surprising given the large number of roadway segments with a wide range of AADTs and geometrics and a high percentage of segments with zero crashes.

Substituting the regression coefficients in figure 10 and figure 11 with their corresponding estimates in table 8, the prediction models for FI and PDO crashes/mi/year are as follows:

$N_{F I}=\exp \left[-8.76+1.00 \ln (\mathrm{AADT})+0.044 G+0.19 \ln \left(2 \times \frac{5,730}{\mathrm{R}}\right) \times I_{H C}+4.52\left(\frac{1}{\mathrm{R}}\right)\left(\frac{1}{L_{C}}\right) \times I_{H C}\right]$

Figure 12. Equation. Predicted FI crashes on horizontal curves and tangents on straight grades (explicit form).

$N_{P D O}=\exp \left[-8.63+1.03 \ln (\mathrm{AADT})+0.040 G+0.13 \ln \left(2 \times \frac{5,730}{\mathrm{R}}\right) \times I_{H C}+3.80\left(\frac{1}{\mathrm{R}}\right)\left(\frac{1}{L_{C}}\right) \times I_{H C}\right]$

Figure 13. Equation. Predicted PDO crashes on horizontal curves and tangents on straight grades (explicit form).

$$
N_{\text {Total }}=N_{F I}+N_{P D O}
$$

Figure 14. Equation. Predicted total crashes on horizontal curves and tangents on straight grades (general form). 
Table 8 clearly shows that AADT is the most predominant predictor of crashes as indicated by its high chi-squared statistic. Other parameters and interaction are one or two orders of magnitude smaller and indicate that once the variability due to traffic volume is accounted for, the remaining parameters explain only a small portion of the remaining variability in the data. This is a consistent trait across all models developed in this project.

These final models include only two significant parameters and an interaction from the list of parameters and interactions originally considered. This is in large part because all safety effects are estimated relative to level tangents as the base condition. Crash frequencies in this group of roadway segments alone (5,701 segments for a total of $779 \mathrm{mi}$ ) exhibit considerable variability (e.g., FI crash rates range from zero to 34.21 with a mean of 0.46 and a median of zero crashes per MVMT as shown in table 7). To detect a significant effect of any horizontal curve characteristic on straight grades, the effect of such a characteristic would need to be large relative to the variability in the base condition set. This, in effect, is the challenge in finding statistically significant safety effects of practical engineering relevance.

Figure 12 and figure 13 show that crash frequency increases with increasing percent grade and decreases with increasing curve radius, as expected. The interaction term between radius and curve length represents an additional effect on safety for short and sharp horizontal curves —as the radius decreases and the curve shortens, the last term in figure 12 and figure 13 increases, adding to the crash frequency. For long horizontal curves and curves with larger radii, this term approaches zero and thus will have little impact on the predicted crash frequency.

Of interest is the fact that the effects of percent grade, curve radius, and the interaction between radius and curve length is more pronounced for FI crashes than for PDO crashes.

Initial modeling effects indicated that there might be an interaction between horizontal curve radius and percent grade on straight grade segments, suggesting that the effect of curve radius on crash frequency might change with increasing percent grade. However, this effect was found to be an artifact of a few data points that were clearly outliers. These outliers were eliminated from the dataset used to produce the final models presented in figure 12 and figure 13. Thus, the analysis did not find a statistically significant interaction between horizontal curve radius and percent grade. The results of the study presented in this report are as follows:

- The results show an interaction between horizontal curve radius and length, such that short and sharp horizontal curves have particularly high crash frequencies.

- The effects of horizontal curve radius, horizontal curve length, and percent grade were fit in the same model rather than in separate research studies, as is the case with the curve and grade effects currently in the HSM.

\section{Horizontal Curves and Tangents at Type 1 Crest Vertical Curves}

The following three alignment combinations shaded in figure 15 were included in the analysis:

- Horizontal curves at type 1 crest vertical curves $(N=1,219$ and total roadway length $=87 \mathrm{mi})$. 
- $\quad$ Tangents at type 1 crest vertical curves $(N=2,089$ and total roadway length $=200 \mathrm{mi})$.

- Level tangents—base condition (grade $<1$ percent) $(N=5,743$ and total roadway length $=833 \mathrm{mi})$.

\begin{tabular}{|c|c|c|c|c|c|c|}
\hline & \multicolumn{2}{|c|}{ Straight Grades } & \multicolumn{4}{|c|}{ Vertical Curves } \\
\hline & $\begin{array}{c}\text { Level } \\
\text { Abs(Grade) } \\
<1 \text { percent }\end{array}$ & $\begin{array}{c}\text { Nonlevel } \\
\text { Abs(Grade) } \\
\geq 1 \text { percent }\end{array}$ & $\begin{array}{c}\text { Type } 1 \\
\text { Crest }\end{array}$ & $\begin{array}{c}\text { Type } 1 \\
\text { Sag }\end{array}$ & $\begin{array}{c}\text { Type } 2 \\
\text { Crest }\end{array}$ & $\begin{array}{c}\text { Type } 2 \\
\text { Sag }\end{array}$ \\
\hline 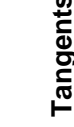 & $\begin{array}{c}\text { Base } \\
\text { Condition }\end{array}$ & & & & & \\
\hline 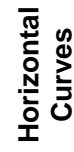 & & & & & & \\
\hline
\end{tabular}

Note: Data in the three shaded cells were used in this analysis, while data in the blank cells were not used in this analysis.

Figure 15. Illustration. Alignment combinations used in the analysis of horizontal curves and tangents at type 1 crest vertical curves.

Basic descriptive statistics such as sample size (i.e., number of roadway sections); total roadway length; and minimum, maximum, mean, and median values for specific parameters are shown in table 9 for each of the three alignment types included in the analysis.

Table 9. Descriptive statistics for horizontal curves and tangents at type 1 crest vertical curves.

\begin{tabular}{|l|r|r|r|r|}
\hline \multicolumn{1}{|c|}{ Parameter } & Minimum & Maximum & Mean & Median \\
\hline $\begin{array}{l}\text { Horizontal Curves at Type 1 Crest Vertical Curves } \\
\text { (N = 1,219; total roadway length = 87 mi) }\end{array}$ \\
\hline AADT (vehicles/day) & 175 & 26,088 & 3,059 & 1,877 \\
\hline Section length (mi) & 0.01 & 0.72 & 0.07 & 0.06 \\
\hline Horizontal curve length (mi) & 0.02 & 1.00 & 0.16 & 0.12 \\
\hline Curve radius (ft) & 100 & 11,459 & 2,102 & 1,433 \\
\hline Vertical curve length (ft) & 100 & 4,000 & 824 & 600 \\
\hline A & 1.0 & 14.7 & 5.2 & 4.9 \\
\hline$K$ & 11.1 & 985.2 & 186.2 & 147.9 \\
\hline FI crashes per MVMT & 0 & 23.10 & 0.55 & 0 \\
\hline PDO crashes per MVMT & 0 & 28.12 & 0.66 & 0 \\
\hline Total crashes per MVMT & 0 & 28.12 & 1.21 & 0 \\
\hline $\begin{array}{l}\text { Tangents at Type 1 Crest Vertical Curves } \\
\text { (N = 2,089; nonlevel total roadway length = 200 mi) }\end{array}$ & & \\
\hline AADT (vehicles/day) & 169 & 26,088 & 3,105 & 1,858 \\
\hline Section length (mi) & 0.01 & 0.59 & 0.10 & 0.08 \\
\hline Horizontal curve length (mi) & & & & \\
\hline Curve radius (ft) & 60 & 4,000 & 776 & 600 \\
\hline Vertical curve length (ft) & &
\end{tabular}




\begin{tabular}{|c|c|c|c|c|}
\hline Parameter & Minimum & Maximum & Mean & Median \\
\hline$A$ & 1.0 & 14.7 & 4.7 & 4.3 \\
\hline$K$ & 5.4 & 985.2 & 192.4 & 151.5 \\
\hline FI crashes per MVMT & 0 & 20.85 & 0.40 & 0 \\
\hline PDO crashes per MVMT & 0 & 25.43 & 0.57 & 0 \\
\hline Total crashes per MVMT & 0 & 33.85 & 0.98 & 0 \\
\hline \multicolumn{5}{|c|}{$\begin{array}{l}\text { Level Tangents-Base Condition } \\
(\mathrm{N}=5,743 \text {; total roadway length }=833 \mathrm{mi})\end{array}$} \\
\hline AADT (vehicles/day) & 169 & 26,088 & 3,287 & 2,160 \\
\hline Section length (mi) & 0.01 & 2.10 & 0.15 & 0.09 \\
\hline \multicolumn{5}{|l|}{ Horizontal curve length (mi) } \\
\hline \multicolumn{5}{|l|}{ Curve radius (ft) } \\
\hline \multicolumn{5}{|l|}{ Vertical curve length (ft) } \\
\hline \multicolumn{5}{|l|}{$A$} \\
\hline \multicolumn{5}{|l|}{$K$} \\
\hline FI crashes per MVMT & 0 & 34.21 & 0.46 & 0 \\
\hline PDO crashes per MVMT & 0 & 39.50 & 0.67 & 0 \\
\hline Total crashes per MVMT & 0 & 39.50 & 1.13 & 0 \\
\hline
\end{tabular}

Note: No roadway segments exist in the shaded cells.

The final crash prediction models for FI and PDO crashes are as follows:

$$
N_{F I}=\exp \left[b_{0}+b_{1} \ln (\mathrm{AADT})+b_{2}\left(\frac{5,730}{\mathrm{R}}\right) A \times I_{V C} \times H C\right]
$$

Figure 16. Equation. Predicted FI crashes on horizontal curves and tangents at type 1 crest vertical curves (general form).

$$
N_{P D O}=\exp \left[b_{0}+b_{1} \ln (\mathrm{AADT})+b_{2}\left(\frac{5,730}{\mathrm{R}}\right) A \times I_{V C} \times H C\right]
$$

Figure 17. Equation. Predicted PDO crashes on horizontal curves and tangents at type 1 crest vertical curves (general form).

Where:

$A=\operatorname{abs}\left(G_{1}-G_{2}\right)$ (percent); not applicable for level tangents.

$G_{1}=$ Initial grade (percent) (positive for upgrade; negative for downgrade).

$G_{2}=$ Final grade (percent) (positive for upgrade; negative for downgrade).

$I_{V C} \times H C=$ Combined vertical and horizontal curve indicator (1 for combined vertical and horizontal curves; 0 otherwise).

The regression results, including the significant interaction, are shown in table 10. 
Table 10. FI and PDO crash modeling results for horizontal curves and tangents at type 1 crest vertical curves.

\begin{tabular}{|c|c|c|c|c|c|c|c|}
\hline $\begin{array}{l}\text { Parameter } \\
\text { Description }\end{array}$ & $\begin{array}{l}\text { Regression } \\
\text { Coefficient }\end{array}$ & $\begin{array}{c}\text { Coefficient } \\
\text { Estimate } \\
\end{array}$ & $\begin{array}{c}\text { Standard } \\
\text { Error }\end{array}$ & $\begin{array}{c}\text { Lower } \\
\text { 95 Percent } \\
\text { Confidence } \\
\text { Limit } \\
\end{array}$ & $\begin{array}{c}\text { Upper } \\
95 \text { Percent } \\
\text { Confidence } \\
\text { Limit } \\
\end{array}$ & $\begin{array}{c}\text { Chi- } \\
\text { Squared } \\
\text { Statistic }\end{array}$ & $\begin{array}{c}\text { Significance } \\
\text { Level }\end{array}$ \\
\hline \multicolumn{8}{|c|}{ FI Crashes/Mi/Year } \\
\hline Intercept & $b_{0}$ & -9.56 & 0.23 & -10.01 & -9.11 & N/A & N/A \\
\hline $\ln (\mathrm{AADT})$ & $b_{1}$ & 1.09 & 0.03 & 1.04 & 1.15 & $1,661.0$ & $<0.0001$ \\
\hline $\begin{array}{l}1 / \mathrm{R} \times A \\
\text { interaction }^{\mathrm{a}}\end{array}$ & $b_{2}$ & 0.0088 & 0.003 & 0.004 & 0.014 & 11.1 & 0.001 \\
\hline Dispersion & N/A & 0.70 & 0.05 & 0.60 & 0.81 & N/A & N/A \\
\hline \multicolumn{8}{|c|}{ PDO Crashes/Mi/Year } \\
\hline Intercept & $b_{0}$ & -8.46 & 0.20 & -8.85 & -8.08 & N/A & N/A \\
\hline $\ln (\mathrm{AADT})$ & $b_{1}$ & 1.01 & 0.02 & 0.96 & 1.05 & $1,858.8$ & $<0.0001$ \\
\hline $\begin{array}{l}1 / \mathrm{R} \times A \\
\text { interaction }^{\mathrm{a}}\end{array}$ & $b_{2}$ & 0.0046 & 0.002 & 0.001 & 0.008 & 6.4 & 0.011 \\
\hline Dispersion & N/A & 0.72 & 0.04 & 0.64 & 0.82 & N/A & N/A \\
\hline
\end{tabular}

a $1 / \mathrm{R} \times A$ interaction $=(5,730 / \mathrm{R}) \times A$.

N/A = Not applicable.

Using figure 8, the percentage of roadway segments with extremely high observed FI crash frequencies was 6.50 percent across all roadway segments, which was slightly above the expected 5 percent. The percentages of roadway segments with extremely high observed FI crash frequencies were 6.37 percent for level tangents, 6.52 percent for tangents at type 1 crests, and 7.08 percent for horizontal curves on type 1 crests, indicating that a few roadway segments in these roadway categories experienced unusually high FI crash frequencies given the prediction model used. None of the segments experienced extremely low FI crash frequencies under the assumed model at the 5 percent significance level.

Similarly, the percentage of roadway segments with extremely high observed PDO crash frequencies was 6.70 percent across all roadway segments, similar to that for FI crashes. The percentages were 7.00 percent for level tangents, 5.94 percent for tangents at type 1 crests, and 6.59 percent for horizontal curves on type 1 crests, indicating that a few roadway segments in these roadway categories experienced unusually high FI crash frequencies given the prediction model used. None of the segments experienced extremely low FI crash frequencies under the assumed model at the 5 percent significance level.

The average probability of predicting a more extreme than observed FI crash frequency was calculated using figure 7 . Across all roadway segments, the average probability was 0.13 . The probability was 0.13 for level tangents, 0.11 for tangents at type 1 crests, and 0.11 for horizontal curves on type 1 crests, which are all considerably lower than the theoretically expected value of 0.25 .

Similarly, the average probability of predicting a more extreme than observed PDO crash frequency was 0.15 across all roadway segments. The probability was 0.16 for level tangents, 0.14 for tangents on type 1 crests, and 0.13 for horizontal curves on type 1 crests, which are all 
considerably lower than the theoretically expected value of 0.25 . For both FI and PDO crashes, these low probabilities indicate that the model might not provide an adequate fit to the data.

Substituting the regression coefficients in figure 16 and figure 17 with their corresponding estimates shown in table 10, the prediction models for FI and PDO crashes/mi/year are obtained as follows:

$$
N_{F I}=\exp \left[-9.56+1.09 \ln (\mathrm{AADT})+0.0088\left(\frac{5,730}{\mathrm{R}}\right) A \times I_{V C \times H C}\right]
$$

Figure 18. Equation. Predicted FI crashes on horizontal curves and tangents at type 1 crest vertical curves (explicit form).

$$
N_{P D O}=\exp \left[-8.46+1.01 \ln (\mathrm{AADT})+0.0046\left(\frac{5,730}{\mathrm{R}}\right) A \times I_{V C \times H C}\right]
$$

\section{Figure 19. Equation. Predicted PDO crashes on horizontal curves and tangents at type 1 crest vertical curves (explicit form).}

For horizontal curves and tangents at type 1 crest vertical curves, only the interaction term between curve radius (a characteristic of horizontal curves) and $A$, the algebraic difference in initial and final grades (a vertical curve characteristic), was found to be statistically significant. Crash frequency increased with the combination of decreasing curve radius and an increasing difference in grades.

Of interest is the fact that the marginal effect of the interaction, once the effect of AADT is accounted for, is very small as indicated by the extremely small chi-squared value in comparison to that for AADT (shown in table 10). After traffic volume was accounted for, there was little difference among the three roadway groups (i.e., level tangents, tangents on nonlevel grades, and horizontal curves at type 1 crest vertical curves). The argument can be made that the crash variability in all three groups was large (as seen in table 9). Additionally, the horizontal curves group consisted of only $87 \mathrm{mi}$ of roadway as compared to the $833 \mathrm{mi}$ of level tangents and $200 \mathrm{mi}$ of tangents at type 1 crests.

In summary, the predictive model developed for type 1 crest vertical curves includes a term representing the interaction between the horizontal curve radius and the algebraic difference in grade for the crest vertical curve. The main effects of horizontal curve radius and algebraic difference in grade were not statistically significant. The interaction term indicates that the crash frequency increased as the horizontal curve radius decreased, the length of the vertical curve increased, and the sharpness of the vertical curve increased (i.e., as $K$ decreases). This interaction term, while not nearly as strongly related to crash frequency as AADT, is potentially useful in the AASHTO HSM because it currently does not contain CMFs for crest vertical curves. $^{(1)}$

A model with a main effect or interaction for $K$, representing the sharpness of the vertical curve, would potentially be more useful to designers than a model containing the algebraic difference in grade. However, neither the main effect of $K$ nor any interactions involving $K$ were statistically significant for type 1 crest vertical curves. The models in figure 18 and figure 19 can also be written with $L_{V C} / K$ substituted for $A$. The effect expressed in this form makes engineering sense 
as it indicates that crash frequency would increase as the length of the vertical curve increases and as the sharpness of the vertical curve increases (i.e., as $K$ gets smaller). Therefore, it is suggested that figure 18 and figure 19 be recast as follows:

$$
N_{F I}=\exp \left[b_{0}+b_{1} \ln (\mathrm{AADT})+b_{2}\left(\frac{5,730}{\mathrm{R}}\right)\left(\frac{\mathrm{L}_{\mathrm{VC}}}{K}\right) \times I_{V C} \times H C\right]
$$

Figure 20. Equation. Predicted FI crashes on horizontal curves and tangents at type 1 crest vertical curves (alternate form).

$$
N_{P D O}=\exp \left[b_{0}+b_{1} \ln (\mathrm{AADT})+b_{2}\left(\frac{5,730}{\mathrm{R}}\right)\left(\frac{L_{V C}}{K}\right) \times I_{V C} \times H C\right]
$$

Figure 21. Equation. Predicted PDO crashes on horizontal curves and tangents at type 1 crest vertical curves (alternate form).

\section{Horizontal Curves and Tangents at Type 1 Sag Vertical Curves}

The following three alignment combinations shaded in figure 22 were included in the analysis:

- Horizontal curves at type 1 sag vertical curves ( $N=982$ and total roadway length $=57 \mathrm{mi})$.

- $\quad$ Tangents at type 1 sag vertical curves $(N=1,973$ and total roadway length $=145 \mathrm{mi})$.

- Level tangents-base condition (grade $<1$ percent) $(N=5,744$ and total roadway length

\begin{tabular}{|c|c|c|c|c|c|c|}
\hline & \multicolumn{2}{|c|}{ Straight Grades } & \multicolumn{4}{|c|}{ Vertical Curves } \\
\hline & $\begin{array}{c}\text { Level } \\
\text { Abs(Grade) } \\
<1 \text { percent } \\
\end{array}$ & $\begin{array}{c}\text { Nonlevel } \\
\text { Abs(Grade) } \\
\geq 1 \text { percent } \\
\end{array}$ & $\begin{array}{c}\text { Type } 1 \\
\text { Crest }\end{array}$ & $\begin{array}{c}\text { Type } 1 \\
\text { Sag }\end{array}$ & $\begin{array}{c}\text { Type } 2 \\
\text { Crest }\end{array}$ & $\begin{array}{c}\text { Type } 2 \\
\text { Sag } \\
\end{array}$ \\
\hline 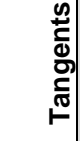 & $\begin{array}{c}\text { Base } \\
\text { condition }\end{array}$ & & & & & \\
\hline 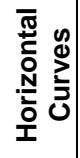 & & & & & & \\
\hline
\end{tabular}
$=833 \mathrm{mi})$.

Note: Data in the three shaded cells were used in this analysis, while data in the blank cells were not used in this analysis.

Figure 22. Illustration. Alignment combinations used in the analysis of horizontal curves and tangents at type 1 sag vertical curves.

Basic descriptive statistics such as sample size (i.e., number of roadway sections); total roadway length; and minimum, maximum, mean, and median values for specific parameters are shown in table 11 for each of the three alignment types included in the analysis. 
Table 11. Descriptive statistics for horizontal curves and tangents at type 1 sag vertical curves.

\begin{tabular}{|c|c|c|c|c|}
\hline Parameter & Minimum & Maximum & Mean & Median \\
\hline \multicolumn{5}{|c|}{$\begin{array}{l}\text { Horizontal Curves at Type } 1 \text { Sag Vertical Curves } \\
\text { (N=982; total roadway length }=57 \mathrm{mi})\end{array}$} \\
\hline AADT (vehicles/day) & 169 & 19,373 & 3,074 & 1,821 \\
\hline Section length (mi) & 0.01 & 0.31 & 0.06 & 0.05 \\
\hline Horizontal curve length (mi) & 0.01 & 1.00 & 0.15 & 0.12 \\
\hline Curve radius (ft) & 100 & 11,459 & 2,085 & 1,433 \\
\hline Vertical curve length (ft) & 92 & 2,200 & 545 & 500 \\
\hline$A$ & 1.0 & 13.0 & 4.4 & 3.8 \\
\hline K & 10.4 & 966.2 & 153.2 & 116.4 \\
\hline FI crashes per MVMT & 0 & 36.61 & 0.71 & \\
\hline PDO crashes per MVMT & 0 & 21.35 & 0.81 & \\
\hline Total crashes per MVMT & 0 & 52.06 & 1.53 & \\
\hline \multicolumn{5}{|c|}{$\begin{array}{l}\text { Tangents at Type } 1 \text { Sag Vertical Curves } \\
\text { (N=1,973; total roadway length }=145 \mathrm{mi} \text { ) }\end{array}$} \\
\hline AADT (vehicles/day) & 175 & 26,088 & 3,098 & 1,828 \\
\hline Section length (mi) & 0.01 & 0.51 & 0.07 & 0.06 \\
\hline \multicolumn{5}{|l|}{ Horizontal curve length (mi) } \\
\hline \multicolumn{5}{|l|}{ Curve radius $(\mathrm{ft})$} \\
\hline Vertical curve length (ft) & 60 & 2,800 & 523 & 400 \\
\hline$A$ & 1.0 & 15.1 & 4.2 & 3.6 \\
\hline K & 6.8 & 969.7 & 153.0 & 120.2 \\
\hline FI crashes per MVMT & 0 & 46.26 & 0.48 & \\
\hline PDO crashes per MVMT & 0 & 40.11 & 0.65 & 0 \\
\hline Total crashes per MVMT & 0 & 70.19 & 1.12 & \\
\hline \multicolumn{5}{|c|}{$\begin{array}{l}\text { Level Tangents-Base Condition } \\
\text { (N=5,744; total roadway length }=833 \mathrm{mi})\end{array}$} \\
\hline AADT (vehicles/day) & 169 & 26,088 & 3,287 & 2,160 \\
\hline Section length (mi) & 0.01 & 2.10 & 0.15 & 0.09 \\
\hline \multicolumn{5}{|l|}{ Horizontal curve length (mi) } \\
\hline \multicolumn{5}{|l|}{ Curve radius (ft) } \\
\hline \multicolumn{5}{|l|}{ Vertical curve length (ft) } \\
\hline \multirow{2}{*}{\multicolumn{5}{|c|}{$\begin{array}{l}A \\
K\end{array}$}} \\
\hline & & & & \\
\hline FI crashes per MVMT & 0 & 34.21 & 0.46 & 0 \\
\hline PDO crashes per MVMT & 0 & 39.50 & 0.67 & 0 \\
\hline Total crashes per MVMT & 0 & 55.38 & 1.14 & 0 \\
\hline
\end{tabular}

Note: No roadway segments exist in the shaded cells. 
The final crash prediction models for FI and PDO crashes are as follows:

$$
N_{F I}=\exp \left[b_{0}+b_{1} \ln (\mathrm{AADT})+b_{2} \frac{1}{K} \times I_{V C}+b_{3}\left(\frac{5,730}{\mathrm{R}}\right) A \times I_{V C \times H C}\right]
$$

Figure 23. Equation. Predicted FI crashes on horizontal curves and tangents at type 1 sag vertical curves (general form).

$$
N_{P D O}=\exp \left[b_{0}+b_{1} \ln (\mathrm{AADT})+b_{2} \frac{1}{K} \times I_{V C}+b_{3}\left(\frac{5,730}{\mathrm{R}}\right) A \times I_{V C \times H C}\right]
$$

Figure 24. Equation. Predicted PDO crashes on horizontal curves and tangents at type 1 sag vertical curves (general form).

Where:

$K=L_{V C} / A$; not applicable for level tangents.

$L_{V C}=$ Vertical curve length (ft).

$I_{V C}=$ Vertical curve indicator (1 for vertical curves; 0 otherwise).

The regression results, including all statistically significant parameters and interaction, are shown in table 12.

Table 12. FI and PDO crash modeling results for horizontal curves and tangents at type 1

\begin{tabular}{|c|c|c|c|c|c|c|c|}
\hline $\begin{array}{l}\text { Parameter } \\
\text { Description }\end{array}$ & $\begin{array}{l}\text { Regression } \\
\text { Coefficient }\end{array}$ & $\begin{array}{c}\text { Coefficient } \\
\text { Estimate }\end{array}$ & $\begin{array}{l}\text { Standard } \\
\text { Error }\end{array}$ & $\begin{array}{c}\text { Lower } \\
95 \text { percent } \\
\text { Confidence } \\
\text { Limit }\end{array}$ & $\begin{array}{c}\text { Upper 95 } \\
\text { percent } \\
\text { Confidence } \\
\text { Limit }\end{array}$ & $\begin{array}{c}\text { Chi- } \\
\text { Squared } \\
\text { Statistic }\end{array}$ & $\begin{array}{c}\text { Significance } \\
\text { Level }\end{array}$ \\
\hline \multicolumn{8}{|c|}{ FI Crashes/Mi/Year } \\
\hline Intercept & $b_{0}$ & -9.55 & 0.24 & -10.02 & -9.08 & N/A & $\mathrm{N} / \mathrm{A}$ \\
\hline $\ln (\mathrm{AADT})$ & $b_{1}$ & 1.10 & 0.03 & 1.04 & 1.15 & $1,516.6$ & $<0.0001$ \\
\hline $1 / K$ & $b_{2}$ & 10.51 & 5.18 & 0.36 & 20.66 & 3.9 & 0.048 \\
\hline $\begin{array}{l}1 / \mathrm{R} \times A \\
\text { interaction }^{\mathrm{a}}\end{array}$ & $b_{3}$ & 0.011 & 0.003 & 0.005 & 0.017 & 12.3 & 0.0005 \\
\hline Dispersion & N/A & 0.86 & 0.06 & 0.75 & 0.99 & N/A & $\mathrm{N} / \mathrm{A}$ \\
\hline \multicolumn{8}{|c|}{ PDO Crashes/Mi/Year } \\
\hline Intercept & $b_{0}$ & -8.63 & 0.20 & -9.03 & -8.24 & & \\
\hline $\ln (\mathrm{AADT})$ & $b_{1}$ & 1.03 & 0.03 & 0.98 & 1.08 & $1,776.9$ & $<0.0001$ \\
\hline $1 / K$ & $b_{2}$ & 8.62 & 4.41 & -0.02 & 17.26 & 3.7 & 0.055 \\
\hline $\begin{array}{l}1 / \mathrm{R} \times A \\
\text { interaction }^{\mathrm{a}}\end{array}$ & $b_{3}$ & 0.010 & 0.002 & 0.005 & 0.014 & 16.7 & $<0.0001$ \\
\hline Dispersion & N/A & 0.79 & 0.05 & 0.70 & 0.89 & N/A & $\mathrm{N} / \mathrm{A}$ \\
\hline
\end{tabular}
sag vertical curves.

${ }_{\mathrm{a}} 1 / \mathrm{R} \times A$ interaction $=(5,730 / \mathrm{R}) \times A$.

N/A $=$ Not applicable .

Using figure 8, the percentage of roadway segments with extremely high observed FI crash frequencies was 5.90 percent across all roadway segments, slightly above the expected 5 percent. The percentages of roadway segments with extremely high observed FI crash frequencies were 
6.03 percent for level tangents, 5.23 percent for tangents at type 1 sags, and 6.51 percent for horizontal curves on type 1 sags, indicating that a few roadway segments in these roadway categories experienced unusually high FI crash frequencies given the prediction model used. None of the segments experienced extremely low FI crash frequencies under the assumed model at the 5 percent significance level.

Similarly, the percentage of roadway segments with extremely high observed PDO crash frequencies was 6.60 percent across all roadway segments, slightly higher than that for FI crashes. The percentages were 6.79 percent for level tangents, 6.39 percent for tangents at type 1 sags, and 5.90 percent for horizontal curves on type 1 sags, indicating that a few roadway segments in these roadway categories experienced unusually high FI crash frequencies given the prediction model used. None of the segments experienced extremely low FI crash frequencies under the assumed model at the 5 percent significance level.

The average probability of predicting a more extreme than observed FI crash frequency was calculated using figure 7 . Across all roadway segments, the average probability was 0.13 . The probability was 0.14 for level tangents, 0.11 for tangents at type 1 sags, and 0.12 for horizontal curves on type 1 sags, which were all considerably lower than the theoretically expected value of 0.25 .

Similarly, the average probability of predicting a more extreme than observed PDO crash frequency was 0.15 across all roadway segments. The probability was 0.16 for level tangents, 0.14 for tangents on type 1 sags, and 0.14 for horizontal curves on type 1 sags, which were all considerably lower than the theoretically expected value of 0.25 . For both FI and PDO crashes, these low probabilities indicate that the model might not provide an adequate fit to the data.

Substituting the regression coefficients in figure 23 and figure 24 with their corresponding estimates in table 12, the prediction models for FI and PDO crashes/mi/year are as follows:

$$
N_{F I}=\exp \left[-9.55+1.10 \ln (\mathrm{AADT})+10.51 \frac{1}{K} \times I_{V C}+0.011\left(\frac{5,730}{\mathrm{R}}\right) A \times I_{V C} \times H C\right]
$$

Figure 25. Equation. Predicted FI crashes on horizontal curves and tangents at type 1 sag vertical curves (explicit form).

$$
N_{P D O}=\exp \left[-8.63+1.03 \ln (\mathrm{AADT})+8.62 \frac{1}{K} \times I_{V C}+0.010\left(\frac{5,730}{\mathrm{R}}\right) A \times I_{V C} \times H C\right]
$$

Figure 26. Equation. Predicted PDO crashes on horizontal curves and tangents at type 1 sag vertical curves (explicit form).

For horizontal curves and tangents at type 1 sag vertical curves, the inverse of $K$, a measure of vertical curvature, and the interaction term between curve radius (a characteristic of horizontal curves) and $A$ (a vertical curve characteristic) were found to be statistically significant in both models. These models show that crash frequency increases with decreasing $K$ (i.e., with sharper sags). The interaction term between $\mathrm{R}$ and $A$ shows that crash frequency increases with the decreasing curve radius and increasing difference in grades. In both models, the effect of the interaction is greater than that of $K$ as reflected in the comparison of their chi-squared values in table 12. 
As noted earlier for the crash model at type 1 crest vertical curves shown in figure 18, figure 19, and table 10, the marginal effect of the parameters in each model after the effect of AADT is accounted for is small, as indicated by the small chi-squared values in comparison to that for AADT (see table 12). This is an indication that after traffic volume is accounted for, there is little difference among the three groups of roadway (i.e., level tangents, tangents on nonlevel grades, and horizontal curves at type 1 sag vertical curves). The argument can be made that the crash variability in all three groups is large (see in table 11). Additionally, the horizontal curves group consists of only $57 \mathrm{mi}$ of roadway as compared to the $833 \mathrm{mi}$ of level tangents and $145 \mathrm{mi}$ of tangents at type 1 sags.

As in the case for type 1 crest vertical curves, it makes engineering sense to replace $A$ with $L_{V C} / K$ in figure 25 and figure 26. In this form, both the main effect and the interaction term include $K$ in the denominator rather than having an inconsistency with the main effect including $K$ and the interaction including $A$. Thus, it is recommended that figure 25 and figure 26 be recast as follows:

$$
N_{F I}=\exp \left[b_{0}+b_{1} \ln (\mathrm{AADT})+b_{2} \frac{1}{K} \times I_{V C}+b_{3}\left(\frac{5,730}{\mathrm{R}}\right)\left(\frac{L_{V C}}{K}\right) \times I_{V C} \times H C\right]
$$

Figure 27. Equation. Predicted FI crashes on horizontal curves and tangents at type 1 sag vertical curves (alternate form).

$$
N_{P D O}=\exp \left[b_{0}+b_{1} \ln (\mathrm{AADT})+b_{2} \frac{1}{K} \times I_{V C}+b_{3}\left(\frac{5,730}{\mathrm{R}}\right)\left(\frac{L_{V C}}{K}\right) \times I_{V C} \times H C\right]
$$

Figure 28. Equation. Predicted PDO crashes on horizontal curves and tangents at type 1 sag vertical curves (alternate form).

In summary, the predictive model developed for type 1 sag vertical curves includes a term representing the sharpness of the vertical curve as a main effect and an interaction between the horizontal curve radius, the vertical curve length, and the sharpness of the vertical curve. The model indicates that crash frequency increases as the horizontal curve radius decreases, the length of the vertical curve increases, and the sharpness of the vertical curve increases (i.e., as $K$ decreases). The main effect and the interaction, while not as strongly related to crash frequency as AADT, are potentially useful in the AASHTO HSM because it does not currently contain CMFs for sag vertical curves. ${ }^{(1)}$

\section{Horizontal Curves and Tangents at Type 2 Crest Vertical Curves}

The following three alignment combinations shaded in figure 29 were included in the analysis:

- Horizontal curves at type 2 crest vertical curves $(N=1,071$ and total roadway length $=62 \mathrm{mi}$ ).

- $\quad$ Tangents at type 2 crest vertical curves $(N=1,922$ and total roadway length $=132 \mathrm{mi})$.

- Level tangents-base condition (grade $<1$ percent) $(N=5,742$ and total roadway length $=833 \mathrm{mi})$. 


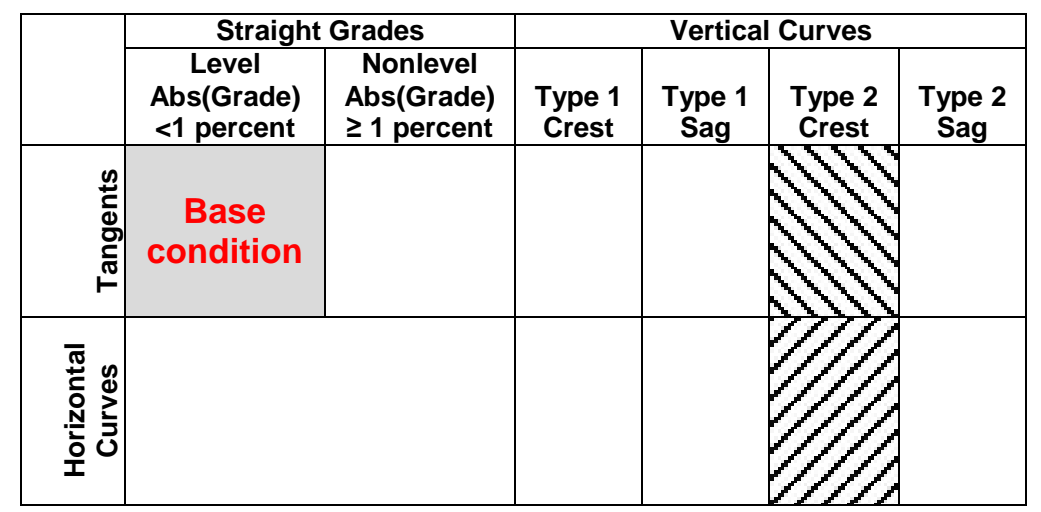

Note: Data in the three shaded cells were used in this analysis, while data in the blank cells were not used in this analysis.

Figure 29. Illustration. Alignment combinations used in the analysis of horizontal curves and tangents at type 2 crest vertical curves.

Basic descriptive statistics such as sample size (i.e., number of roadway sections); total roadway length; and minimum, maximum, mean, and median values for specific parameters are shown in table 13 for each of the three alignment types included in the analysis.

Table 13. Descriptive statistics for horizontal curves and tangents at type 2 crest vertical curves.

\begin{tabular}{|c|c|c|c|c|}
\hline Parameter & Minimum & Maximum & Mean & Median \\
\hline \multicolumn{5}{|c|}{$\begin{array}{l}\text { Horizontal Curves at Type } 2 \text { Crest Vertical Curves } \\
\text { (N=1,071; total roadway length }=62 \mathrm{mi} \text { ) }\end{array}$} \\
\hline AADT (vehicles/day) & 202 & 20,931 & 2,603 & 1,607 \\
\hline Section length (mi) & 0.01 & 0.34 & 0.06 & 0.05 \\
\hline Horizontal curve length (mi) & 0.01 & 1.09 & 0.16 & 0.12 \\
\hline Curve radius (ft) & 100 & 11,459 & 1,960 & 1,433 \\
\hline Vertical curve length (ft) & 75 & 2,400 & 543 & 400 \\
\hline$A$ & 1.0 & 8.3 & 2.8 & 2.4 \\
\hline$K$ & 15.9 & 952.4 & 227.0 & 178.8 \\
\hline FI crashes per MVMT & 0 & 28.16 & 0.63 & 0 \\
\hline PDO crashes per MVMT & 0 & 30.02 & 0.87 & 0 \\
\hline Total crashes per MVMT & 0 & 30.02 & 1.50 & 0 \\
\hline \multicolumn{5}{|c|}{$\begin{array}{l}\text { Tangents at Type } 2 \text { Crest Vertical Curves } \\
\text { ( } \mathrm{N}=1,922 ; \text { total roadway length }=132 \mathrm{mi} \text { ) }\end{array}$} \\
\hline AADT (vehicles/day) & 175 & 21,825 & 2,741 & 1,652 \\
\hline Section length (mi) & 0.01 & 0.38 & 0.07 & 0.06 \\
\hline \multicolumn{5}{|l|}{ Horizontal curve length (mi) } \\
\hline Curve radius (ft) & & & & \\
\hline Vertical curve length (ft) & 60 & 2,400 & 498 & 400 \\
\hline$A$ & 1.0 & 8.0 & 2.6 & 2.2 \\
\hline$K$ & 16.2 & 985.9 & 222.4 & 176.3 \\
\hline FI crashes per MVMT & 0 & 36.12 & 0.42 & 0 \\
\hline PDO crashes per MVMT & 0 & 27.05 & 0.61 & 0 \\
\hline
\end{tabular}




\begin{tabular}{|l|r|r|r|r|}
\hline \multicolumn{1}{|c|}{ Parameter } & Minimum & Maximum & \multicolumn{1}{c|}{ Mean } & \multicolumn{1}{c|}{ Median } \\
\hline Total crashes per MVMT & 0 & 36.12 & 1.03 & 0 \\
\hline $\begin{array}{l}\text { Level Tangents-Base Condition } \\
\text { (N=5,742; total roadway length = 833 mi) }\end{array}$ \\
\hline AADT (vehicles/day) & 169 & 26,088 & 3,287 & 2,160 \\
\hline Section length (mi) & 0.01 & 2.10 & 0.15 & 0.09 \\
\hline Horizontal curve length (mi) & & & & \\
\hline Curve radius (ft) & & & & \\
\hline Vertical curve length (ft) & & & & \\
\hline$A$ & & & & \\
\hline$K$ & & & & 0 \\
\hline FI crashes per MVMT & 0 & 34.21 & 0.46 & 0.66 \\
\hline PDO crashes per MVMT & 0 & 31.60 & 0 & 0 \\
\hline Total crashes per MVMT & 0 & 36.34 & 1.12 & \\
\hline
\end{tabular}

Note: No roadway segments exist in the shaded cells.

The final crash prediction models for FI and PDO crashes are as follows:

$$
N_{F I}=\exp \left[b_{0}+b_{1} \ln (\mathrm{AADT})+b_{2} \ln \left(2 \times \frac{5,730}{\mathrm{R}}\right) \times I_{H C}\right]
$$

Figure 30. Equation. Predicted FI crashes on horizontal curves and tangents at type 2 crest vertical curves (general form).

$$
N_{P D O}=\exp \left[b_{0}+b_{1} \ln (\mathrm{AADT})+b_{2} \ln \left(2 \times \frac{5,730}{\mathrm{R}}\right) \times I_{H C}\right]
$$

Figure 31. Equation. Predicted PDO crashes on horizontal curves and tangents at type 2 crest vertical curves (general form).

The regression results, including all statistically significant parameters, are shown in table 14 . There were no statistically significant interactions for type 2 crest vertical curves.

Using figure 8, the percentage of roadway segments with extremely high observed FI crash frequencies was 6.46 percent across all roadway segments, slightly above the expected percentage, which was 5 percent. The percentages of roadway segments with extremely high observed FI crash frequencies were 6.46 percent for level tangents, 5.84 percent for tangents at type 2 crests, and 7.55 percent for horizontal curves on type 2 crests, indicating that a few roadway segments in these roadway categories experienced unusually high FI crash frequencies given the prediction model used. None of the segments experienced extremely low FI crash frequencies under the assumed model at the 5 percent significance level. 
Table 14. FI and PDO crash modeling results for horizontal curves and tangents at type 2 crest vertical curves.

\begin{tabular}{|c|c|c|c|c|c|c|c|}
\hline $\begin{array}{l}\text { Parameter } \\
\text { Description }\end{array}$ & $\begin{array}{l}\text { Regression } \\
\text { Coefficient }\end{array}$ & $\begin{array}{c}\text { Coefficient } \\
\text { Estimate }\end{array}$ & $\begin{array}{c}\text { Standard } \\
\text { Error }\end{array}$ & $\begin{array}{c}\text { Lower } \\
95 \text { percent } \\
\text { Confidence } \\
\text { Limit } \\
\end{array}$ & \begin{tabular}{|c|} 
Upper \\
95 percent \\
Confidence \\
Limit \\
\end{tabular} & $\begin{array}{c}\text { Chi- } \\
\text { Squared } \\
\text { Statistic }\end{array}$ & $\begin{array}{c}\text { Significance } \\
\text { Level }\end{array}$ \\
\hline \multicolumn{8}{|c|}{ FI Crashes/Mi/Year } \\
\hline Intercept & $b_{0}$ & -9.52 & 0.24 & -9.99 & -9.05 & N/A & N/A \\
\hline $\ln (\mathrm{AADT})$ & $b_{1}$ & 1.09 & 0.03 & 1.03 & 1.14 & $1,470.5$ & $<0.0001$ \\
\hline $1 / \mathrm{R}$ term $^{\mathrm{a}}$ & $b_{2}$ & 0.20 & 0.04 & 0.12 & 0.28 & 20.4 & $<0.0001$ \\
\hline Dispersion & N/A & 0.67 & 0.06 & 0.57 & 0.79 & N/A & N/A \\
\hline \multicolumn{8}{|c|}{ PDO Crashes/Mi/Year } \\
\hline Intercept & $b_{0}$ & -8.38 & 0.20 & -8.78 & -7.99 & N/A & $\mathrm{N} / \mathrm{A}$ \\
\hline $\ln (\mathrm{AADT})$ & $b_{1}$ & 1.00 & 0.02 & 0.95 & 1.05 & $1,699.0$ & $<0.0001$ \\
\hline $1 / \mathrm{R}$ term $^{\mathrm{a}}$ & $b_{2}$ & 0.10 & 0.04 & 0.03 & 0.18 & 6.6 & 0.010 \\
\hline Dispersion & N/A & 0.65 & 0.05 & 0.57 & 0.74 & N/A & N/A \\
\hline
\end{tabular}

${ }^{a} 1 /$ R term $=\ln (2 \times 5,730 / \mathrm{R})$.

N/A = Not applicable.

The percentage of roadway segments with extremely high observed PDO crash frequencies was 6.93 percent across all roadway segments, slightly higher than that for FI crashes. The percentages were 6.99 percent for level tangents, 6.61 percent for tangents at type 2 crests, and 7.16 percent for horizontal curves on type 2 crests, indicating that a few roadway segments in these roadway categories experienced unusually high FI crash frequencies given the prediction model used. None of the segments experienced extremely low FI crash frequencies under the assumed model at the 5 percent significance level.

The average probability of predicting a more extreme than observed FI crash frequency was calculated using figure 7 . Across all roadway segments, the average probability was 0.12 . The probability was 0.13 for level tangents, 0.09 for tangents at type 2 crests, and 0.11 for horizontal curves on type 2 crests, which were all considerably lower than the theoretically expected value of 0.25 .

Similarly, the average probability of predicting a more extreme than observed PDO crash frequency was 0.14 across all roadway segments. The probability was 0.16 for level tangents, 0.12 for tangents on type 2 crests, and 0.12 for horizontal curves on type 2 crests, which were all considerably lower than the theoretically expected value of 0.25 . For both FI and PDO crashes, these low probabilities indicate that the model might not provide an adequate fit to the data.

Substituting the regression coefficients in figure 30 and figure 31 with their corresponding estimates in table 14, the prediction models for FI and PDO crashes/mi/year are as follows:

$$
N_{F I}=\exp \left[-9.52+1.09 \ln (\mathrm{AADT})+0.20 \ln \left(2 \times \frac{5,730}{\mathrm{R}}\right) \times I_{H C}\right]
$$

Figure 32. Equation. Predicted FI crashes on horizontal curves and tangents at type 2 crest vertical curves (explicit form). 


$$
N_{P D O}=\exp \left[-8.38+1.00 \ln (\mathrm{AADT})+0.10 \ln \left(2 \times \frac{5,730}{\mathrm{R}}\right) \times I_{H C}\right]
$$

Figure 33. Equation. Predicted PDO crashes on horizontal curves and tangents at type 2 crest vertical curves (explicit form).

The horizontal curves group consists of only $62 \mathrm{mi}$ of roadway as compared to the $833 \mathrm{mi}$ of level tangents and $132 \mathrm{mi}$ of tangents at type 2 crests. For horizontal curves and tangents at type 2 crest vertical curves, curve radius (a characteristic of horizontal curves) was the only parameter found to be statistically significant in both models. Although its effect is more pronounced for FI than for PDO crashes, it is small compared to that of AADT. It is interesting to note that the effect of curve radius for horizontal curves and tangents at type 2 crest vertical curves is comparable to the effect of curve radius for horizontal curves on straight grades (compare coefficient estimates in table 14 to those in table 8).

The models developed for type 2 crest vertical curves include a main effect for horizontal curve radius but no effect for any vertical curve elements. This makes the models for type 2 crest vertical curves less useful than the models for type 1 crest vertical curves. Sensitivity analyses are needed to establish whether the straight grade models in figure 10 and figure 11 might be applied to type 2 crest vertical curves, with $G$ set equal to the average of $G_{1}$ and $G_{2}$ instead of figure 32 and figure 33.

\section{Horizontal Curves and Tangents at Type 2 Sag Vertical Curves}

The following three alignment combinations shaded in figure 34 were included in the analysis:

- Horizontal curves at type 2 sag vertical curves $(N=1,217$ and total roadway length $=63 \mathrm{mi})$.

- Tangents at type 2 sag vertical curves $(N=2,174$ and total roadway length $=129 \mathrm{mi})$.

- Level tangents—base condition (grade $<1$ percent) $(N=5,741$ and total roadway length $=833 \mathrm{mi})$.

\begin{tabular}{|c|c|c|c|c|c|c|}
\hline & \multicolumn{2}{|c|}{ Straight Grades } & \multicolumn{4}{|c|}{ Vertical Curves } \\
\hline & $\begin{array}{c}\text { Level } \\
\text { Abs(Grade) } \\
<1 \text { percent }\end{array}$ & $\begin{array}{l}\text { Nonlevel } \\
\text { Abs(Grade) } \\
\geq 1 \text { percent }\end{array}$ & $\begin{array}{c}\text { Type } 1 \\
\text { Crest }\end{array}$ & $\begin{array}{l}\text { Type } 1 \\
\text { Sag }\end{array}$ & $\begin{array}{c}\text { Type } 2 \\
\text { Crest }\end{array}$ & $\begin{array}{c}\text { Type } 2 \\
\text { Sag }\end{array}$ \\
\hline 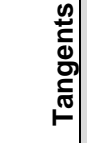 & $\begin{array}{c}\text { Base } \\
\text { condition }\end{array}$ & & & & & \\
\hline 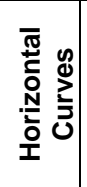 & & & & & & 8111 \\
\hline
\end{tabular}

Note: Data in the three shaded cells were used in this analysis, while data in the blank cells were not used in this analysis.

Figure 34. Illustration. Alignment combinations used in the analysis of horizontal curves and tangents at type 2 sag vertical curves. 
Basic descriptive statistics such as sample size (i.e., number of roadway sections); total roadway length; and minimum, maximum, mean, and median values for specific parameters are shown in table 15 for each of the three alignment types included in the analysis.

Table 15. Descriptive statistics for horizontal curves and tangents at type 2 sag vertical curves.

\begin{tabular}{|c|c|c|c|c|}
\hline Parameter & Minimum & Maximum & Mean & Median \\
\hline \multicolumn{5}{|c|}{$\begin{array}{l}\text { Horizontal Curves at Type } 2 \text { Sag Vertical Curves } \\
(\mathrm{N}=1,217 \text {; total roadway length }=63 \mathrm{mi})\end{array}$} \\
\hline AADT (vehicles/day) & 175 & 21,825 & 2,691 & 1,742 \\
\hline Section length (mi) & 0.01 & 0.30 & 0.05 & 0.04 \\
\hline Horizontal curve length (mi) & 0.01 & 1.09 & 0.17 & 0.13 \\
\hline Curve radius (ft) & 100 & 11,459 & 1,964 & 1,433 \\
\hline Vertical curve length (ft) & 60 & 1,600 & 424 & 400 \\
\hline$A$ & 1.0 & 7.7 & 2.7 & 2.5 \\
\hline$K$ & 9.7 & 917.4 & 185.6 & 149.3 \\
\hline FI crashes per MVMT & 0 & 26.06 & 0.60 & 0 \\
\hline PDO crashes per MVMT & 0 & 27.82 & 0.95 & 0 \\
\hline Total crashes per MVMT & 0 & 27.82 & 1.54 & 0 \\
\hline \multicolumn{5}{|c|}{$\begin{array}{l}\text { Tangents at Type } 2 \text { Sag Vertical Curves } \\
(\mathrm{N}=2,174 \text {; total roadway length }=129 \mathrm{mi})\end{array}$} \\
\hline AADT (vehicles/day) & 169 & 23,334 & 2,909 & 1,776 \\
\hline Section length (mi) & 0.01 & 0.38 & 0.06 & 0.05 \\
\hline \multicolumn{5}{|l|}{ Horizontal curve length (mi) } \\
\hline \multicolumn{5}{|l|}{ Curve radius (ft) } \\
\hline Vertical curve length (ft) & 60 & 2,000 & 400 & 400 \\
\hline$A$ & 1.0 & 7.6 & 2.6 & 2.2 \\
\hline$K$ & 16.2 & 970.9 & 184.3 & 148.1 \\
\hline FI crashes per MVMT & 0 & 27.82 & 0.44 & 0 \\
\hline PDO crashes per MVMT & 0 & 28.27 & 0.61 & 0 \\
\hline Total crashes per MVMT & 0 & 38.20 & 1.05 & 0 \\
\hline \multicolumn{5}{|c|}{$\begin{array}{l}\text { Level Tangents-Base Condition } \\
(\mathrm{N}=5,741 \text {; total roadway length = } 833 \mathrm{mi})\end{array}$} \\
\hline AADT (vehicles/day) & 169 & 26,088 & 3,288 & 2,160 \\
\hline Section length (mi) & 0.01 & 2.10 & 0.15 & 0.09 \\
\hline \multicolumn{5}{|l|}{ Horizontal curve length (mi) } \\
\hline \multicolumn{5}{|l|}{ Curve radius (ft) } \\
\hline \multicolumn{5}{|l|}{ Vertical curve length (ft) } \\
\hline \multicolumn{5}{|l|}{$A$} \\
\hline \multicolumn{5}{|l|}{$K$} \\
\hline FI crashes per MVMT & 0 & 34.21 & 0.46 & 0 \\
\hline PDO crashes per MVMT & 0 & 25.79 & 0.66 & 0 \\
\hline Total crashes per MVMT & 0 & 36.34 & 1.12 & 0 \\
\hline
\end{tabular}

Note: No roadway segments exist in the shaded cells. 
The final crash prediction models for FI and PDO crashes are:

$$
N_{F I}=\exp \left[b_{0}+b_{1} \ln (\mathrm{AADT})+b_{2} \ln \left(2 \times \frac{5,730}{\mathrm{R}}\right) \times I_{H C}\right]
$$

Figure 35. Equation. Predicted FI crashes on horizontal curves and tangents at type 2 sag vertical curves (general form).

$$
N_{P D O}=\exp \left[b_{0}+b_{1} \ln (\mathrm{AADT})+b_{2}\left(\frac{5,730}{\mathrm{R}}\right) A \times I_{V C \times H C}\right]
$$

Figure 36. Equation. Predicted PDO crashes on horizontal curves and tangents at type 2 sag vertical curves (general form).

The regression results, including all statistically significant parameters and interaction, are shown in table 16.

Table 16. FI and PDO crash modeling results for horizontal curves and tangents at type 2

\begin{tabular}{|c|c|c|c|c|c|c|c|}
\hline $\begin{array}{c}\text { Parameter } \\
\text { Description }\end{array}$ & $\begin{array}{l}\text { Regression } \\
\text { Coefficient }\end{array}$ & $\begin{array}{c}\text { Coefficient } \\
\text { Estimate } \\
\end{array}$ & $\begin{array}{c}\text { Standard } \\
\text { Error }\end{array}$ & $\begin{array}{c}\text { Lower } \\
95 \text { percent } \\
\text { Confidence } \\
\text { Limit } \\
\end{array}$ & $\begin{array}{c}\text { Upper } \\
95 \text { percent } \\
\text { Confidence } \\
\text { Limit } \\
\end{array}$ & $\begin{array}{c}\text { Chi- } \\
\text { Squared } \\
\text { Statistic }\end{array}$ & $\begin{array}{c}\text { Significance } \\
\text { Level }\end{array}$ \\
\hline \multicolumn{8}{|c|}{ FI Crashes/Mi/Year } \\
\hline Intercept & $b_{0}$ & -9.42 & 0.24 & -9.90 & -8.95 & N/A & N/A \\
\hline $\ln (\mathrm{AADT})$ & $b_{1}$ & 1.08 & 0.03 & 1.02 & 1.13 & $1,427.2$ & $<0.0001$ \\
\hline 1/R term ${ }^{\mathrm{a}}$ & $b_{2}$ & 0.188 & 0.04 & 0.11 & 0.27 & 18.2 & $<0.0001$ \\
\hline Dispersion & N/A & 0.76 & 0.06 & 0.65 & 0.88 & NA & NA \\
\hline \multicolumn{8}{|c|}{ PDO Crashes/Mi/Year } \\
\hline Intercept & $b_{0}$ & -8.30 & 0.20 & -8.69 & -7.90 & N/A & N/A \\
\hline $\ln (\mathrm{AADT})$ & $b_{1}$ & 0.99 & 0.02 & 0.94 & 1.03 & $1,648.2$ & $<0.0001$ \\
\hline $\begin{array}{l}1 / \mathrm{R} \times \mathrm{A} \\
\text { interaction }^{\mathrm{b}}\end{array}$ & $b_{2}$ & 0.022 & 0.005 & 0.013 & 0.031 & 20.8 & $<0.0001$ \\
\hline Dispersion & N/A & 0.64 & 0.05 & 0.56 & 0.73 & N/A & N/A \\
\hline
\end{tabular}
sag vertical curves.

${ }^{\mathrm{a}} 1 / \mathrm{R}$ term $=\ln (2 \times 5,730 / \mathrm{R})$.

${ }^{\mathrm{b}} 1 / \mathrm{R} \times \mathrm{A}$ interaction $=(5,730 / \mathrm{R}) \times A$.

N/A = Not applicable.

Using figure 8, the percentage of roadway segments with extremely high observed FI crash frequencies was 6.08 percent across all roadway segments, which was slightly above the expected percentage of 5 percent. The percentage of roadway segments with extremely high observed FI crash frequencies was 6.24 percent for level tangents, 5.53 percent for tangents at type 2 sags, and 6.32 percent for horizontal curves on type 2 sags, indicating that a few roadway segments in these categories experienced unusually high FI crash frequencies given the prediction model used. None of the segments experienced extremely low FI crash frequencies under the assumed model at the 5 percent significance level.

Similarly, the percentage of roadway segments with extremely high observed PDO crash frequencies was 6.99 percent across all roadway segments, which was slightly higher than that 
for FI crashes. The percentages were 7.10 percent for level tangents, 6.46 percent for tangents at type 2 sags, and 7.42 percent for horizontal curves on type 2 sags, indicating that a few roadway segments in these roadway categories experienced unusually high FI crash frequencies given the prediction model used. None of the segments experienced extremely low FI crash frequencies under the assumed model at the 5 percent significance level.

The average probability of predicting a more extreme than observed FI crash frequency was calculated using figure 7 . Across all roadway segments, the average probability was 0.12 . The probability was 0.13 for level tangents, 0.09 for tangents at type 2 sags, and 0.10 for horizontal curves on type 2 sags, which were all considerably lower than the theoretically expected value of 0.25 .

Similarly, the average probability of predicting a more extreme than observed PDO crash frequency was 0.14 across all roadway segments. The probability was 0.16 for level tangents, 0.12 for tangents on type 2 sags, and 0.12 for horizontal curves on type 2 sags, which were all considerably lower than the theoretically expected value of 0.25 . For both FI and PDO crashes, these low probabilities indicate that the model might not provide an adequate fit to the data.

Substituting the regression coefficients in figure 35 and figure 36 with their corresponding estimates in table 16, the prediction models for FI and PDO crashes/mi/year are as follows:

$$
N_{F I}=\exp \left[-9.42+1.08 \ln (\mathrm{AADT})+0.188 \ln \left(2 \times \frac{5,730}{\mathrm{R}}\right) \times I_{H C}\right]
$$

Figure 37. Equation. Predicted FI crashes on horizontal curves and tangents at type 2 sag vertical curves (explicit form).

$$
N_{P D O}=\exp \left[-8.30+0.99 \ln (\mathrm{AADT})+0.022\left(\frac{5,730}{\mathrm{R}}\right) A \times I_{V C \times H C}\right]
$$

Figure 38. Equation. Predicted PDO crashes on horizontal curves and tangents at type 2 sag vertical curves (explicit form).

The horizontal curves group consists of only $63 \mathrm{mi}$ of roadway as compared to $833 \mathrm{mi}$ of level tangents and $129 \mathrm{mi}$ of tangents at type 2 sags. For horizontal curves and tangents at type 2 sag vertical curves, curve radius (a characteristic of horizontal curves) was the only parameter found to be statistically significant in the FI crash prediction model. The model in figure 37 shows that FI crash frequency increases with decreasing curve radius, as expected. For the PDO crash prediction model, only the interaction term between curve radius (a characteristic of horizontal curves) and $A$ (a vertical curve characteristic), was found to be statistically significant. The model in figure 38 shows that crash frequency increases with the combination of decreasing curve radius and increasing difference in grades.

In either model, the effect of the significant parameter or interaction of parameters is more pronounced than in previous models as reflected in the slightly higher chi-squared values. The magnitude of the coefficients is consistent between this set of models and previous models. There is a substantial inconsistency between the FI and PDO crash models for type 2 sag vertical curves in that the PDO crash model includes a statistically significant interaction between horizontal curve radius and algebraic difference in grade, but the FI crash model does not. This 
is the only situation in the study where different parameters or functional forms had to be used for the corresponding FI and PDO crash models. This inconsistency makes the models for type 2 sag vertical curves less useful than the models for type 1 sag vertical curves. $L_{V C} / K$ could be substituted for $A$ in figure 38, as was done for type 1 crest vertical curves and type 1 sag vertical curves, but it seems pointless to do this in the PDO crash model when the more important FI crash model does not include a similar interaction term. Sensitivity analyses might establish whether, as an alternative to the inconsistent models in figure 37 and figure 38, the straight grade models in figure 10 and figure 11 might be applied to type 2 sag vertical curves with the value of $G$ set equal to the average of $G_{1}$ and $G_{2}$.

\section{STUDY LIMITATIONS}

The major limitation of the study results is that data from only one State were used in the analysis. It would have been desirable to use data from additional States, but Washington is the only known State for which curve and grade data are available for the entire State highway system in a form that can be linked to crash data.

The study divided the roadway into segments for analysis. A new segment started at each point where a horizontal curve or vertical alignment feature (straight grade or vertical curve) began or ended. Segmenting the roadway in this way resulted in a number of very short segments. The shortest of these segments were dropped from the analysis, but some of the segments that were analyzed may be shorter than the expected accuracy of reported crash locations. Nevertheless, this approach to segmenting roadways appears to be the best method to the authors of this report for analyzing these data because the geometrics of each analysis section are known to be homogeneous with respect to horizontal and vertical alignment features. Alternative analysis approaches that use fixed-length study sections (typically 0.5 or $1.0 \mathrm{mi}$ long) and model the percentage of section length over which particular geometric features (or combinations of features) are present do not appear likely to provide satisfactory results for this application.

As noted earlier, the analysis considered the effects of horizontal and vertical geometrics on crashes but did not consider other features known to affect crashes such as lane and shoulder widths. In fact, the AASHTO HSM includes 12 factors that are known to affect safety on rural two-lane highways. ${ }^{(1)}$ Consideration of all these factors was not beyond the scope of this current study. A future study is necessary to develop safety prediction models for rural two-lane highways considering all 12 factors and their interactions. 


\section{CHAPTER 5-CRASH MODIFICATION FACTORS}

CMFs used in the AASHTO HSM can be derived from the predictive models developed in chapter 4 of this current report. A CMF is a factor that represents the effect on crash frequency for a given crash severity level of varying geometric design or traffic control feature of interest (or a particular combination of geometric design or traffic control feature). Each CMF has a nominal value of 1.0 for a specified base condition. A CMF with a value greater than 1.0 represents a condition for which more crashes would be expected for the base condition. A CMF with a value less than 1.0 represents a condition for which fewer crashes would be expected than for the base condition. The base condition for all CMFs developed in this research is a level tangent roadway.

For each combination of alignment type (and for FI crashes and PDO crashes), CMFs were calculated as the ratio of the predicted crash frequency for a given horizontal curve and grade combination to the predicted crash frequency for the level tangent base condition. The following subsections provide equations for each CMF and figures illustrating the relationships of each roadway parameter to crash frequency and to the relevant CMF. Sample CMF calculations are also presented.

\section{HORIZONTAL CURVES AND TANGENTS ON STRAIGHT GRADES}

CMFs for horizontal curves and tangents on straight grades can be derived from figure 12 and figure 13 as follows:

$$
C M F_{S G, F I}=\left\{\begin{array}{lr}
\exp \left[0.044 G+0.19 \ln \left(2 \times \frac{5,730}{\mathrm{R}}\right)+4.52\left(\frac{1}{\mathrm{R}}\right)\left(\frac{1}{L_{C}}\right)\right] & \text { for horizontal curves } \\
\exp [0.044 G] & \text { for tangents on nonlevel grades } \\
1.0 & \text { for level tangents (base condition) }
\end{array}\right\}
$$

Figure 39. Equation. FI CMF for horizontal curves and tangents on straight grades.

$$
C M F_{S G, P D O}=\left\{\begin{array}{lr}
\exp \left[0.040 G+0.13 \ln \left(2 \times \frac{5,730}{\mathrm{R}}\right)+3.80\left(\frac{1}{\mathrm{R}}\right)\left(\frac{1}{L_{C}}\right)\right] \text { for horizontal curves } \\
\exp [0.040 G] & \text { for tangents on nonlevel grades } \\
1.0 & \text { for level tangents (base condition) }
\end{array}\right\}
$$

Figure 40. Equation. PDO CMF for horizontal curves and tangents on straight grades.

The functional relationships shown in figure 12 (crashes/mi/year) and figure 39 (CMF) for FI crashes are illustrated in figure 41 for combinations of horizontal curve lengths and percent grades. Curve radius ranged from 100 to $11,460 \mathrm{ft}$; AADT was fixed at 2,000 vehicles/day; the median traffic volume was for rural two-lane roadways in the database; the horizontal curve length was set at $0.05,0.10,0.15$, and $0.20 \mathrm{mi}$; and grade was set at level (i.e., 0 percent) and 1 to 6 percent in increments of 1 percent. Similarly, figure 42 illustrates the relationships shown in figure 13 and figure 40 for PDO crashes. 


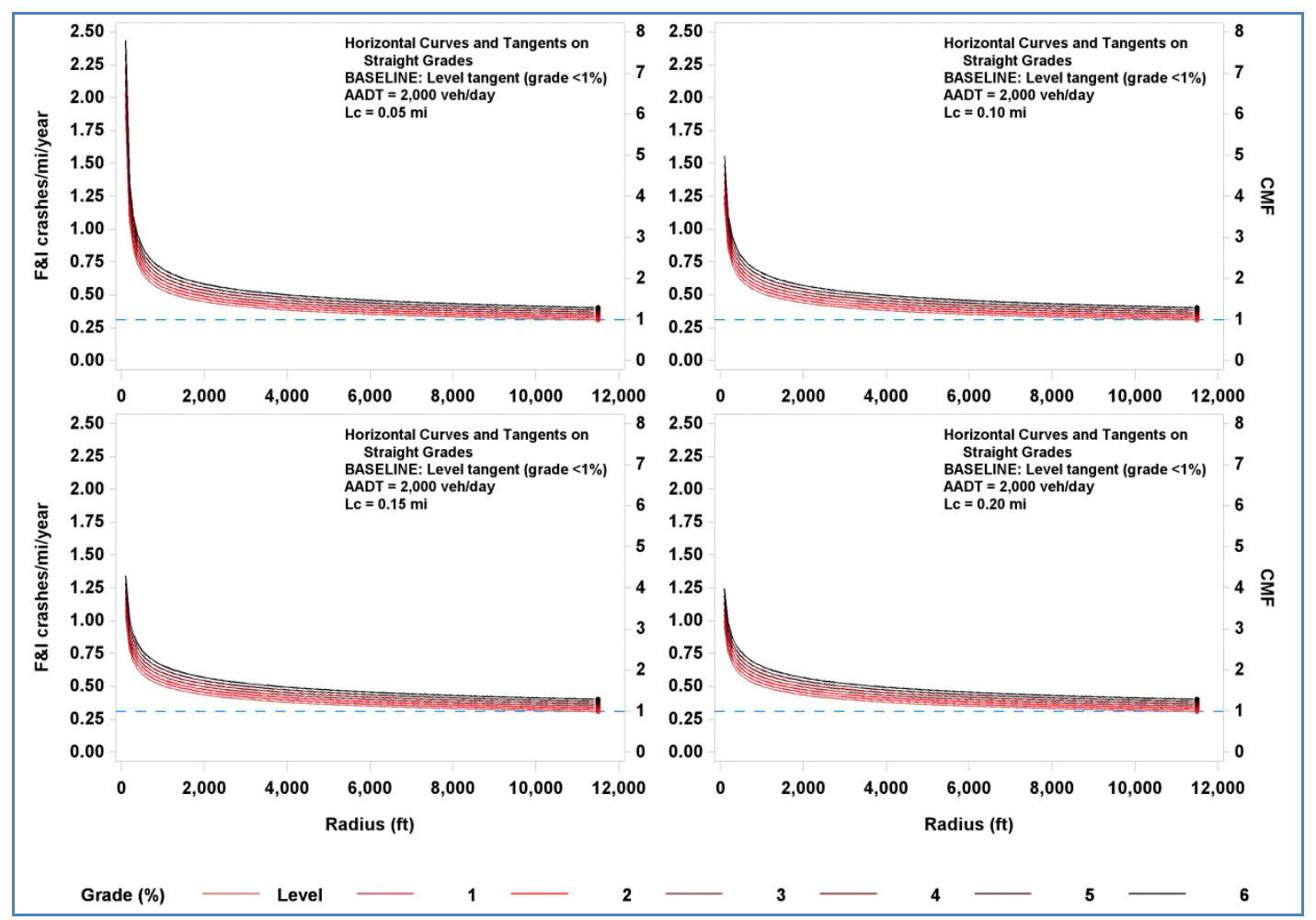

Figure 41. Graph. Predicted FI crashes/mi/year and CMFs for horizontal curves and tangents on straight grades.

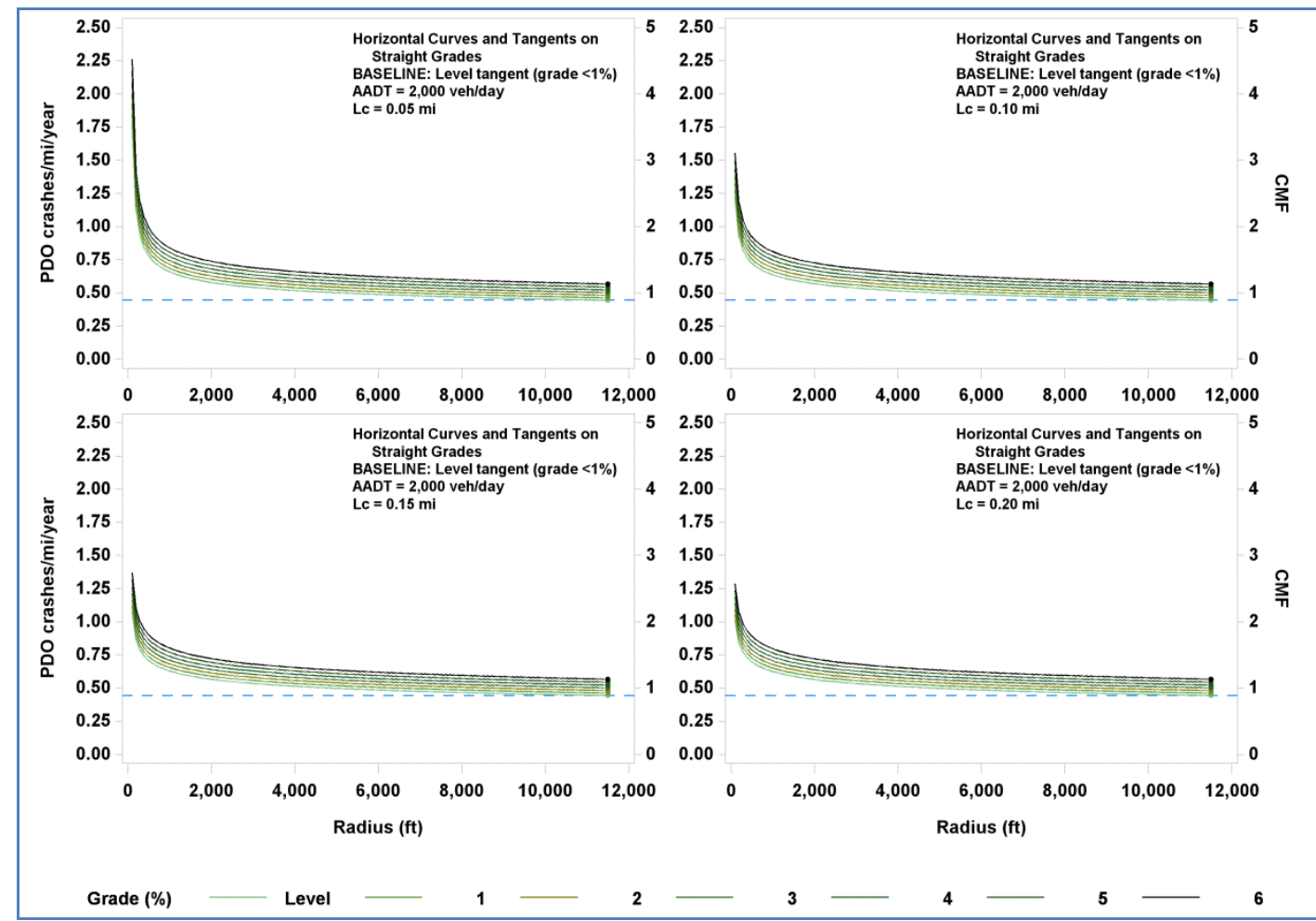

Figure 42. Graph. Predicted PDO crashes/mi/year and CMFs for horizontal curves and tangents on straight grades. 
In figure 41 and figure 42, crashes/mi/year are shown on the left y-axis, and the corresponding CMFs are shown on the right $y$-axis. The dotted blue line corresponds to a base condition tangent with an AADT of 2,000 vehicles/day and therefore has a CMF of 1.0.

To calculate CMF for FI or PDO crashes for a given horizontal curve on a level or nonlevel grade or a tangent on a nonlevel grade, $G$ (percent), $\mathrm{R}(\mathrm{ft})$, and $L_{C}(\mathrm{mi})$ are substituted in figure 39 or figure 40. Example CMFs were calculated for rural two-lane roadways with a $\mathrm{R}$ of 1,433 or $5,730 \mathrm{ft}$; $L_{C}$ of $0.05,0.10$, and $0.50 \mathrm{mi}$; and $G$ ranging from level to 6 percent. The results are shown in table 17 for rural two-lane roadways with AADTs from 200 to 26,000 vehicles/day.

Table 17. Example CMFs for FI and PDO crashes on horizontal curves and tangents on straight grades.

\begin{tabular}{|c|c|c|c|c|c|c|c|}
\hline \multirow[b]{3}{*}{$\begin{array}{c}\text { Grade } \\
\text { (Percent) }\end{array}$} & \multirow{3}{*}{$\begin{array}{c}\text { Tangent } \\
\text { on } \\
\text { Nonlevel } \\
\text { Grade }\end{array}$} & \multicolumn{3}{|c|}{$R=1,433 \mathrm{ft}$} & \multicolumn{3}{|c|}{$\mathrm{R}=5,730 \mathrm{ft}$} \\
\hline & & \multicolumn{3}{|c|}{ Horizontal Curve Length (mi) } & \multicolumn{3}{|c|}{ Horizontal Curve Length (mi) } \\
\hline & & 0.05 & 0.10 & 0.50 & 0.05 & 0.10 & 0.50 \\
\hline \multicolumn{8}{|c|}{ CMFs for FI Crashes } \\
\hline $\begin{array}{c}\text { Level } \\
(<1 \text { percent })\end{array}$ & 1.00 & 1.57 & 1.53 & 1.49 & 1.15 & 1.15 & 1.14 \\
\hline 1 & 1.04 & 1.64 & 1.59 & 1.56 & 1.20 & 1.20 & 1.19 \\
\hline 2 & 1.09 & 1.71 & 1.67 & 1.63 & 1.25 & 1.25 & 1.25 \\
\hline 3 & 1.14 & 1.79 & 1.74 & 1.70 & 1.31 & 1.31 & 1.30 \\
\hline 4 & 1.19 & 1.87 & 1.82 & 1.78 & 1.37 & 1.36 & 1.36 \\
\hline 5 & 1.25 & 1.95 & 1.9 & 1.86 & 1.43 & 1.42 & 1.42 \\
\hline 6 & 1.30 & 2.04 & 1.98 & 1.94 & 1.49 & 1.49 & 1.48 \\
\hline \multicolumn{8}{|c|}{ CMFs for PDO Crashes } \\
\hline $\begin{array}{c}\text { Level } \\
(<1 \text { percent })\end{array}$ & 1.00 & 1.38 & 1.35 & 1.32 & 1.10 & 1.10 & 1.10 \\
\hline 1 & 1.04 & 1.44 & 1.40 & 1.38 & 1.15 & 1.14 & 1.14 \\
\hline 2 & 1.08 & 1.49 & 1.46 & 1.43 & 1.20 & 1.19 & 1.19 \\
\hline 3 & 1.13 & 1.56 & 1.52 & 1.49 & 1.25 & 1.24 & 1.24 \\
\hline 4 & 1.17 & 1.62 & 1.58 & 1.55 & 1.30 & 1.29 & 1.29 \\
\hline 5 & 1.22 & 1.69 & 1.65 & 1.62 & 1.35 & 1.35 & 1.34 \\
\hline 6 & 1.27 & 1.76 & 1.72 & 1.69 & 1.41 & 1.40 & 1.40 \\
\hline
\end{tabular}

In any given column in table 17, the CMFs show the increasing effect on crashes of an increasing grade for a horizontal curve or tangent on a straight grade. In any given row for a given curve radius, the CMFs show the increasing effect on crashes of horizontal curve length. The decreasing effect on crashes of longer curve radii is shown by comparing any two columns for the same curve length between the two radii. The effect of a short and sharp curve (due to the last term in figure 39 and figure 40) is reflected in the high CMFs in the third column of the table. As the curve radius increases and becomes a tangent for all practical purposes, the CMFs for the curve approach in value those of a tangent with the same percent grade. When percent grade nears zero (level roadway) and the radius becomes infinite (tangent roadway), the roadway becomes a level tangent, and CMF becomes 1 . 


\section{HORIZONTAL CURVES AND TANGENTS AT TYPE 1 CREST VERTICAL CURVES}

CMFs for horizontal curves and tangents at type 1 crest vertical curves can be derived from figure 18 and figure 19 as follows:

$$
C M F_{C 1, F I}=\left\{\begin{array}{lr}
\exp \left[0.0088\left(\frac{5,730}{\mathrm{R}}\right) \frac{L_{V C}}{K}\right] & \text { for horizontal curves } \\
1.0 & \text { for tangents at type } 1 \text { crests } \\
1.0 & \text { for level tangents (base condition) }
\end{array}\right\}
$$

Figure 43. Equation. FI CMF for horizontal curves and tangents at type 1 crest vertical curves.

$$
C M F_{C I_{2} P D O}=\left\{\begin{array}{lr}
\exp \left[0.0046\left(\frac{5,730}{\mathrm{R}}\right) \frac{L_{V C}}{K}\right] & \text { for horizontal curves } \\
1.0 & \text { for tangents at type } 1 \text { crests } \\
1.0 & \text { for level tangents (base condition) }
\end{array}\right\}
$$

Figure 44. Equation. PDO CMF for horizontal curves and tangents at type 1 crest vertical curves.

The functional relationships shown in figure 18 (crashes/mi/year) and figure 43 (CMF) for FI crashes are illustrated in figure 45 for selected values of $K$. Curve radius ranged from 100 to $11,460 \mathrm{ft}$, AADT was fixed at 2,000 vehicles/day, and $L_{V C}$ was fixed at $500 \mathrm{ft}$, the median $L_{V C}$ in the database. Values of $K$ were set at 250, 125, 83, 63, and 50, which correspond to a grade difference of 2, 4, 6, 8, and 10 percent, respectively, for a curve length of $500 \mathrm{ft}$. Similarly, figure 46 illustrates the relationships shown in figure 19 and figure 44 for PDO crashes.

To calculate CMF for FI or PDO crashes for a given horizontal curve at a type 1 crest vertical curve, the actual values of $\mathrm{R}(\mathrm{ft}), L_{V C}(\mathrm{ft})$, and parameter $K(\mathrm{ft} /$ percent) are substituted in figure 43 or figure 44. Example CMFs were calculated for rural two-lane roadways with an $L_{V C}$ of $500 \mathrm{ft}$, R of 1,433 or 5,730 ft, and $K$ values of 250, 125, 83, 63, and $50 \mathrm{ft} /$ percent using figure 43 and figure 44 . The results are shown in table 18 for rural two-lane roadways with AADTs from 200 to 26,000 vehicles/day and $L_{V C}$ of $500 \mathrm{ft}$.

Table 18. Example CMFs for FI and PDO crashes on horizontal curves and tangents at type 1 crest vertical curves.

\begin{tabular}{|c|c|c|c|c|c|}
\hline & Tangent & \multicolumn{2}{|c|}{ FI CMFs } & \multicolumn{2}{c|}{ PDO CMFs } \\
\cline { 3 - 6 } $\boldsymbol{K}$ & at Crest & $\mathbf{R = 1 , 4 3 3} \mathbf{f t}$ & $\mathbf{R}=\mathbf{5 , 7 3 0 ~ f t ~}$ & $\mathbf{R}=\mathbf{1 , 4 3 3} \mathbf{f t}$ & $\mathbf{R}=\mathbf{5 , 7 3 0 ~ f t}$ \\
\hline 250 & 1.0 & 1.07 & 1.02 & 1.04 & 1.01 \\
\hline 125 & 1.0 & 1.15 & 1.04 & 1.08 & 1.02 \\
\hline 83 & 1.0 & 1.24 & 1.05 & 1.12 & 1.03 \\
\hline 63 & 1.0 & 1.33 & 1.07 & 1.16 & 1.04 \\
\hline 50 & 1.0 & 1.42 & 1.09 & 1.20 & 1.05 \\
\hline
\end{tabular}




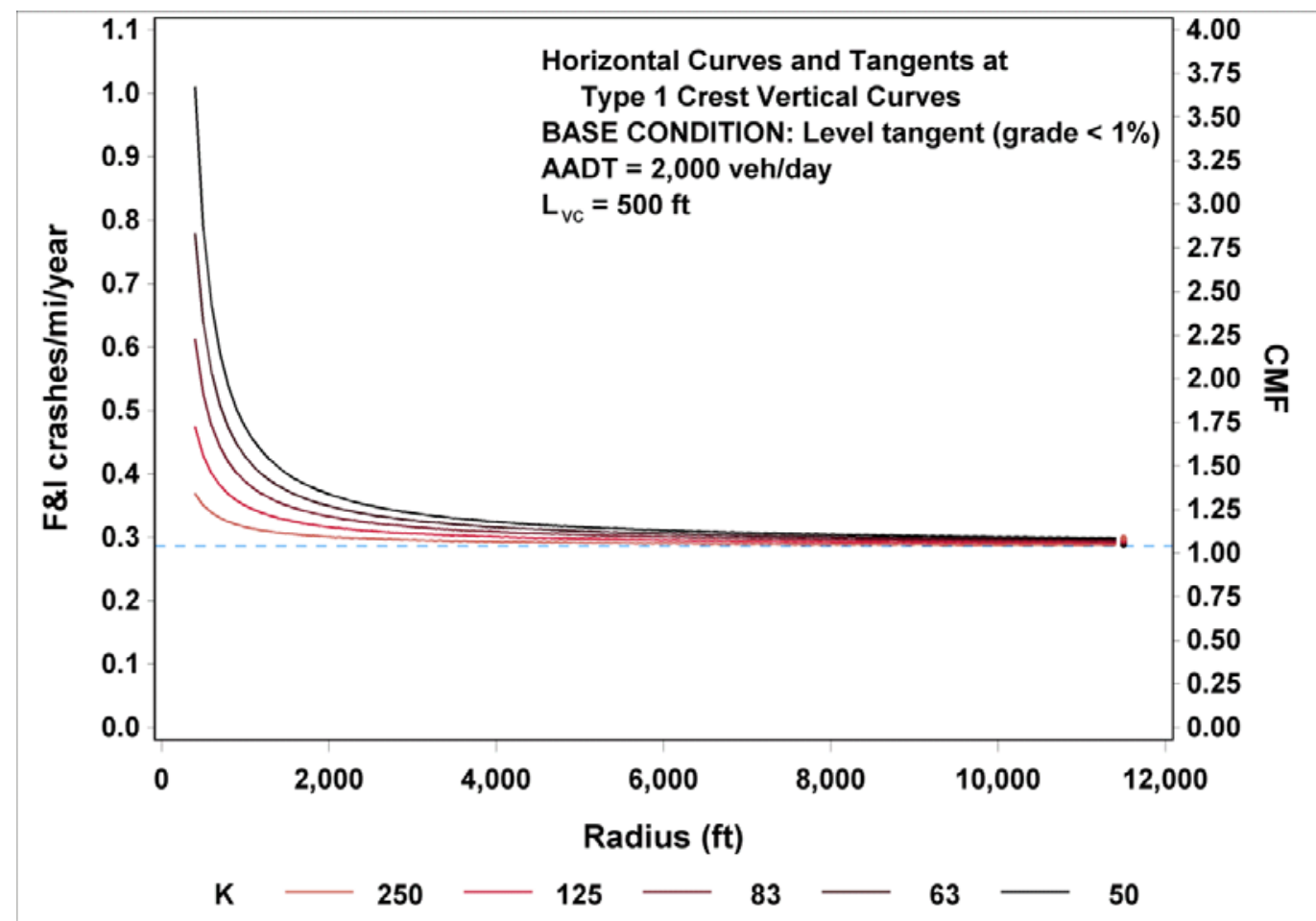

Figure 45. Graph. Predicted FI crashes/mi/year and CMFs for horizontal curves and tangents at type 1 crest vertical curves.

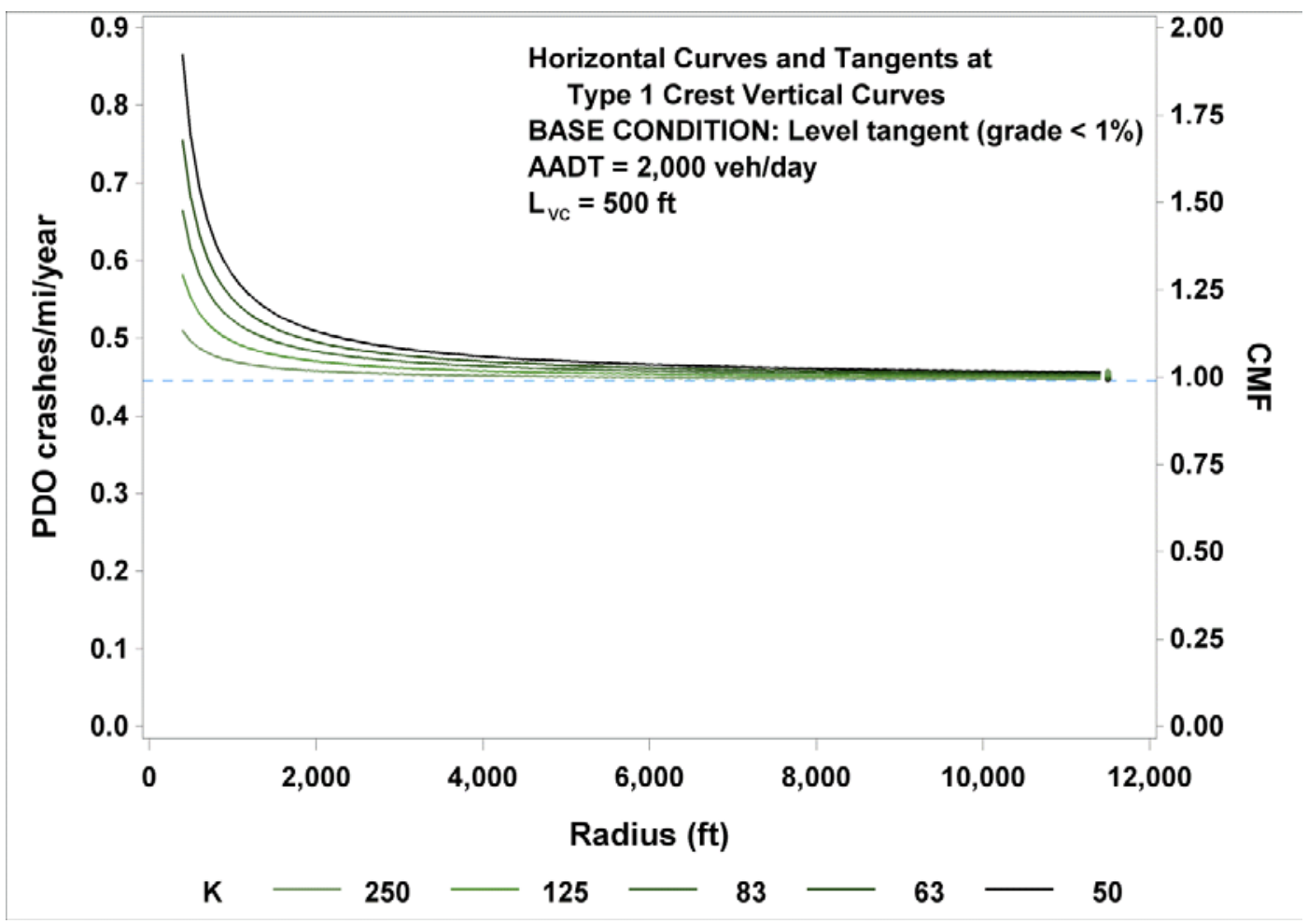

Figure 46. Graph. Predicted PDO crashes/mi/year and CMFs for horizontal curves and tangents at type 1 crest vertical curves. 
In any given column in table 18, the CMFs show the increasing effect on crashes of a decreasing $K$ (steeper crest) of a horizontal curve at a type 1 crest vertical curve. This effect is less pronounced for PDO crashes than for FI crashes. The combined effect of a sharp horizontal curve on a steep vertical crest is reflected in the last rows of the third and fifth columns. When $K$ becomes infinite (i.e., level roadway) and $\mathrm{R}$ becomes infinite (i.e., tangent roadway), the roadway becomes a level tangent, and CMF becomes 1.0.

\section{HORIZONTAL CURVES AND TANGENTS AT TYPE 1 SAG VERTICAL CURVES}

CMFs for horizontal curves and tangents at type 1 sag vertical curves can be derived from figure 25 and figure 26 as follows:

$$
C M F_{S 1, F I}=\left\{\begin{array}{lr}
\exp \left[10.51 \frac{1}{K}+0.011\left(\frac{5,730}{\mathrm{R}}\right) \frac{L_{V C}}{K}\right] & \text { for horizontal curves } \\
\exp \left[10.51 \frac{1}{K}\right] & \text { for tangents at type } 1 \text { sags } \\
1.0 & \text { for level tangents (base condition) }
\end{array}\right\}
$$

Figure 47. Equation. FI CMF for horizontal curves and tangents at type 1 sag vertical curves.

$$
C M F_{S 1, P D O}=\left\{\begin{array}{lr}
\exp \left[8.62 \frac{1}{K}+0.010\left(\frac{5,730}{\mathrm{R}}\right) \frac{L_{V C}}{K}\right] & \text { for horizontal curves } \\
\exp \left[8.62 \frac{1}{K}\right] & \text { for tangents at type } 1 \text { sags } \\
1.0 & \text { for level tangents (base condition) }
\end{array}\right\}
$$

Figure 48. Equation. PDO CMF for horizontal curves and tangents at type 1 sag vertical curves.

The functional relationships shown in figure 25 (crashes/mi/year) and figure 47 (CMF) for FI crashes are illustrated in figure 49 for $K$ values of 250, 125, 83, 63, and 50. R ranged from 100 to $11,460 \mathrm{ft}$, AADT was fixed at 2,000 vehicles/day, and $L_{V C}$ was fixed at $500 \mathrm{ft}$. Similarly, figure 50 illustrates the relationships shown in figure 26 and figure 48 for PDO crashes.

To calculate CMF for FI or PDO crashes for a given horizontal curve at a type 1 sag vertical curve, the actual values of $\mathrm{R}(\mathrm{ft}), L_{V C}(\mathrm{ft})$, and parameter $K$ (ft/percent) are substituted in figure 47 or figure 48. Example CMFs were calculated for rural two-lane roadways with a vertical curve length of $500 \mathrm{ft}$, an $\mathrm{R}$ of 1,433 or 5,730 ft, and $K$ values of 250, 125, 83, 63, and 50 using figure 47 and figure 48 . The results are shown in table 19 for rural two-lane roadways with AADTs from 200 to 26,000 vehicles/day. 


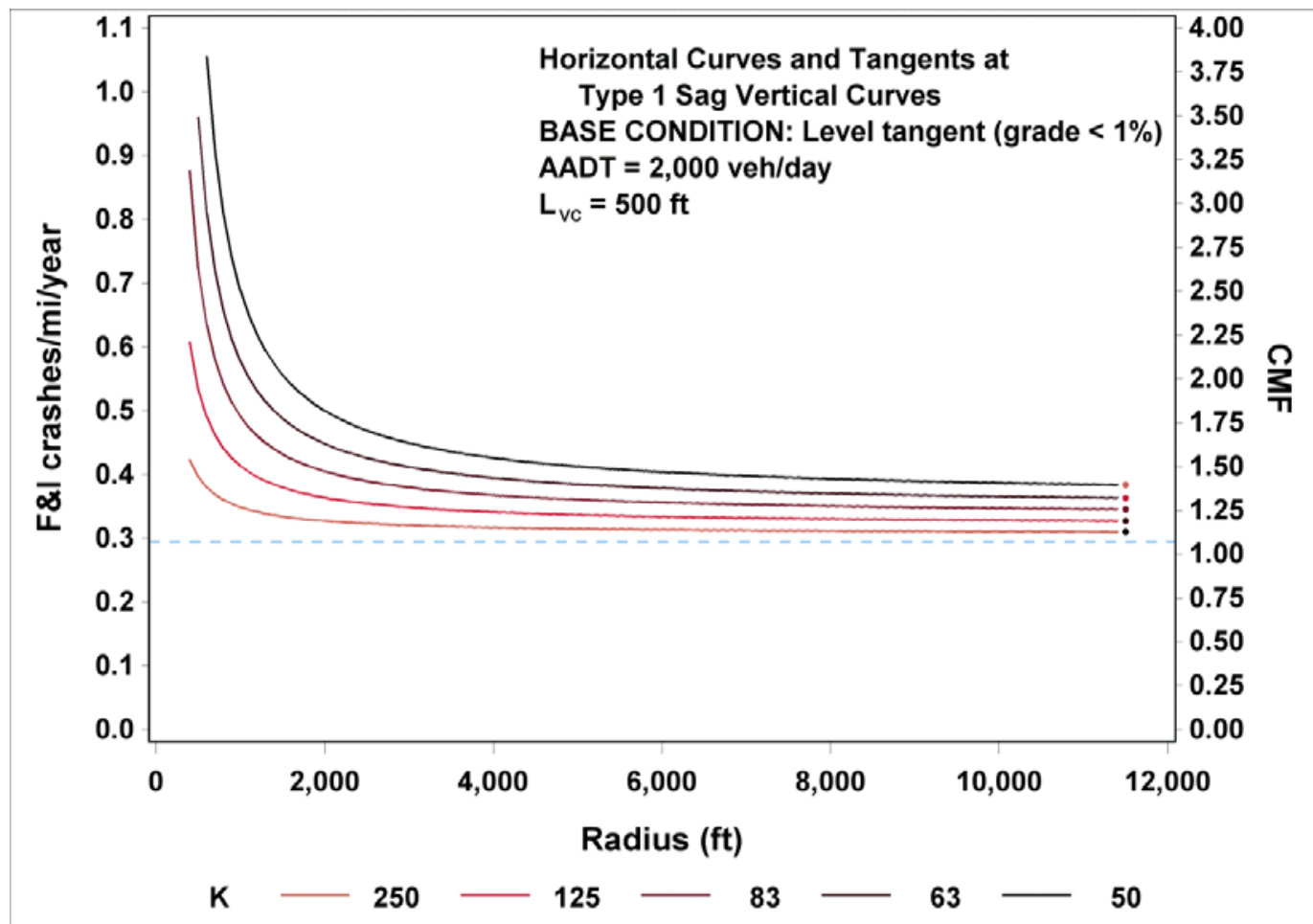

Figure 49. Graph. Predicted FI crashes/mi/year and CMFs for horizontal curves and tangents at type 1 sag vertical curves.

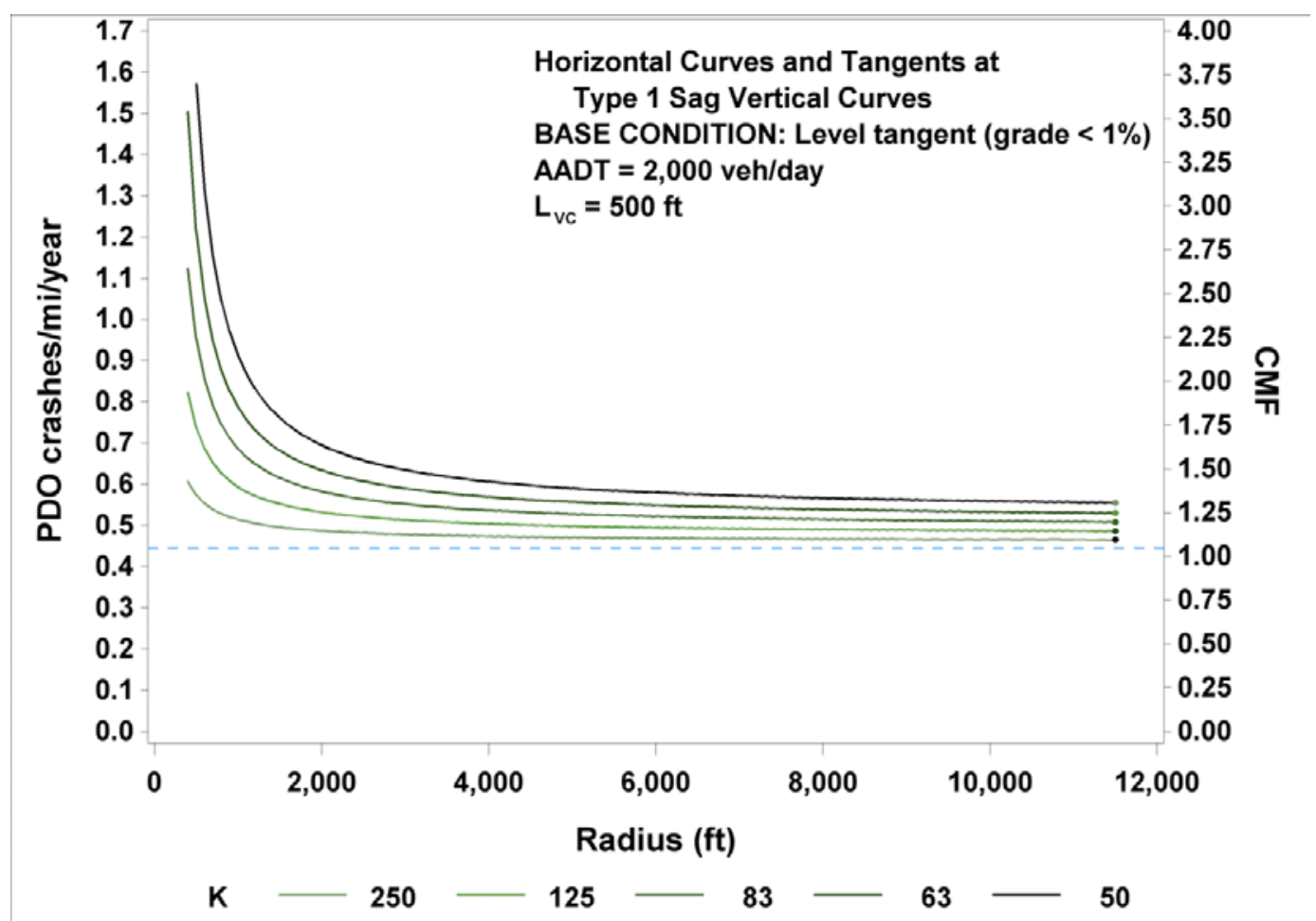

Figure 50. Graph. Predicted PDO crashes/mi/year and CMFs for horizontal curves and tangents at type 1 sag vertical curves. 
Table 19. Example CMFs for FI and PDO crashes on horizontal curves and tangents at type 1 sag vertical curves.

\begin{tabular}{|c|c|c|c|c|c|c|}
\hline & \multicolumn{3}{|c|}{ FI CMFs } & \multicolumn{3}{c|}{ PDO CMFs } \\
\cline { 2 - 7 } $\boldsymbol{K}$ & $\begin{array}{c}\text { Tangent } \\
\text { at Sag }\end{array}$ & $\mathbf{R = 1 , 4 3 3 ~ f t}$ & $\mathbf{R = 5 , 7 3 0 ~ f t}$ & $\begin{array}{c}\text { Tangent } \\
\text { at Sag }\end{array}$ & $\mathbf{R = 1 , 4 3 3 ~ f t}$ & $\mathbf{R}=\mathbf{5 , 7 3 0 ~ f t}$ \\
\hline 250 & 1.04 & 1.14 & 1.07 & 1.04 & 1.12 & 1.05 \\
\hline 125 & 1.09 & 1.30 & 1.14 & 1.07 & 1.25 & 1.11 \\
\hline 83 & 1.13 & 1.49 & 1.21 & 1.11 & 1.39 & 1.17 \\
\hline 63 & 1.18 & 1.68 & 1.29 & 1.15 & 1.55 & 1.24 \\
\hline 50 & 1.23 & 1.93 & 1.38 & 1.19 & 1.74 & 1.31 \\
\hline
\end{tabular}

In any given column in table 19, CMFs show the increasing effect on crashes of decreasing $K$ (sharper sag) for a horizontal curve or tangent at a type 1 sag vertical curve. This effect is slightly less pronounced for PDO than for FI crashes. When $K$ becomes very large (i.e., level roadway), and $\mathrm{R}$ becomes infinite (i.e., tangent roadway), the roadway becomes a level tangent, and CMF becomes 1.0.

\section{HORIZONTAL CURVES AND TANGENTS AT TYPE 2 CREST VERTICAL CURVES}

CMFs for horizontal curves and tangents at type 2 crest vertical curves can be derived from figure 32 and figure 33 as follows:

$$
C M F_{C 2, F I}=\left\{\begin{array}{lr}
\exp \left[0.20 \ln \left(2 \times \frac{5,730}{\mathrm{R}}\right)\right] & \text { for horizontal curves } \\
1.0 & \text { for tangents at type } 2 \text { crests } \\
1.0 & \text { for level tangents (base condition) }
\end{array}\right\}
$$

Figure 51. Equation. FI CMF for horizontal curves and tangents at type 2 crest vertical curves.

$$
C M F_{C 2, P D O}=\left\{\begin{array}{lr}
\exp \left[0.10 \ln \left(2 \times \frac{5,730}{\mathrm{R}}\right)\right] & \text { for horizontal curves } \\
1.0 & \text { for tangents at type } 2 \text { crests } \\
1.0 & \text { for level tangents (base condition) }
\end{array}\right\}
$$

Figure 52. Equation. PDO CMF for horizontal curves and tangents at type 2 crest vertical curves.

The functional relationships shown in figure 32 (crashes/mi/year) and figure 51 (CMF) for FI crashes are illustrated in figure 53 for an R range from 100 to 11,460 ft and AADTs of 1,000, 2,000, 4,000, and 7,000 vehicles/day (corresponding approximately to the 25th, 50th, 75th, and 90th percentile AADTs for rural two-lane highways in the database). Similarly, figure 54 illustrates the relationships shown in figure 33 and figure 52 for PDO crashes.

To calculate CMF for FI or PDO crashes for a given horizontal curve at a type 2 crest vertical curve, the actual value of $\mathrm{R}(\mathrm{ft})$ is substituted in figure 51 or figure 52. Example CMFs were calculated for rural two-lane roadways with an $\mathrm{R}$ of $1,433,5,730$, or $11,460 \mathrm{ft}$ using figure 51 
and figure 52. The results are shown in table 20 for rural two-lane roadways with AADTs from 200 to 26,000 vehicles/day.

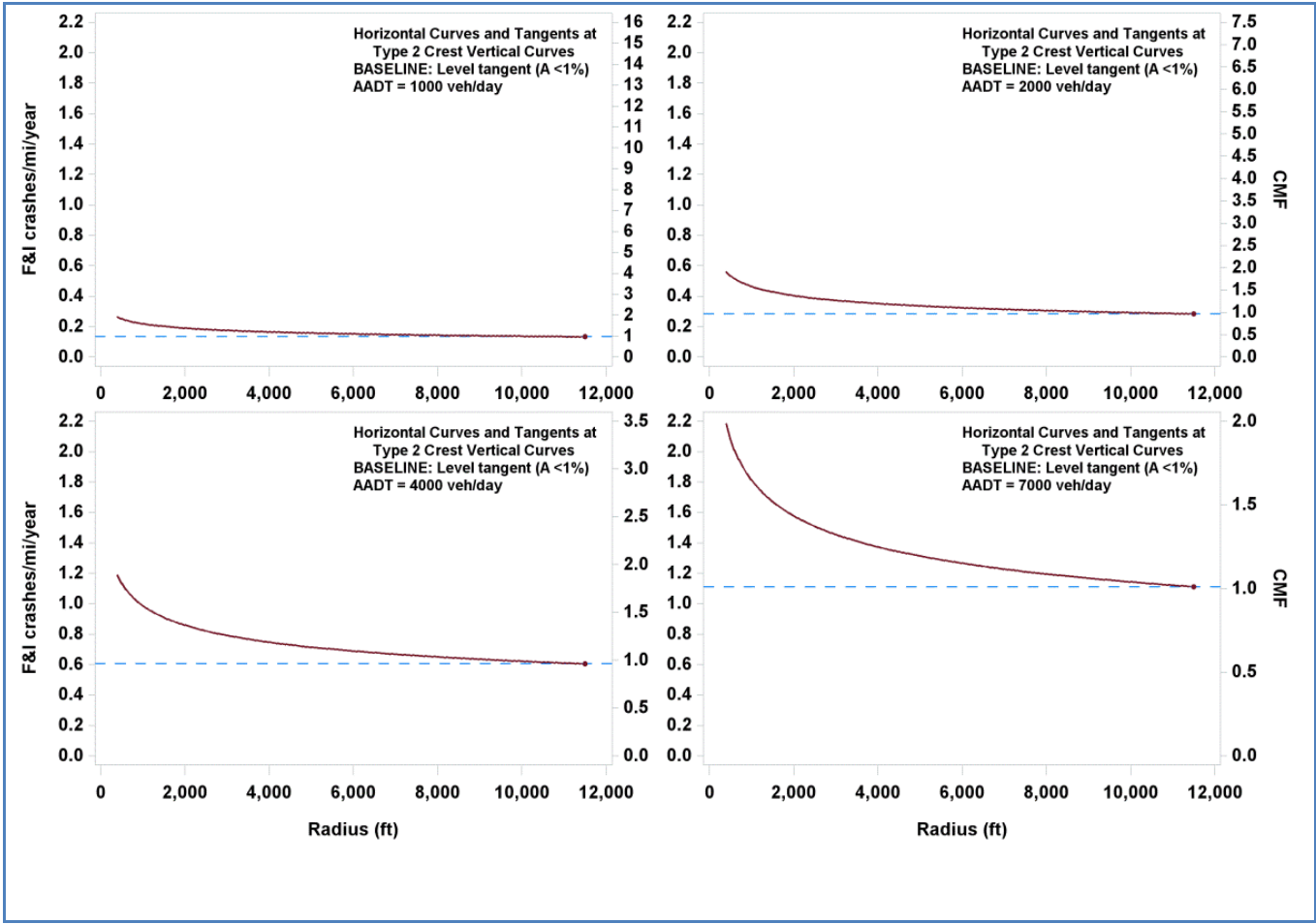

Figure 53. Graph. Predicted FI crashes/mi/year and CMFs for horizontal curves and tangents at type 2 crest vertical curves.

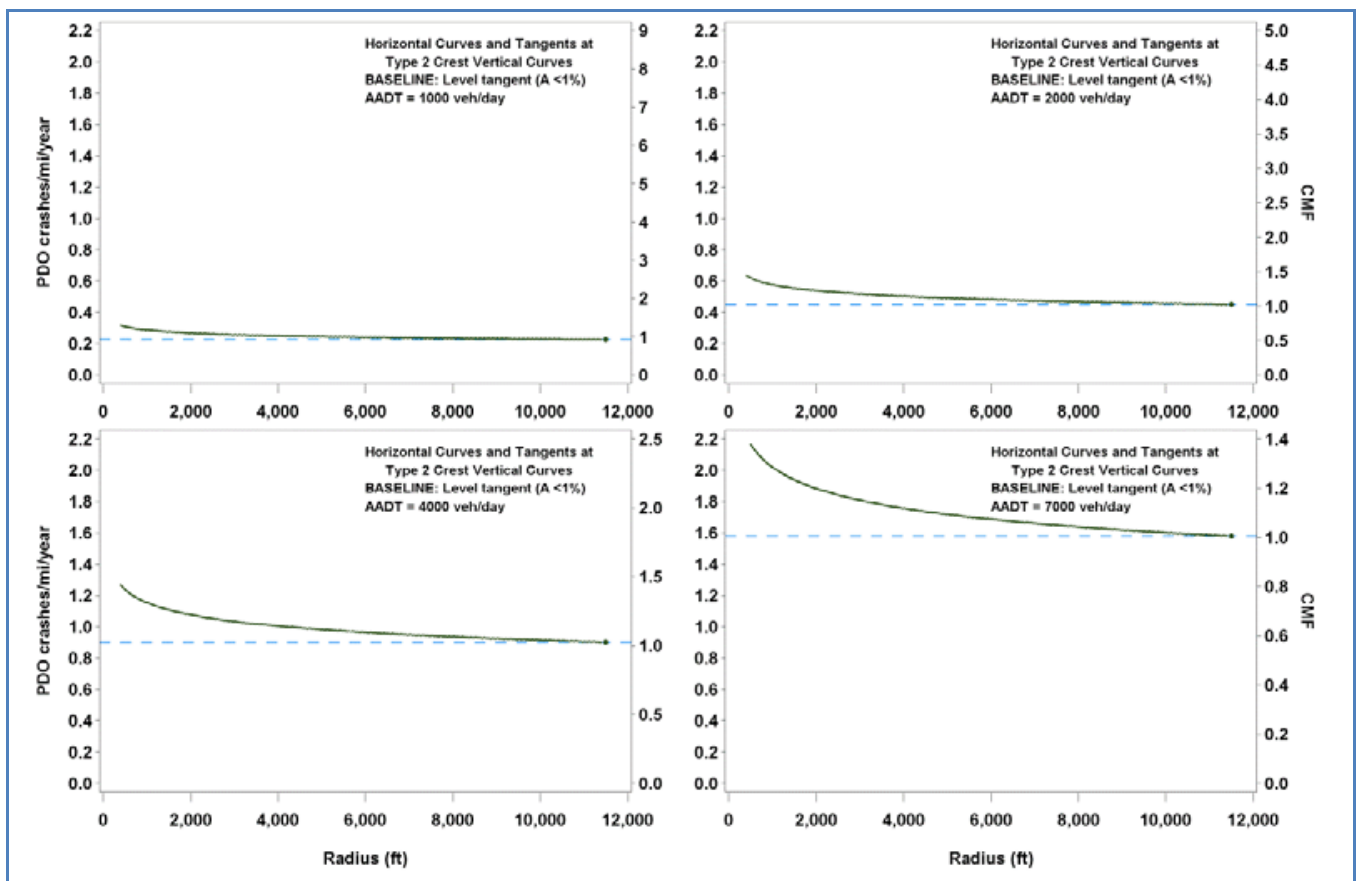

Figure 54. Graph. Predicted PDO crashes/mi/year and CMFs for horizontal curves and tangents at type 2 crest vertical curves. 
Table 20. Example CMFs for FI and PDO crashes on horizontal curves and tangents at type 2 crest vertical curves.

\begin{tabular}{|c|c|c|c|c|c|}
\hline \multicolumn{3}{|c|}{ FI CMFs } & \multicolumn{3}{c|}{ PDO CMFs } \\
\hline $\mathbf{R}=\mathbf{1 , 4 3 3} \mathbf{f t}$ & $\mathbf{R}=\mathbf{5 , 7 3 0} \mathbf{f t}$ & $\mathbf{R = 1 1 , 4 6 0} \mathbf{~ f t}$ & $\mathbf{R = 1 , 4 3 3} \mathbf{f t}$ & $\mathbf{R}=\mathbf{5 , 7 3 0} \mathbf{f t}$ & $\mathbf{R}=\mathbf{1 1 , 4 6 0} \mathbf{f t}$ \\
\hline 1.52 & 1.15 & 1.00 & 1.23 & 1.07 & 1.00 \\
\hline
\end{tabular}

Only R of the horizontal curve at a type 2 vertical crest has an effect on crash rates, with increasing radii producing smaller CMFs. The effect of $\mathrm{R}$ is more pronounced for FI crashes than for PDO crashes. When $\mathrm{R}$ becomes infinite, the roadway becomes a tangent, and CMF becomes 1.0 regardless of the vertical curve characteristics.

Because this CMF lacks any measure of vertical alignment, consideration may be given to replacing this CMF with a CMF based on figure 10 and figure 11.

\section{HORIZONTAL CURVES AND TANGENTS AT TYPE 2 SAG VERTICAL CURVES}

CMFs for horizontal curves and tangents at type 2 sag vertical curves can be derived from figure 37 and figure 38 as follows:

$$
C M F_{S 2, F I}=\left\{\begin{array}{lr}
\exp \left[0.188 \ln \left(2 \times \frac{5,730}{\mathrm{R}}\right)\right] & \text { for horizontal curves } \\
1.0 & \text { for tangents at type 2 sags } \\
1.0 & \text { for level tangents (base condition) }
\end{array}\right\}
$$

Figure 55. Equation. FI CMF for horizontal curves and tangents at type 2 sag vertical curves.

$$
C M F_{S 2, P D O}=\left\{\begin{array}{lr}
\exp \left[0.022\left(\frac{5,730}{\mathrm{R}}\right) A\right] & \text { for horizontal curves } \\
1.0 & \text { for tangents at type } 2 \text { sags } \\
1.0 & \text { for level tangents (base condition) }
\end{array}\right\}
$$

Figure 56. Equation. PDO CMF for horizontal curves and tangents at type 2 sag vertical curves.

The functional relationships shown in figure 37 (crashes/mi/year) and figure 55 (CMF) for FI crashes are illustrated in figure 57 for an R range from 100 to 11,460 ft and AADTs of 1,000, 2,000, 4,000, and 7,000 vehicles/day. Similarly, figure 58 illustrates the relationships shown in figure 38 and figure 56 for PDO crashes for $K$ values of 250, 125, 83, 63, and 50; curve radii ranging from 100 to 11,460 ft; and AADT fixed at 2,000 vehicles/day.

To calculate CMF for FI crashes for a given horizontal curve at a type 2 sag vertical curve, the actual value of $\mathrm{R}(\mathrm{ft})$ is substituted in figure 55. To calculate CMF for PDO crashes, the actual value of $\mathrm{R}(\mathrm{ft}), L_{V C}$, and $K$ are substituted in figure 56 . Example FI CMFs were calculated for rural two-lane roadways with an $\mathrm{R}$ of 1,433, 5,730, or 11,460 ft using figure 55. Example PDO CMFs were calculated using figure 56 for rural two-lane roadways with an $\mathrm{R}$ of 1,433 or 5,730 ft, an $L_{V C}$ of $500 \mathrm{ft}$, and $A$ values ranging from 2 to 10 percent. The results are shown in 
table 21 for FI crashes and table 22 for PDO crashes for rural two-lane roadways with AADTs from 200 to 26,000 vehicles/day.

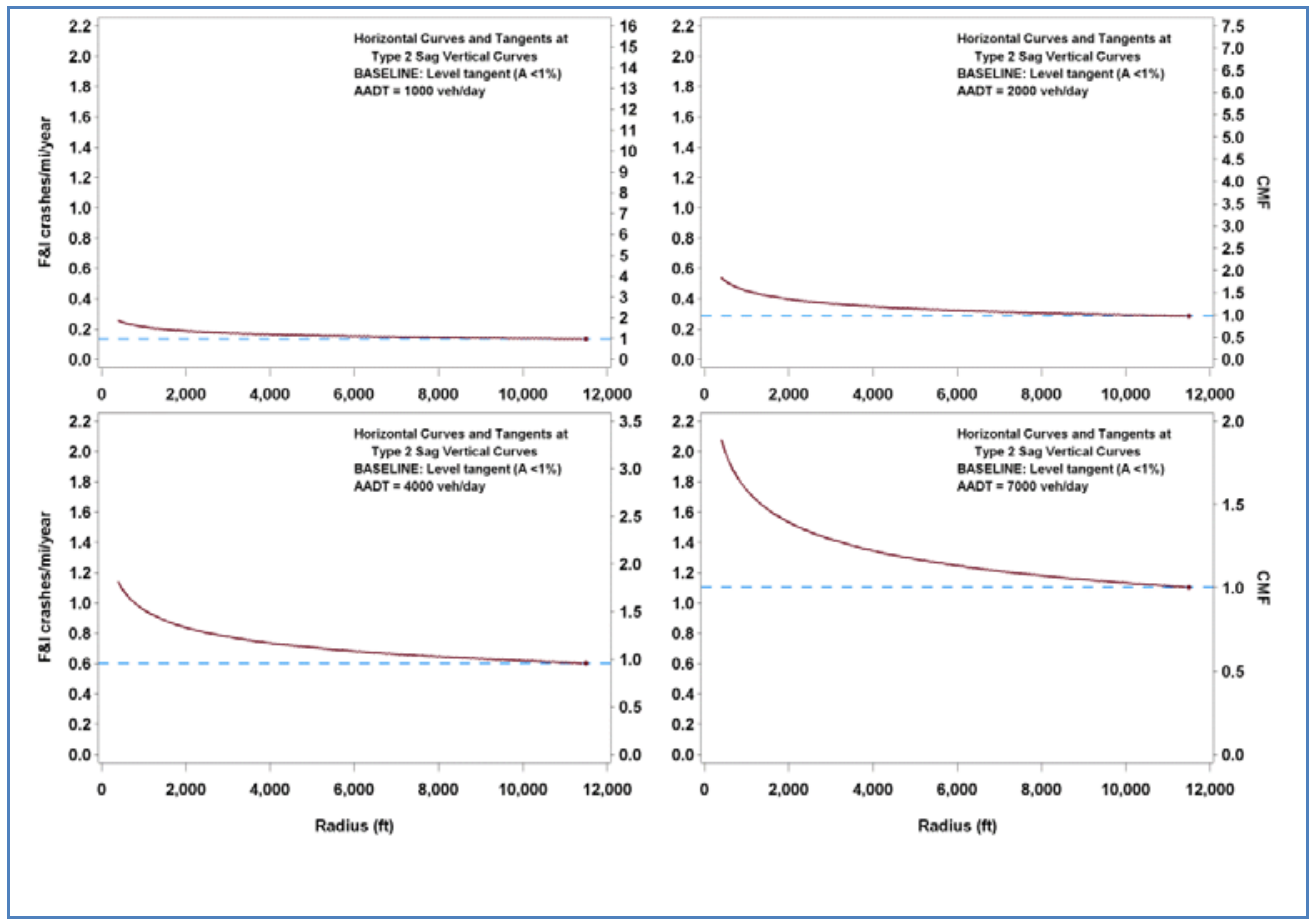

Figure 57. Graph. Predicted FI crashes/mi/year and CMFs for horizontal curves and tangents at type 2 sag vertical curves.

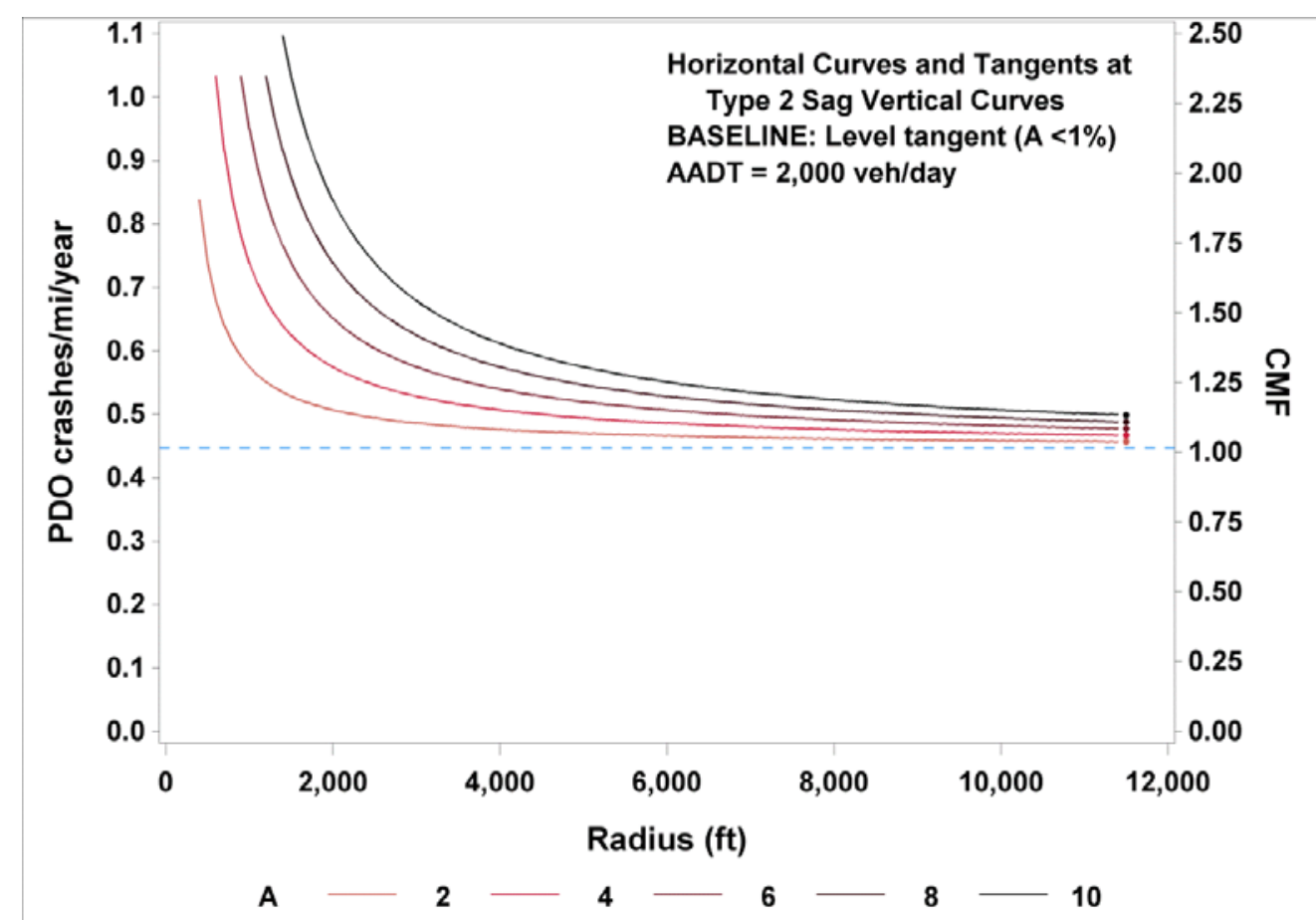

Figure 58. Graph. Predicted PDO crashes/mi/year and CMFs for horizontal curves and tangents at type 2 sag vertical curves. 
Table 21. Example CMFs for FI crashes on horizontal curves and tangents at type 2 sag vertical curves.

\begin{tabular}{|c|c|c|}
\hline \multicolumn{3}{|c|}{ FI CMFs } \\
\hline $\mathbf{R}=\mathbf{1 , 4 3 3} \mathbf{f t}$ & $\mathbf{R}=\mathbf{5 , 7 3 0} \mathbf{f t}$ & $\mathbf{R}=\mathbf{1 1 , 4 6 0} \mathbf{f t}$ \\
\hline 1.48 & 1.14 & 1.00 \\
\hline
\end{tabular}

Table 22. Example CMFs PDO crashes on horizontal curves and tangents at type 2 sag vertical curves.

\begin{tabular}{|c|c|c|c|}
\hline \multirow{2}{*}{$\boldsymbol{A}$} & \multicolumn{3}{|c|}{ PDO CMFs } \\
\cline { 2 - 4 } & $\mathbf{R}=\mathbf{1 , 4 3 3} \mathbf{f t}$ & $\mathbf{R}=\mathbf{5 , 7 3 0} \mathbf{~ f t}$ & $\mathbf{R}=\mathbf{1 1 , 4 6 0} \mathbf{~ f t}$ \\
\hline All tangents & 1.00 & 1.00 & 1.00 \\
\hline 2 & 1.19 & 1.04 & 1.02 \\
\hline 4 & 1.42 & 1.09 & 1.04 \\
\hline 6 & 1.69 & 1.14 & 1.07 \\
\hline 8 & 2.02 & 1.19 & 1.09 \\
\hline 10 & 2.40 & 1.24 & 1.12 \\
\hline
\end{tabular}

Only R of the horizontal curve at a type 2 vertical sag has an effect on FI crash rates, with increasing radii producing smaller CMFs (see table 21). When R becomes infinite, the roadway becomes a tangent and CMF becomes 1.0 regardless of the characteristics of the vertical curve. Only the interaction term of $A$ and inverse R has an effect on PDO crash rates (see table 22), highlighting the joint effect of sharp horizontal curves at steep vertical curves on PDO crashes. When the initial and final grade difference, $A$, nears zero (i.e., level roadway) and the $\mathrm{R}$ becomes infinite (i.e., tangent roadway), the roadway becomes a level tangent, and CMF becomes 1.0.

Because this CMF (at least for FI crashes) lacks any measure of vertical alignment, consideration may be given to replacing this CMF with a CMF based on figure 10 and figure 11 .

\section{CMFS FOR COMBINED CRASH SEVERITY LEVELS}

This study provides separate CMFs for FI and PDO crashes. At some future time, the AASHTO HSM may be structured to provide separate CMFs by severity level for all CMFs. In the meantime, if users want a CMF for total crashes (i.e., all crash severity levels combined), it can be computed from the results in this report as follows:

$$
C M F_{T O T}=\left[\left(C M F_{F I}-1.0\right) \times P_{F I}+\left(C M F_{P D O}-1.0\right) \times P_{P D O}\right]+1.0
$$

Figure 59. Equation. CMF for combined crash severity level.

Where:

$C M F_{T O T}=\mathrm{CMF}$ for total crashes (i.e., all severity levels combined).

$C M F_{F I}=\mathrm{CMF}$ for FI crashes.

$C M F_{P D O}=\mathrm{CMF}$ for $\mathrm{PDO}$ crashes.

$P_{F I}=$ FI crashes expressed as a proportion of total crashes.

$P_{P D O}=$ PDO crashes expressed as a proportion of total crashes. 
Values used for $P_{F I}$ and $P_{P D O}$ must always sum to 1.0. Values of $P_{F I}$ and $P_{P D O}$ indicated for rural two-lane highways in AASHTO HSM table 10-3 $\left(P_{F I}=0.321\right.$ and $\left.P_{P D O}=0.679\right)$ may be used, or users may develop values for $P_{F I}$ and $P_{P D O}$ from their agencies' data. ${ }^{(1)}$

\section{COMPARISON OF RESULTS TO EXISTING HSM CMFS}

The current AASHTO HSM presents separate CMFs for horizontal curves and straight grades, as seen as $C M F_{H C}$ in figure 3 and $C M F_{G}$ in figure 5, respectively. ${ }^{(1)}$ The combined effect of horizontal curves and grades is represented in the AASHTO HSM as the product of $C M F_{H C}$ and $C M F_{G}$. Figure 60 illustrates a comparison of CMFs for horizontal curves on straight grades developed in this study, and shown in figure 39 and figure 40 for FI and PDO crashes, respectively, to the combined AASHTO HSM CMF, holding length of horizontal curve and radius constant while varying percent grade. Figure 61 is an analogous plot, keeping the length of horizontal curve and percent grade constant while varying the radius of horizontal curve.

The plots show that the new CMF for FI crashes is consistently larger than the new CMF for PDO crashes. This represents an advance in knowledge over the AASHTO HSM, which treats CMFs for all severity levels as equal. ${ }^{(1)}$ The plots also show that the new CMFs are generally larger than the combined AASHTO HSM CMFs, except that the new CMF for PDO crashes is smaller than the existing CMFs for horizontal curves with short radii. No other comparisons between the HSM CMFs and the CMFs developed in this study are relevant because the AASHTO HSM does not address the safety effects of crest or sag vertical curves.

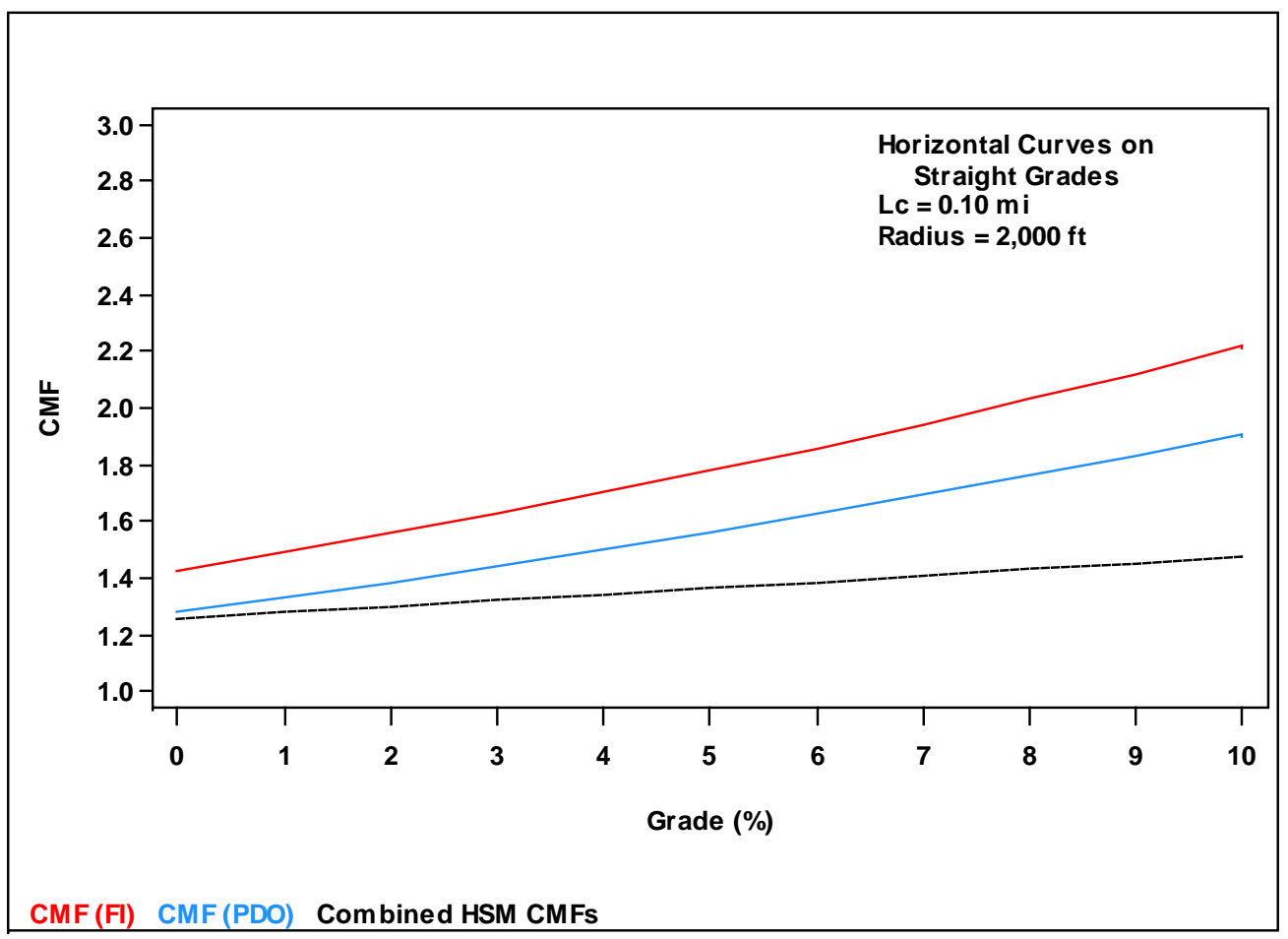

Figure 60. Graph. Comparison of CMFs developed in this study to the combined AASHTO HSM CMFs for horizontal curves and grades for fixed radius and varying percent grades. ${ }^{(1)}$ 


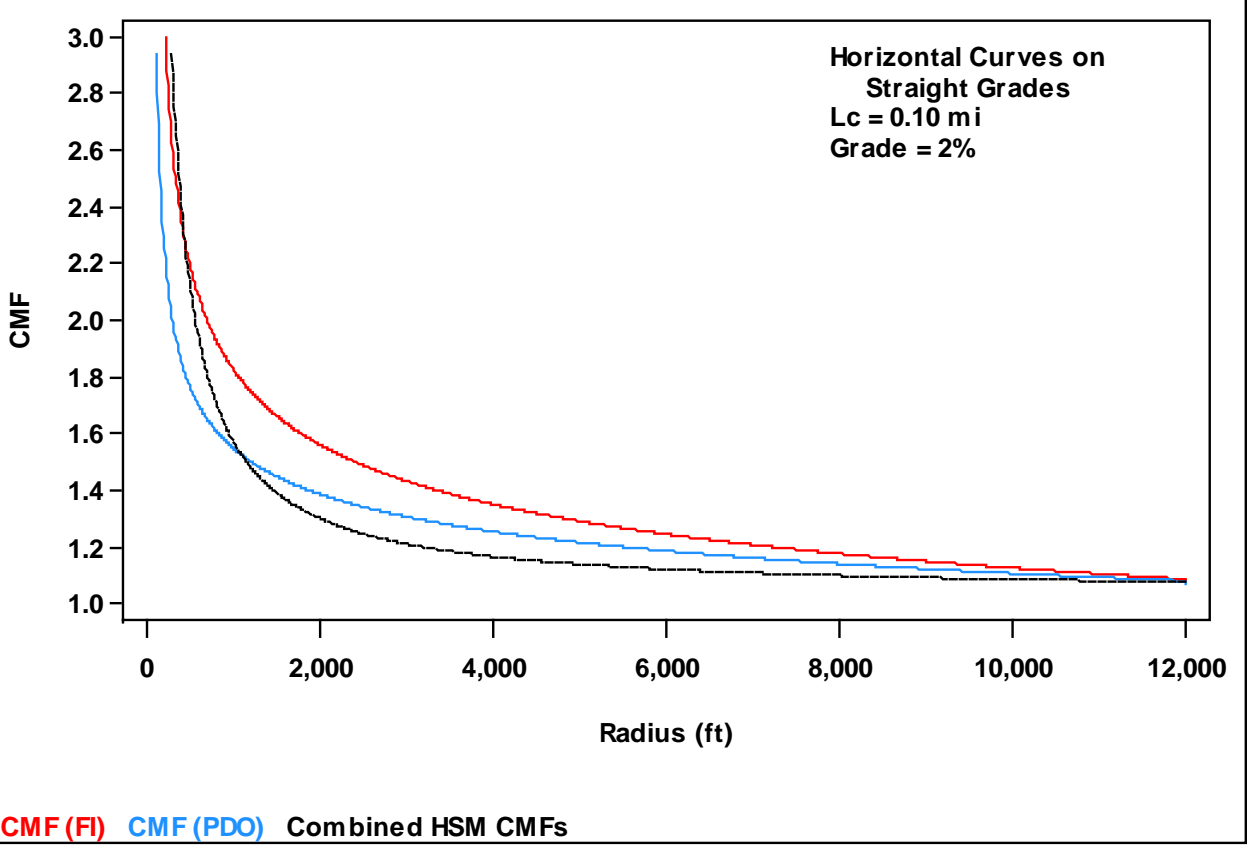

Figure 61. Graph. Comparison of CMFs developed in this study to the combined AASHTO HSM CMFs for horizontal curves and grades for fixed percent grade and varying radii. ${ }^{(1)}$ 


\section{CHAPTER 6-CONCLUSIONS AND RECOMMENDATIONS}

This chapter presents the conclusions and recommendations based on the results of the study.

\section{CONCLUSIONS}

Conclusions for this study are as follows:

- For tangents and horizontal curves on straight grades, prediction models for crash frequency by severity level are presented in figure 10 and figure 11, with parameter estimates presented in table 8 . These models include a main effect for AADT, a main effect for horizontal curve radius, a main effect for percent grade, and an interaction between horizontal curve radius and length of curve. The models indicate that crash frequency increases with decreasing horizontal curve radius, decreasing horizontal curve length, and increasing percent grade. The interaction term shows that short sharp horizontal curves are associated with higher crash frequencies. CMFs corresponding to the crash prediction models are presented in figure 39, figure 40, and table 17.

- For tangents and horizontal curves at type 1 crest vertical curves, prediction models for crash frequency by severity level are presented in figure 16 and figure 17, with parameter estimates presented in table 10. Alternate prediction models are shown in figure 20 and figure 21. These models include a main effect for AADT and an interaction between horizontal curve radius and the difference between initial and final grade (alternatively, an interaction between horizontal curve radius, vertical curve length, and $K$ ). The models indicate that crash frequency increases with decreasing horizontal curve radius and increases with increasing grade difference. The interaction term shows that short horizontal curves at sharp crest vertical curves are associated with higher crash frequencies. CMFs corresponding to the crash prediction models are presented in figure 43, figure 44, and table 18.

- For tangents and horizontal curves at type 1 sag vertical curves, prediction models for crash frequency by severity level are presented in figure 23 and figure 24, with parameter estimates presented in table 12. Alternate prediction models are shown in figure 27 and figure 28. These models include a main effect for AADT, a main effect for $K$, and an interaction between horizontal curve radius and the difference between initial and final grade (alternatively, an interaction between horizontal curve radius, vertical curve length, and $K$ ). The models indicate that crash frequency increases with decreasing $K$, decreasing horizontal curve radius, and increasing grade difference. The interaction term shows that short horizontal curves at sharp sag vertical curves are associated with higher crash frequencies. CMFs corresponding to the crash prediction models are presented in figure 47, figure 48, and table 19.

- For tangents and horizontal curves at type 2 crest vertical curves, prediction models for crash frequency by severity level are presented in figure 30 and figure 31, with parameter estimates presented in table 14 . These models include only two main effects: a main effect for AADT and a main effect for horizontal curve radius. The models indicate that 
crash frequency increases with decreasing horizontal curve radius. CMFs corresponding to the crash prediction models are presented in figure 51, figure 52, and table 20. Consideration will be given to using figure 10 and figure 11, with grade set equal to the average of $G_{1}$ and $G_{2}$ in place of figure 30 and figure 31 .

- For tangents and horizontal curves at type 2 sag vertical curves, prediction models for crash frequency by severity level are presented in figure 35 and figure 36, with parameter estimates presented in table 16. The FI crash prediction model includes only two main effects: a main effect for AADT and a main effect for horizontal curve radius. This model indicates that FI crash frequency increases with decreasing horizontal curve radius. The PDO crash prediction model includes a main effect for AADT, an interaction between horizontal curve radius, and the difference between $G_{1}$ and $G_{2}$. The PDO model indicates that crash frequency increases with decreasing horizontal curve radius and increases with increasing grade difference. The interaction term shows that short horizontal curves at sharp sag vertical curves are associated with higher crash frequencies. CMFs corresponding to the crash prediction models are presented in figure 55 , figure 56 , table 21 , and table 22 . Consideration will be given to using figure 10 and figure 11 with grade set equal to the average of $G_{1}$ and $G_{2}$ in place of figure 30 and figure 17.

- For all five horizontal and vertical alignment combinations, the coefficient of the AADT term in the crash prediction models is nearly equal to 1.0, indicating that crash frequencies are proportional to AADT.

- The AADT coefficients in the models range from 0.99 to 1.10. Consideration will be given as to whether the AADT coefficient should be set equal to 1.0 for consistency with the current AASHTO HSM. ${ }^{(1)}$

\section{RECOMMENDATIONS}

Recommendations based on the study results are as follows:

- CMFs developed in this report should be considered for incorporation in the next edition of the AASHTO HSM.

- It would be desirable to validate the CMFs developed in this report using data from one or more additional States. The current emphasis being placed on roadway inventories for asset management may lead to additional suitable databases.

- Ultimately, it would be desirable to have safety prediction models for rural two-lane highways for use in the AASHTO HSM that consider the safety effects of a full range of variables of interest and all of their combinations and interactions. This will require more comprehensive databases than those currently available. 


\section{REFERENCES}

1. American Association of State Highway and Transportation Officials. (2010). Highway Safety Manual, 1st Edition, AASHTO, Washington, DC.

2. American Association of State Highway and Transportation Officials. (2011). A Policy on Geometric Design of Highways and Streets, AASHTO, Washington, DC.

3. Zegeer, C.V., Stewart, J.R., Council, F.M., Reinfurt, D.W., and Hamilton, E. (1992). "Safety Effects of Geometric Improvements on Horizontal Curves," Transportation Research Record 1356, Transportation Research Board, Washington, DC.

4. Zegeer, C.V., Stewart, J.R., Reinfurt, D.W., Council, F.M., Neuman, T., Hamilton, E., Miller, T., and Hunter, W. (1991). Cost-Effective Geometric Improvements for Safety Upgrading of Horizontal Curves, Report No. FHWA-RD-90-021, Federal Highway Administration, Washington, DC.

5. Bonneson, J.A., Geedipally, S., Pratt, M.P., and Lord, D. (2012). Safety Prediction Methodology and Analysis Tool for Freeways and Interchanges, Final Report, National Cooperative Highway Research Program Project 17-45, Texas Transportation Institute, College Station, TX.

6. Harwood, D.W., Council, F.M., Hauer, E., Hughes, W.E., and Vogt, A. (2000). Prediction of the Expected Safety Performance of Rural Two-Lane Highways, Report No. FHWA-RD-99207, Federal Highway Administration, Washington, DC.

7. U.S. Department of Transportation. Interactive Highway Safety Design (IHSDM) Software Download Website, Washington, DC. Obtained from: http://www.ihsdm.org/. Site last accessed July 14, 2012.

8. Easa, S.M. and You, Q.C. (2009). "Collision Prediction Models for Three-Dimensional TwoLane Highways: Horizontal Curves," Transportation Research Record 2092, Transportation Research Board, Washington, DC.

9. You, Q.C. and Easa, S.M. (2009). Collision Prediction Models for Three-Dimensional TwoLane Highways: II. Horizontal Tangents, Presented at the 88th Annual Meeting of the Transportation Research Board, Washington, DC.

10. SAS Institute Inc. (2011). SAS/STAT ${ }^{\circledR} 9.3$ User’s Guide, SAS Institute Inc., Cary, NC. 


